\title{
FLOOD HAZARDS OF DISTRIBUTARY-FLOW AREAS IN SOUTHWESTERN ARIZONA
}

By H.W. Hjalmarson and S.P. Kemna

U.S. GEOLOGICAL SURVEY

Water-Resources Investigations Report 91-4171

Prepared in cooperation with the

ARIZONA DEPARTMENT OF WATER RESOURCES and the FLOOD CONTROL DISTRICT OF MARICOPA COUNTY

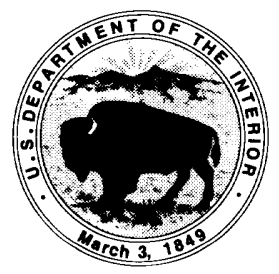




\section{U.S. DEPARTMENT OF THE INTERIOR}

MANUEL LUJAN, JR., Secretary

U.S. GEOLOGICAL SURVEY

Dallas L. Peck, Director

For additional information write to:

District Chief U.S. Geological Survey 375 South Euclid Avenue Tucson, Arizona 85719
Copies of this report can be purchased from:

U.S. Geological Survey Books and Open-File Reports Section Federal Center, Box 25425

Denver, Colorado 80225 


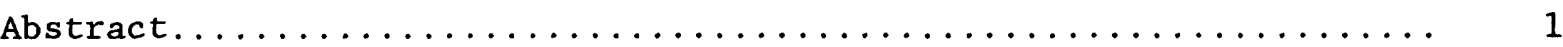

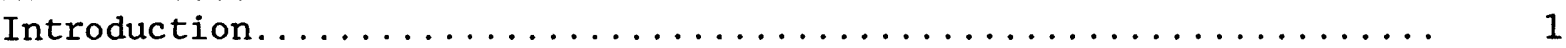

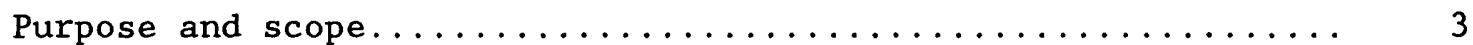

Relation between alluvial fans and distributary-flow areas..... 4

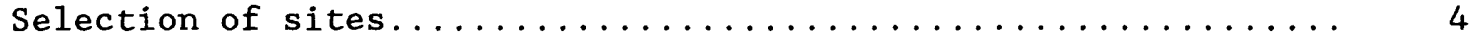

Geomorphic features and flood-hazard zones................ 4

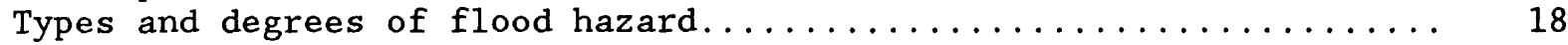

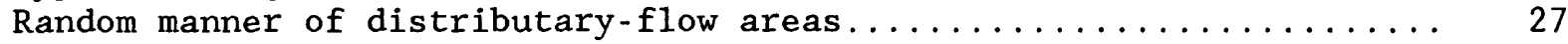

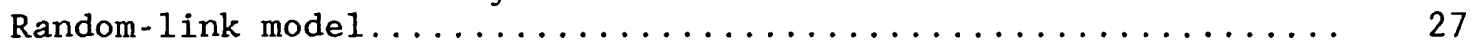

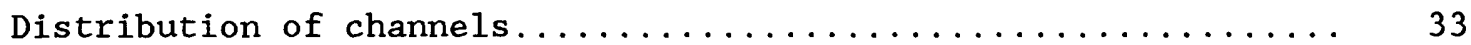

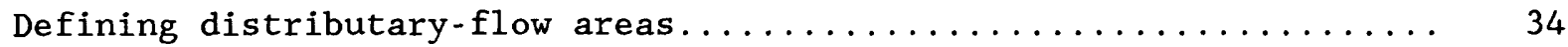

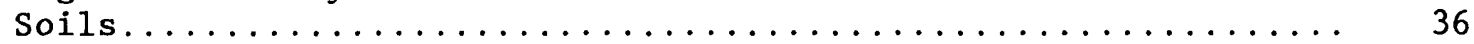

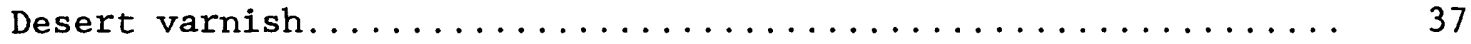

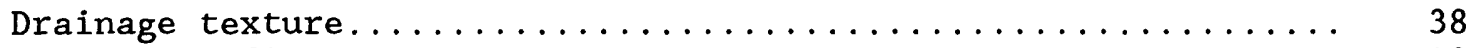

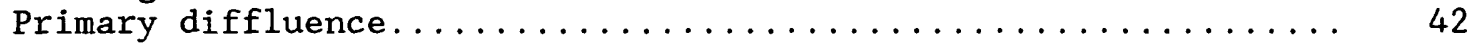

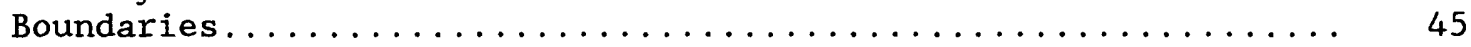

Miscellaneous relations between geomorphic variables.......... 45

Regression analysis.............................. 49

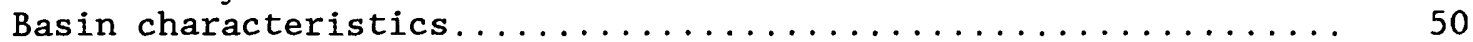

Characteristics of distributary-flow areas............. 51

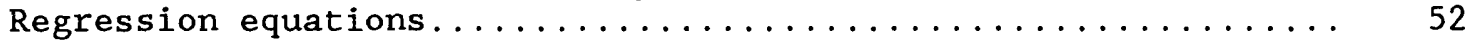

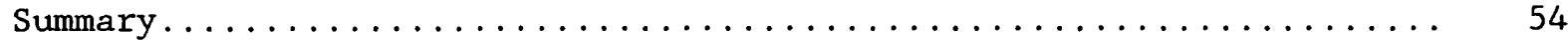

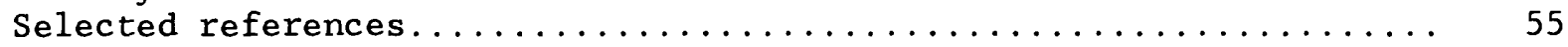

Figure 1. Map showing study area, distributary-flow sites, drainage-texture sites, and streamflow-gaging station.............................................

2. Drawing showing diagrammatic geologic section of
typical geomorphic components and flood-hazard

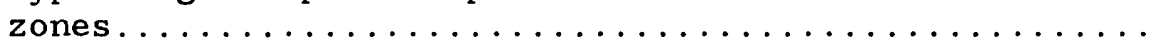

3. Drawings showing typical diagrammatic profiles, stream patterns, and cross sections for types of flood hazards in distributary-flow areas

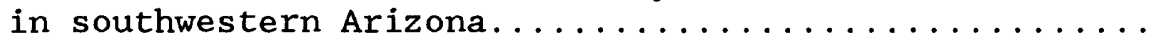

4. Graph showing relations between distributary-flow area and drainage area for sites with random

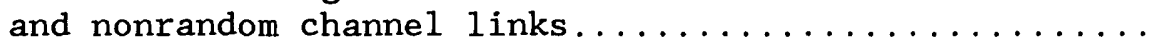

5. Graphs showing stream profile and average slope of channel between topographic-map contours showing location of primary diffluence for site $1 \ldots \ldots \ldots \ldots$ 
Figure 6. Graphs showing drainage-texture relations for distributary-flow areas, old fans, pediments, and typical transition from pediment to alluvial

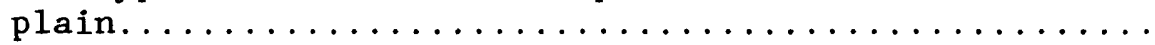

7. Flow chart showing steps in delineation of primary diffluence and boundaries of distributary-flow

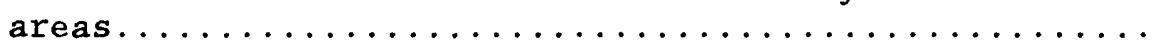

8. Graphs showing relations between distributary-flow area and drainage area and mean-relief ratio of distributary-flow area (MRDFA) and drainage area (DA) for sample sites in Arizona and groups of

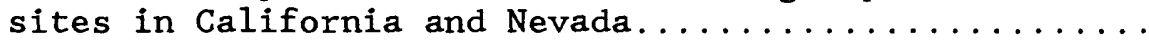

\section{TABLES}

Table 1. Location and selected characteristics of

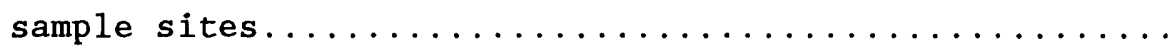

2. Summary of channel characteristics, estimated discharge, and Froude number of the 100-year

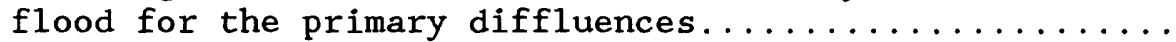

3. Topological characteristics and statistical data of sites used for the analysis of

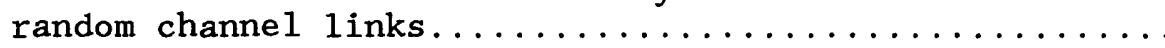

4. Discharge intensities for sites that have random and nonrandom channel links and that have high

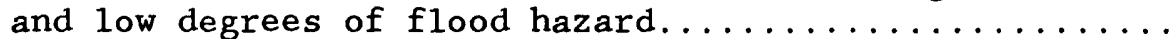

5. Location of active channels near longitudinal center of distributary-flow areas that have flood-hazard

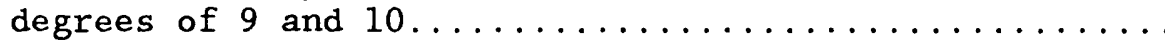

6. Location and type of landform for miscellaneous

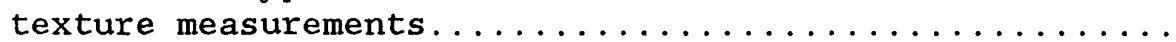

7. Physiographic and hydrologic characteristics of

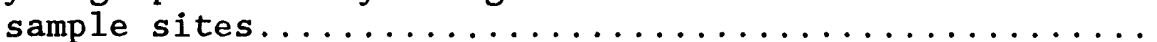

8. Correlation matrix for independent variables

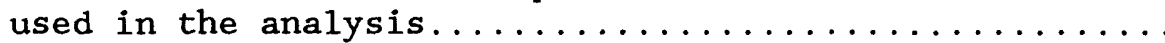


CONVERSION FACTORS AND VERTICAL DATUM

Multiply

inch (in.)

foot ( $f t)$

mile (mi)

square mile $\left(\mathrm{mi}^{2}\right)$

cubic foot per second $\left(\mathrm{ft}^{3} / \mathrm{s}\right)$

pound per cubic foot $\left(\mathrm{lb} / \mathrm{ft} \mathrm{t}^{3}\right)$

degree Fahrenheit $\left({ }^{\circ} \mathrm{F}\right)$
By

To obtain

25.40

0.3048

1.609

2.590

0.02832

0.4536

${ }^{\circ} \mathrm{C}=5 / 9 \times\left({ }^{\circ} \mathrm{F}-32\right)$ millimeter

meter

kilometer

square kilometer

cubic meter per second

kilogram per cubic meter

degree Celsius

Sea level: In this report, "sea level" refers to the National Geodetic Vertical Datum of 1929-A geodetic datum derived from a general adjustment of the first-order level nets of the United States and Canada, formerly called Sea Level Datum of 1929. 


\section{GLOSSARY OF TERMS}

Alluvial fan-A geomorphologic feature characterized by a cone- or fanshaped deposit of boulders, gravel, and fine sediments that have been eroded from mountain slopes, transported by floodflows, and then deposited on the valley floors, and which is subject to flashflooding, high-velocity flows, debris flows, erosion, sediment movement and deposition, and channel migration (Federal Register, 1989, p. 9528). Alluvial fans commonly occur at abrupt hydraulic expansions where the confinement of floodwater ceases. In Arizona, active alluvial fans commonly are recent and of the Holocene Epoch of the late Quaternary Period.

Alluvial plain-A broad area on the piedmont with little relief and covered with alluvium.

Alluvium-Sediment, including clay, silt, sand, and gravel, that has been deposited by running water.

Anabranch-A diverging branch of a channel that re-enters the main channel (Langbein and Iseri, 1960, p. 4). The contours are generally concave (plan view looking downstream) and there commonly is a confined appearance. Anabranches commonly are found on old fans.

Apex-The highest point on an alluvial fan, usually the point where the stream that formed the fan emerged from the mountain or from confining canyon walls (Bates and Jackson, 1980, p. 28). Also, for the National Flood Insurance Program, a point on an alluvial fan or similar landform below which the flowpath of the major stream that formed the fan becomes unpredictable and alluvial-fan flooding can occur (Federal Emergency Management Agency, 1991, p. A5-1).

Average slope of the main channel (in the distributary-flow area)-Slope of the main channel from the primary diffluence to the toe of the distributary-flow area. Average slope is computed as the ratio of the difference in altitude from the upper to lower end of channel reach, in feet, and the total length of the channel, in feet. The total length of the channel is the sum of the line segments (between contour intervals) that follow the wash.

Avulsion-A sudden change in the course of a channel, or in the present distribution of distributary flow in two or more channels, which commonly occurs during floodflows.

Bajada-A broad deposit of alluvium formed by coallescing alluvial fans.

Base-level plain-A broad area with gentle slopes and little relief at the lower edge of the piedmont plain. A base-level plain commonly is the flood plain of a base-level stream or a playa. 
Base-level stream-A large wash or river at the lower edge of the piedmont plain. Base level is a local level in the larger basin, that in a geologic sense is temporary, to which tributary runoff flows.

Braided channel (stream)-A channel that divides into or follows an interlacing or tangled network of several small branching and reuniting shallow channels separated from each other by branch islands or channel bars, resembling in plan the strands of a complex braid (Bates and Jackson, 1980, p. 79). On the average, for every fork there is a corresponding joining of the small channels.

Channel link-A segment of a channel on a distributary-flow area defined by one of three types of vertice on each end: (1) forks where a channel bifurcates, (2) joins where channels combine, and (3) outlets where channels leave the toe of the distributary-flow area.

Concave/convex contours-General shape of the contour in plan view looking downstream. Convex contours bow downstream and concave contours bow upstream.

Contour-band width-Distance between a tangent to the largest crenulation of a contour that points upstream and a tangent to the largest crenulation of the same contour that points downstream (the distance, in inches, on a 7.5-minute topographic map). The largest crenulations commonly are at a canyon at a high-order drainage channel.

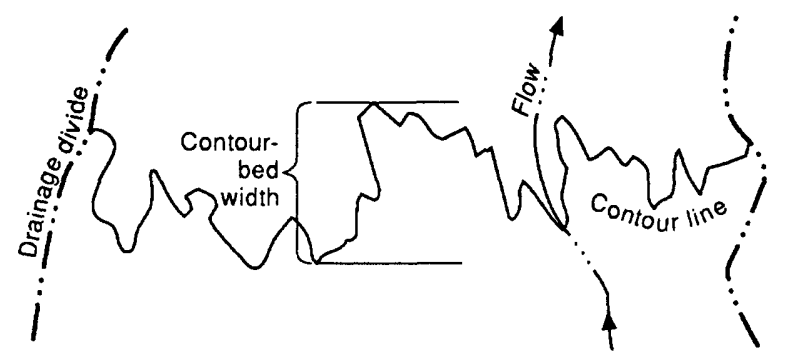

Contour crenulation-A small rounded projection of a contour line. Where used in reference to drainage texture, the projections or barbs are in the upslope direction.

Contour sinuosity-Ratio of the length of the contour, in miles, and the length of the straight line, in miles, that approximately splits the distance between the largest and smallest crenulations and generally parallels the trend of the contour.

Debris flow-Rapid mass movement of a dense, viscous mixture of rock fragments, fine earth, water, and possibly entrapped air. A mudflow is a debris flow that has dominately sand size or smaller particles (Peterson, 1981, p. 50). 
VIII

Desert varnish (rock varnish)-A natural accretion of manganese and iron oxides, clay minerals, trace elements, and small quantities of organic matter that form dark coatings on stable surfaces in terrestrial weathering environments (Dorn and Deniro, 1985 , p. 1472).

Diffluence-Point of separation of a stream channel into two or more channe1s (streams).

Distributary channel (stream)-Diffluent or separated channel downstream of a diffluence commonly having a terrace independent of other distributary channels. The number of forks in the channels commonly exceeds the number of locations where channels join.

Distributary-flow area (DFA)-Area, in square miles, on the piedmont downstream from the primary diffluence and limited by the potential areal extent of major floods. The stream channels below the diffluence are separated by a wide variety of interfluves that range from high ridges well above large floods to low indistinct ridges (as found on many alluvial fans that are subject to frequent flooding and scour and fill).

Drainage-basin area (DA)-Area, in square miles, drained by a stream that is upstream from the primary diffluence.

Drainage-basin axis (LB)-Air-line distance, in miles, from the outlet of the longest water course at the primary diffluence to the point on the basin divide used to determine the longest water course (the longest water course includes an extension of the map stream symbol to the drainage-basin divide; Office of Water Data Coordination, 1977, p. 7-10).

Drainage texture-The spacing of low-order drainage channels across a land surface at right angles to the drainage axis or direction. For this study, the number of uphill kinks or barbs in 1 -inch widths of contour lines on 7.5-minute topographic maps were used to define low-order drainage channels (Doehring, 1970, p. 3111). Broad gradual bends of contour lines were not used to represent the active channels.

Engineering time-For this report, a period of about 100 years. The 100 -year flood commonly is used for the regulation of flood plains. The design life of engineering structures commonly is less than 100 years.

Fanhead trench-A stream channel entrenched into the upper, and possibly the middle, part of the fan (Bull, 1964, p. iv).

Flood hazard-Flood discharge, flood depth, flood velocities, rapid rise of flow depth, and erratic or unpredictable floodflow paths that potentially can result in personal injury, loss of 1 ife, damage and (or) loss of property, and personal inconvenience such as travel delays. 
Inselberg-A prominent isolated residual knob or hill partly buried by the debris derived from and overlapping its slopes (Bates and Jackson, 1980, p. 319).

Inset fan-An alluvial fan that has formed on the surface of an old fan or between old fans.

Interfluve-The ridge between channels.

Intersection point-The point, shown on the longitudinal profile, at which the main channel merges with the fan surface (Hooke, 1967, p. 450). The intersection point on inset fans separates the areas upstream that are undergoing erosion from the depositional areas downstream.

Location factor of primary diffluence (v)-Ten times the ratio of the distance from the primary diffluence to the base of the piedmont plain, in miles, and the total length of the piedmont plain, in miles.

Map stream symbol-Topographic map symbols for sand channels and small washes. Sand channels are shown by a stippled pattern. Small washes and intermittent streams are shown as blue 1 ines on recent and as brown lines on older 7.5-minute topographic maps.

Mean-relief ratio of the drainage basin (MRDA)-Ratio of the total relief of the drainage basin ( $R B$ ), in feet, and the length of the drainage basin axis (LB), in feet. Chow (1964, section 17, p. 13) states the ratio as:

$$
M R D A=R B / L B .
$$

old fan-An alluvial fan or plain that no longer has distributary flow and was commonly formed before the Holocene Epoch.

0ld-fan remnant-Part of an old-fan surface that has been eroded or partially buried.

Pediment-A low gradient, subplanar, topographic surface located at the foot of a mountain mass and that meets the mountain front at an angular junction. A pediment is underlain by consolidated rock, is usually fan-shaped in plan, and may have an alluvial veneer not exceeding $50 \mathrm{ft}$ in thickness (Doehring, 1970, p. 3109). Floodwater is normally confined to defined channels.

Piedmont plain-Region extending from the mountain front to the basin floor that includes pediments, old fans, alluvial fans, bajadas, and distributary-flow areas. 
Point of origin-Arbitrary location of interest along a wash used to begin the method for delineating distributary-flow areas.

Potential divide-Boundaries delineating the probable limits of distributary flow resulting from floodflow that passes the primary diffluence.

Primary diffluence (PD)-Diffluence or bifurcation below which flow is distributary and above which the 100-year flood is contained in the channel and flood plain and flow is tributary (with the possible exception of minor diffluences in the drainage basin). For alluvial fans, the primary diffluence is the same as the apex.

Ruggedness number of the drainage basin (Relative Relief Number, RN) 一 Ratio of the total relief of the drainage basin (RD), in miles, and the square root of the drainage area (DA), in miles. Ruggedness number of the drainage basin can be stated as

$$
\mathrm{RN}=\mathrm{RD} /\left(\mathrm{DA}^{0.5}\right)
$$

(Melton, 1965, p. 23).

Segmented alluvial fan-An alluvial fan composed of several segments that are the result of erosional and depositional changes over a period of time (French, 1987, p. 226). The segments may be recognized as lengths of uniform slope along a longitudinal profile of the fan surface.

Stream terrace-Level surface in a stream valley commonly parallel to the stream channel and representing the remnants of an abandoned flood plain, streambed, or valley floor produced during a former stage of erosion or deposition (Bates and Jackson, 1980, p. 617).

Texture domain-A region consisting of a unique drainage texture (Doehring, 1970, p. 3111-3113). The region is distinguished by the size and orientation of the crenulations that may be characteristic of the depths of channels, the drainage pattern, and whether erosion or deposition is the dominant process at work.

Toe-Boundary most distant from the primary diffluence that delineates the probable limits of distributary flow resulting from floodflows that pass the primary diffluence.

Tributary channel (stream)-A channel which joins another channel at a confluence. 


\title{
FLOOD HAZARDS OF DISTRIBUTARY-FLOW AREAS IN SOUTHWESTERN ARIZONA
}

\author{
By
}

H.W. Hjalmarson and S.P. Kemna

\begin{abstract}
Distinguishing features of flood hazards of distributary-flow areas in southwestern Arizona were studied using hydrologic and physiographic characteristics. These characteristics were defined for 39 sites that included both areas with a single diffluence (separation of a single channe1) and two channels separated by a high ridge as well as more complex areas where active alluvial fans spread floodflow in an erratic manner. Areas drained above the primary diffluences (apices of alluvial fans) ranged from 0.48 to 95.9 square miles and the distributary-flow areas ranged from 0.32 to 38.8 square miles.

Primary diffluences can be identified by using 7.5 -minute topographic maps, aerial photographs and reconnaissance, soils and geologic maps, and field reconnaissance. A procedure for consistently identifying the primary diffluence is based on established physiographic and hydrologic principles. Major factors used to identify and categorize distributaryflow areas below the primary diffluences include (1) differences in vegetation density across distributary-flow areas; (2) differences in soil color across distributary-flow areas; (3) drainage texture of some distributary-flow areas, pediments, and inactive alluvial fans; and (4) the random nature of channel links.
\end{abstract}

The flood-hazard degree for five types of distributary flow is based on the potentially erratic paths of floodflow. A higher hazard degree was assigned to areas where the potential for lateral relocation of flow paths was large. The flood-hazard degree is related to physiographic characteristics such as the size and number of drainage channels of the distributary-flow area, the slope of the drainage basin, and the average contour-band width of the drainage area.

\section{INTRODUCTION}

\begin{abstract}
Many areas of distributary flow exist in southwestern Arizona (fig. 1). Distributary-flow areas (DFA's) commonly are on piedmonts downslope from mountains. A DFA contains a primary diffluence where floodflow in a single channel separates into two or more channels and is bounded by the potential areal extent of major floods. The channels commonly remain separated and have terraces. In some DFA's, the channels divide and join and are separated by interfluves that are above the level of large floods (recurrence interval at about 100 years) (Hjalmarson, 1980). In other DFA's, the interfluves are below the level of large floods (Hjalmarson, 1978).
\end{abstract}




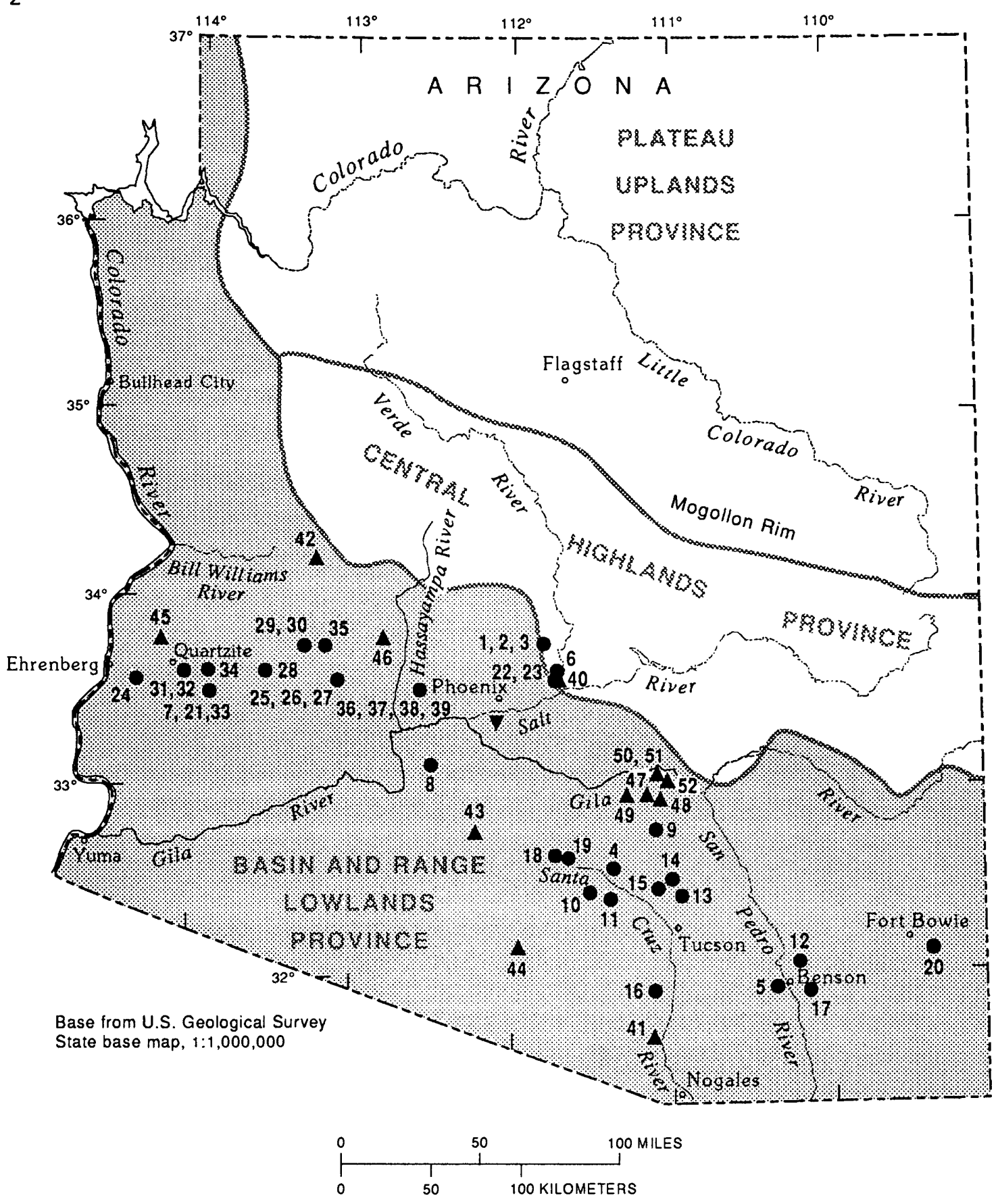

EXPLANATION

5 DISTRIBUTARY-FLOW SITE-Number, 5, is site number

$\$ 52$ DRAINAGE-TEXTURE SITE-Number, 52, is site number

$\nabla$ STREAMFLOW-GAGING STATION 09512200, SALT RIVER TRIBUTARY IN SOUTH MOUNTAIN PARK, AT PHOENIX

Figure 1.-Study area (shaded), distributary-flow sites, drainage-texture sites, and streamflow-gaging station. 
Many DFA's in Arizona have different characteristics than the alluvial-fan areas in Nevada and California that were used to establish Federal Emergency Management Agency (FEMA) guidelines and specifications for work related to flood-insurance studies (DMA Consulting Engineers, 1985; Federal Emergency Management Agency, 1991). The detailed methodology used by FEMA to define the magnitude and areal extent of floodflow is applicable primarily to alluvial fans with the apices in steep canyons at the mountain front (DMA Consulting Engineers, 1985). In Arizona, however, most fan apices (primary diffluence as used in this study) are downslope from the mountain front, commonly in the lower half of the piedmont plain. DFA's in Arizona, which could be the result of climatic changes, are relatively less active (Pleistocene Epoch, Melton, 1965, p. 10) than DFA's in Nevada and California, which could be the result of tectonic activity (DMA Consulting Engineers, 1985; Dawdy, 1979).

Flood hazards of DFA's in Arizona need to be clearly and unambiguously defined so that development of these lands can be appropriately managed. For this reason, flood-hazard characteristics and, in particular, the random manner of flow paths in DFA's were studied by the U.S. Geological Survey in cooperation with the Arizona Department of Water Resources and the Flood Control District of Maricopa County.

\section{Purpose and Scope}

This report presents the results of an investigation of several distinguishing features of flood hazards of DFA's in natural environments in southwestern Arizona. Land-surface features are used to qualitatively and quantitatively identify potential flood hazards. The report describes the analysis and classification of the types of DFA's and the associated potential degree of flood hazard related to the randomness of flow paths. Physiographic characteristics of $\mathrm{DFA}^{\prime}$ 's were identified using topographic maps, aerial photographs, orthophotoquad maps, published soil surveys, and field reconnaissance. The 39 sites selected for this study represent the various types of DFA's in southwestern Arizona. Many of the terms used to describe the geomorphology, flood characteristics, and flood hazards are given in the section "Glossary of Terms."

The characteristics of the drainage basins and DFA's, including topography, geology, soils, precipitation intensity, and vegetation, were defined for the 39 sites. Physical characteristics, such as the mean-relief ratio of the drainage basin and the area of the DFA, were measured on 7.5-minute topographic maps. Additional qualitative characteristics, such as soil color and relative density of vegetation, were obtained from aerial and ground reconnaissance and from photographs. The descriptions of alluvial and geomorphic features are from unpublished and published information by Cooley (1977). The estimated type and degree of flood hazard, which were based mostly on the potential random manner of flow paths, and the potential amount of land inundated by the 100-year flood were related to several geomorphic variables using regression methods. 


\section{Relation Between Alluvial Fans and Distributary-Flow Areas}

01d alluvial fans that were deposited during the Pleistocene Epoch (Melton, 1965, p. 10) are undergoing erosion today and commonly have well-incised tributary-drainage systems. Many alluvial fans, which are actively aggrading today, are component landforms that overlie or are between old-fan surfaces. In places, old-fan remnants crop out in the midst of an actively aggrading area. A complex relation exists between old fans of different ages and active areas of distributary flow that are presently depositing sediment over extensive areas.

DFA's, which include alluvial fans, have a wide variety of geomorphic characteristics and associated flood hazards. The channels of a DFA become separated at the primary diffluence by a variety of interfluves that range from high stable ridges to low indistinct unstable ridges as found on many alluvial fans. The types of DFA's are related to the number of potential paths that floodflow may follow on the DFA. The simplest type of DFA is one in which floodflow separates into two well-defined stable channels with an interfluve higher than the potential 100-year flood. The most complex type of DFA has erratic flow paths that appear to occur randomly over most of the land surface.

\section{Selection of Sites}

The areas studied in southwestern Arizona were selected using 7.5-minute topographic maps, aerial photographs, and a map of Arizona showing geomorphic features by Cooley (1977). The geomorphic map was used to identify general areas of distributary flow, and the 7.5-minute topographic maps and aerial photographs were used to identify specific areas for study. An aerial reconnaissance also was used to confirm selected areas and to select a few additional areas to obtain a wide range of types of DFA's on the basis of visual appearance. The primary goal to obtain a representative sample of the types of DFA's across southern and western Arizona in the Basin and Range lowlands was accomplished (fig. 1 and table 1). The secondary goal to obtain a representative sample of drainage area, distributary-flow area, slope of drainage basin, and location of the primary diffluence on the piedmont plains also appears to be accomplished. The 39 sites are numbered in the order selected. Thirteen additional sites (fig. 1, sites 40-52) on old-alluvial fans where there no longer is distributary flow and on pediments also were used to identify differences of drainage texture between old fans, pediments, and DFA's.

\section{GEOMORPHIC FEATURES AND FLOOD-HAZARD ZONES}

Most of the distributary-flow areas in Arizona are in the Basin and Range lowlands water province. The province has many northwestwardtrending mountain ranges separated by desert base-level plains. Streams generally head in the mountains and sometimes traverse the pediments to the large streams, such as the San Pedro River, in the base-level plains. DFA headwaters drain pediments (fig. 1, sites 1-3), old-fan deposits (sites 23 and 33 ), and mountains (sites 4 and 21). DFA's in southwestern Arizona 
Table 1.--Location and selected characteristics of sample sites

[PD, primary diffluence; DFA, distributary-flow area]

Site name $\begin{gathered}\text { Site } \\ \text { number } \\ (f i g .1)\end{gathered}$ Location of primary diffluence Selected characteristics

\begin{tabular}{|c|c|c|}
\hline $\begin{array}{l}\text { Cave Creek Wash } \\
\text { tributary no. } 1 \\
\text { near Black } \\
\text { Mountain }\end{array}$ & 1 & $\begin{array}{l}\text { Lat } 33^{\circ} 47^{\prime} 37^{\prime \prime}, \text { long } 111^{\circ} 54^{\prime} 53^{\prime \prime}, \\
\text { in sec. } 11, \text { T. } 5 \text { N., R. 4. E., } \\
\text { Maricopa County, } 3 \text { miles } \\
\text { southeast of Cave Creek, } \\
\text { tributary to Cave Creek. }\end{array}$ \\
\hline
\end{tabular}

Cave Creek Wash tributary no. 2 near Black

Mountain

Cave Creek Wash tributary no. 3 near Black Mountain
Lat $33^{\circ} 46^{\prime} 43^{\prime \prime}$, long $111^{\circ} 54^{\prime} 28^{\prime \prime}$, in sec. 13, T. 5 N., R. 4 E., Maricopa County, 4 miles southeast of Cave Creek, tributary to Cave Creek.

The $P D$ is between inselbergs in a transitional area between a pediment and an alluvial plain. On the DFA, the channels divide and combine at many locations, and in places, they are separated by $h$ igh $r i d g e s$ (Hjalmarson, 1978). Soils along active channels are distinctly lighter than soils of interfluves. Density of vegetation increased along active channels. The slope of an active channel is generally uniform with a slight flattening at the lower end. On the alluvial plain, minor irregularities in channel slope occur at local diffluences where there is flattening and steepening of slope. At the lower end of the DFA, the channels become entrenched and are tributary before entering Cave Creek, which acts as a base-Level stream.

At the PD, the flow is confined between an inselberg and a ridge. The PD is in a transitional area between the pediment and an alluvial plain. On the DFA, channels are separated by low ridges and scattered high ridges. Channels divide and combine at many locations over the entire surface. The soils in the active channels are slightly lighter in color than the soils on the ridges. Density of vegetation increased along active channels. The slope of an active channel is uniform with small irregularities to about the middle of the DFA. The profile for the lower DFA has a concave shape. At the lower end of the DFA, the channels become entrenched and are tributary near Cave Creek and Union Hills. Cave Creek acts as a base-level stream but to a lesser degree than at site 1 .

Lat $33^{\circ} 46^{\prime} 10^{\prime \prime}$, long $111^{\circ} 54^{\prime} 08^{\prime \prime}$ in sec. 24, T. 5 N., R. 4 E., Maricopa County, 5 miles southeast of Cave Creek, tributary to Cave Creek.
Unnamed Wash at north side of Picacho Peak
Lat $32^{\circ} 38^{\prime} 35^{\prime \prime}$, long $111^{\circ} 26^{\prime} 22^{\prime \prime}$, in sec. 17, T. 9 S., R. 9 E., Pinal County, 6 miles southeast of Picacho, tributary to the Santa Cruz River.
At the PD, the flow is confined between two ridges that lie between two inselbergs. The PD is in a transi$t i$ onal area between the pediment and an alluvial plain. On the DFA, the channels are separated by low ridges and scattered high ridges. Channels divide and combine at many locations over the entire surface. The soils in the active channels are slightly lighter than the soils on the ridges. Density of vegetation increased along active channels. The slope of an active channel in the DFA is uniform with small irregularities to about the middle of the DFA. Below this point, the profile has a concave shape. The channels become entrenched at the lower end of the DFA near Union Hills. At this location, the channels are near the toes of several bedrock hills.

The PD is at an intersection point, and floodflow is unconfined across the DFA. A distinct change of color occurs from the dark-red surface of the old fan to the light-colored soil of the DFA. Rocks on the old-fan surface that are above and on either side of the DFA are covered with desert varnish. There is a distinct increase in the size and density of vegetation on the DFA. The vegetation on the right side of the DFA is larger and more dense than the vegetation on the left side. The profile of an active channel in the DFA has a slightly concave appearance. About 1.5 miles below the PD, the flow becomes tributary. 
Table 1.--Location and selected characteristics of sample sites--Cont inued

Site name $\begin{gathered}\text { Site } \\ \text { number } \\ (f i g .1)\end{gathered}$ Location of primary diffluence Selected characteristics

Cottonwood
Canyon Wash

at Benson

Indian Bend

Wash tributary

near Pinnacle

Peak
$5 \quad$ Lat $31^{\circ} 56^{\prime} 28^{\prime \prime}$, long $110^{\circ} 18^{\prime} 34^{\prime \prime}$, in sec. 21, T. 17 S., R. 20 E., Cochise County, 2 miles south of Benson, tributary to the San Pedro River.
The PD is at a narrows where the ridges of the basin-fill deposits abruptly end. In the DFA, the color of the more active channels is lighter than the surrounding basin-fill deposits. The color change is not distinct. There is a distinct increase in size and density of the vegetation on the DFA. The profile of an active channel in the DFA is slightly concave with a few irregularities. The San Pedro acts as a base-level stream and forms the boundary at the toe of the DFA. Channels near the river are filled with eroded material from the basin-fill deposits. In contrast, a channel to the right of the DFA is deeply entrenched near the same elevation of the main channel of the San Pedro River.

6 Lat $33^{\circ} 41^{\prime} 48^{\prime \prime}$, long $111^{\circ} 51^{\prime} 56^{\prime \prime}$ in sec. 17, T. 4 N., R. 5 E., Maricopa County, 4 mi les east of Currys Corner, tributary to the Indian Bend Wash.

Flow at the PD is constricted by a high ridge of an oldfan remnant on the right side and by a mountain on the left side. At the PD, floodflow is confined to the deeply entrenched channel. On the DFA, several small channels are separated by low ridges. The entire DFA is subject to inundation during major flooding. The lightest colored soils are in the active channels. Scattered trees are along the active chamels. In the upper DFA, there is a general steepening of channel slope for about 4,000 feet downstream from the PD. The channel profile of the middle and lower DFA has a concave appearance. The contours change from concave to convex (plan view) at the toe and the channels become tributary. Downstream from the toe, there is a large area of unconsolidated, slightly dissected al luvium.

The PD is at the mountain front with a steep mountain slope forming the right bank and an alluvial slope on the left. There is some entrenchment, but, with minor filling of the channel bed, floodwater of the 100-year flood can spread laterally into an adjacent DFA. The main channel generally is well incised in the upper DFA. Several small distributary channels that are separated by high, wide ridges above the level of the 100 -year flood are to the left of the main channel. In most places, there is a distinct boundary between the dark-varnished ridges and the light-colored soils in the active flow areas. In other areas, there is a gradual transition of the darkness, which indicates areas where flooding is infrequent. Trees are dense along active channels and scattered bushes are on the ridges. Overall, the area has little vegetation. The profile of an active chamel is generally uniform with small irregularities. Tyson wash acts as a base-level stream about 9 miles downstream from the $P D$.

The PD is 7,000 feet wide, consists of several channels, and is bounded by mountains on the left and an inselberg on the right. In the DFA, there are many separated streams that divide and combine. A few inselbergs are in the DFA, and most of the ridges are low. The soils are lighter colored along the active channel. Trees are along active channels and scattered bushes are along the ridges. The profile of an active channel is slightly concave with small irregularities at local diffluences. Rainbow Wash and the Gila River act as the base-level streams. Near the toe, many small channels enter a few larger channels. 
Table 1.--Location and selected characteristics of sample sites--Cont inued

\begin{tabular}{|c|c|c|c|}
\hline Site name & $\begin{array}{c}\text { site } \\
\text { number } \\
\text { (fig. 1) }\end{array}$ & Location of primary diffluence & Selected characteristics \\
\hline $\begin{array}{l}\text { Brady Wash } \\
\text { near U.S. } \\
\text { Highway } 89\end{array}$ & 9 & $\begin{array}{l}\text { Lat } 32^{\circ} 46,42^{\prime \prime}, \text { long } 111^{\circ} 10^{\prime} 53^{\prime \prime}, \\
\text { in sec. } 35, \text { T. } 7 \mathrm{~s} ., \mathrm{R} .11 \mathrm{E} ., \\
\text { Pinal County, } 17 \mathrm{mi} \text { iles south- } \\
\text { east of Picacho Reservoir, } \\
\text { tributary to the Santa } \\
\text { Cruz River. }\end{array}$ & $\begin{array}{l}\text { The PD is near the boundary of the pediment and the allu- } \\
\text { vial plain. Floodwater is confined to one incised } \\
\text { channel. In the DFA, several defined stream channels } \\
\text { divide and combine over the entire area. Several } \\
\text { long, wide ridges are above the level of the 100-year } \\
\text { flood. In the lower DFA, the soils are distinctly } \\
\text { lighter in color than the surrounding soils. Soils in } \\
\text { the upper DFA are lighter in color along the defined } \\
\text { channels. Trees are dense along active channels and on } \\
\text { the lower DFA. Scattered trees are along active } \\
\text { channels in the lower DFA and dense trees are at the } \\
\text { toe of the DFA along McClellan Wash. The profile of an } \\
\text { active channel in the DFA has irregularities and is } \\
\text { generally uniform to slightly concave. McClellan Hash } \\
\text { acts as a base-level stream. During major flooding, } \\
\text { most of the water will enter Mcclellan Wash and will } \\
\text { not remain in Brady Wash, which exits the DFA to the } \\
\text { north. }\end{array}$ \\
\hline
\end{tabular}

Santa Cruz

River

tributary

at Samaniego

Hills
10

Lat 32॰30'45", long $111^{\circ} 28^{\prime} 22^{\prime \prime \prime}$, in sec. 36, T. 10 S., R. 9 E., Pinal County, 8 miles southeast of Friendly Corners, tributary to the Santa Cruz River.
At the PD, a single confined channel divides into two distinct confined channels. The channels are wide and flat, composed of loose sand, and are subject to scour and fill. In the upper end of the DFA, the floodwater is confined in two distributary channels. The soil is distinctly lighter in color along the active channels. Trees are dense along active channels and scattered trees and bushes are along ridges. The profile of an active channel is slightly concave. A distinct flattening and then steepening of the channel occurs about $0.3 \mathrm{miles}$ below the $P D$ at the diffluence of a small active alluvial fan. Mountains are near the toe of the DFA about 2.5 miles downstream from the PD.
Los Robles

Wash

tributary

at Samaniego

Hills
11

Lat $32^{\circ} 30^{\prime} 57^{\prime \prime}$, long $111^{\circ} 28^{\prime} 48^{\prime \prime}$, in sec. 34, T. $10 \mathrm{~S} ., \mathrm{R} .9 \mathrm{E}$., Pinal County, 11 miles southeast of Friendly Corners, tributary to the Santa Cruz River.
At the PD, the present channel is confined by a bedrock mountain on the right side and by old alluvium on the left side. In the DFA, the channels are separated by low ridges except for one high ridge in the DFA. The soils in the DFA are lighter in color than the soils of the surrounding old fan. The density of the vegetation is much greater in the DFA than in the surrounding area. The profile of an active channel shows a flattening and then a steepening in the upper DFA followed by about 5,000 feet of fairly uniform slope to the Santa Cruz River. The Santa Cruz River acts as a base-level stream.

\footnotetext{
San Pedro

River

tributary

downstream

from

Johnny Lyon

Hills
}

12 Lat $32^{\circ} 05^{\prime} 00^{\prime \prime}$, long $110^{\circ} 17^{\prime} 24^{\prime \prime}$, in sec. 34, T. 15 S., R. 20 E., Cochise County, 6 miles north of Pomerene, tributary to the San Pedro River.
At the PD, the capacity of the channel is many times the 100-year flood. Below the PD, two distinct wellentrenched distributary channels are separated by a 30-foot-high interfluve, which is a few hundred feet wide. The active channels in the DFA are distinctly lighter in color than the surrounding undisturbed soils. A marked increase occurs in the density of the vegetation along active channels. The channel profile is uniform with several irregularities and a distinct flattening and steepening at small alluvial fans on the flood plain of the San Pedro River, which acts as a base-level stream. 
Table 1.--Location and selected characteristics of sample sites--Cont inued

site
number
Site name 1$) \quad$ Location of primary diffluence

\begin{tabular}{|c|c|c|}
\hline $\begin{array}{l}\text { Santa Cruz } \\
\text { River } \\
\text { tributary } \\
\text { near } \\
\text { Tangerine } \\
\text { Road }\end{array}$ & 13 & $\begin{array}{l}\text { Lat } 32^{\circ} 25^{\prime} 37^{\prime \prime} \text {, long } 111^{\circ} 05^{\prime} 18^{\prime \prime} \text {, } \\
\text { in sec. } 35,{ }^{\prime} \text {. } 11 \mathrm{~S} ., \text { R. } 12 \mathrm{E} . \text {, } \\
\text { Pima County, } 7 \text { miles east of } \\
\text { Marana, tributary to the } \\
\text { Santa Cruz River. }\end{array}$ \\
\hline
\end{tabular}

Ruelas

Canyon

Wash

Cochise

Canyon

Wash

Brawley Wash

tributary

near

Gunsight

Mountain

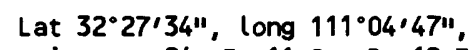
in sec. $24, T .11$ S., R. 12 E., Pima County, 8 miles east of Marana, tributary to the Santa Cruz River.

Lat 32'29'19"', long $111^{\circ} 07^{\prime} 34^{\prime \prime}$, in sec. 9, T. 11 S., R. 12 E., Pima County, 5 miles nor theast of Marana, tributary to the Santa Cruz River.

Lat 32'01'09'", long $111^{\circ} 12^{\prime} 40^{\prime \prime}$, in sec. 22, T. 16 S., R. 11 E.. Pima County, 7 mi les southeast of Three Points, tributary to Brawley Wash.
The PD is on an old-fan surface, and the channel has a capacity several times the 100-year flood. In the DFA, several channels are separated by low ridges. The soils in the active channels are lighter in color than the surrounding old-fan deposits and the interfluves. A marked increase occurs in the density of the vegetation along the active channels, and a gradual increase occurs in the density vegetation from the old-fan surface to the DFA. The channel profile upstream from the PD is uniform. Just below the PD, the channel slope steepens and remains uniform to the toe of the DFA. The Santa Cruz River acts as a base-level stream.

The channel at the PD is wide and $f$ lat. In the DFA, several channels are separated by low ridges. The soils in the active channels are lighter in color than those of the surrounding old-fan deposits and interfluves. A marked increase occurs in the density of the vegetation along the active channel and a gradual increase occurs in the density of vegetation from the old-fan surface to the DFA. The channel profile has a concave shape with a mild steepening for about $1 \mathrm{mile}$ below the PD followed by a uniform slope to the toe of the DFA. The Santa Cruz River acts as a base-level stream.

The PD is at an intersection point on old-fan deposits. In the DFA, the active channels are distinctly lighter in color. The soils on the DFA are lighter in color than the soils on the old-fan remants. The density of the vegetation is greater on the DFA than on the old-fan areas. A distinct flattening and then steepening of the chamel slope occurs at a secondary diffluence 2,500 feet downstream from the PD at the toe of a mountain. The channel profile is uniform with a slightly decreased slope downstream from the secondary diffluence. There is no distinct base-level stream near the toe of the DFA. The precise location of the toe is uncertain because it is in a gradual zone of transition where the channels become entrenched and tributary. The surface of the transition zone has a cone shape.

The PD is at the lower edge of the pediment. The channels of the DFA are incised and separated by high ridges. The soils in the active channels are much lighter in color than soils on the surrounding interfluves. The vegetation is more dense along active channels. The active-channel profile shows a distinct depositional mound at the PD to about 1 mile downstream from the PD. The location of the toe of the DFA is uncertain but appears to be a few miles upslope from Brawley Wash. Brawley Wash appears to act as a base-level stream.

The PD is at a narrows where the ridges of the valleyfill deposits end. In the DFA, several small channels are separated by low ridges. The soils in the DFA are distinctly lighter in color than the soils on the surrounding valley-fill deposits. A distinct increase in the density of the vegetation occurs at and downslope from the PD. In the upper DFA, the 
Table 1.---Location and selected characteristics of sample sites---Cont inued

\begin{tabular}{|c|c|c|c|}
\hline Si te name & $\begin{array}{c}\text { Site } \\
\text { number } \\
\text { (fig. 1) }\end{array}$ & Location of primary diffluence & Selected characteristics \\
\hline $\begin{array}{l}\text { San Pedro } \\
\text { River } \\
\text { tributary } \\
\text { at St. David-- } \\
\text { Cont inued }\end{array}$ & 17 & $\begin{array}{l}\text { Lat } 31^{\circ} 54^{\prime} 08^{\prime \prime}, \text { long } 110^{\circ} 111^{\prime} 34^{\prime \prime}, \\
\text { in sec. } 3 \text {, T. } 18 \mathrm{~S} . \text {. R. } 21 \mathrm{E} . \text {, } \\
\text { Cochise County, } 1 \text { mile east } \\
\text { of Saint David, tributary } \\
\text { to the San Pedro River-. } \\
\text { Cont inued. }\end{array}$ & $\begin{array}{l}\text { vegetation changes from trees to brush to grass in a } \\
\text { downsteam direction. Grass and scattered bushes cover } \\
\text { most of the DFA. The channel profile is slightly } \\
\text { concave in the upper DFA and slightly convex in the } \\
\text { lower DFA. The San Pedro River acts as a base-level } \\
\text { stream. Several headcut channels are in the lower DFA. }\end{array}$ \\
\hline $\begin{array}{l}\text { Greene Wash } \\
\text { tributary } \\
\text { at the } \\
\text { north end } \\
\text { of Sawtooth } \\
\text { Mountains }\end{array}$ & 18 & $\begin{array}{l}\text { Lat } 32^{\circ} 38^{\prime} 45^{\prime \prime}, \text { long } 111^{\circ} 44^{\prime} 42^{\prime \prime}, \\
\text { in sec. } 16, \text { T. } 9 \text { S., R. } 6 \mathrm{E} ., \\
\text { Pinal County, } 7 \text { miles south- } \\
\text { west of Arizona City, } \\
\text { tributary to Greene Wash. }\end{array}$ & $\begin{array}{l}\text { At the PD, several overflow channels occur. The channels } \\
\text { in the upper DFA are smaller and less incised than the } \\
\text { chamels in the lower DFA. Floodflow can spread over } \\
\text { wide areas in the upper DFA, and it becomes conf ined } \\
\text { between ridges in the middle and lower DFA. Within the } \\
\text { upper DFA, light-colored soils appear along the active } \\
\text { channels and local depositional areas. Desert varnish } \\
\text { occurs on high ridges. Vegetation is sparse over most } \\
\text { of the DFA and dense along the active channels. The } \\
\text { channel profile is slightly concave. There appears to } \\
\text { be two segments of uniform slope and the steeper } \\
\text { segment appears to be associated with the upper DFA. } \\
\text { Greene Wash, about } 1 \text { mile below the toe of the DFA, } \\
\text { appears to act as a base-level stream. }\end{array}$ \\
\hline
\end{tabular}

Greene Wash tributary at the east side of Sawtooth Mountains
19 Lat $32^{\circ} 36^{\prime} 52^{\prime \prime}$, long $111^{\circ} 42^{\prime} 04^{\prime \prime}$, in sec. 25, T. 9 S., R. 6 E., Pinal County, 9 miles west of Friendly Corners, tributary to Greene Wash.
Emigrant

Canyon

Wash

near

Fort

Bowie
Lat $32^{\circ} 08^{\prime} 58^{\prime \prime}$, long $109^{\circ} 22^{\prime} 58^{\prime \prime}$, in sec. 3, T. 15 S., R. 29 E., Cochise County, 9 miles south of Olga, tributary to San Simon Creek.
The PD is wide, is generally $V$-shaped, and has a capacity slightly more than the 100-year flood. In the DFA, there is little topographic relief about 1,000 feet below the PD; the main channel is wide and $f l a t$. No apparent change in soil color occurs in the DFA on the bas is of a single aerial photograph. An increase in the density of the vegetation occurs along the larger channels. The ridges are sparsely covered wi th bushes. On the channel profile for the drainage area and the DFA, there appears to be two segments of uniform slope. The junction of the two segments is about 1,000 feet upstream from the PD. Greene Wash acts as a base-level stream.

The PD is bounded by mountains. A single large channel and a few small secondary channels are in the DFA. Light-colored soil occurs in the active channels in the DFA. A distinct increase occurs in the density of vegetation on the DFA and especially along active channels. The channel profile has a general concave shape with two uniform segments. The change in slope that separates the segments occurs about 2 miles downstream from the PD. The location of the toe of the DFA is uncertain and probably occurs where the activechannel profile flattens.

The PD is at the confluence of several tributaries. In the upper DFA, several channels are separated by low ridges. The middle and lower DFA have incised

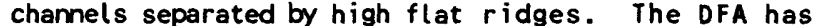
soils that are distinctly lighter in color than soils on the surrounding old-fan surfaces. Desert varnish appears on the ridges in the middle and lower DFA. Density of the vegetation increases at the PD and along the active channels. Vegetation includes trees and bushes, and scattered bushes are on the old-fan deposits. Channel profile is slightly concave, and a large hump is about 2,000 to 3,500 feet downstream from 
Table 1.--Location and selected characteristics of sample sites--Cont inued

\begin{tabular}{|c|c|c|}
\hline Site name & $\begin{array}{c}\text { Site } \\
\text { number } \\
\text { (fig. 1) }\end{array}$ & Location of primary diffluence \\
\hline $\begin{array}{l}\text { Tyson Wash } \\
\text { tributary } \\
\text { downstream } \\
\text { from } \\
\text { Livingston } \\
\text { Hills--Continued }\end{array}$ & 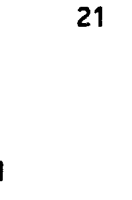 & $\begin{array}{l}\text { Lat } 33^{\circ} 30^{\prime} 48^{\prime \prime}, \text { long } 114^{\circ} 09^{\prime} 42^{\prime \prime}, \\
\text { in sec. } 18, \mathrm{~T} .2 \mathrm{~N} ., \mathrm{R} .18 \mathrm{H} \text {. } \\
\text { Yuma County, } 10^{\mathrm{mil} \text { es south }} \\
\text { of Quartzite, tributary } \\
\text { to Tyson Wash--Cont inued. }\end{array}$ \\
\hline $\begin{array}{l}\text { Indian Bend } \\
\text { Wash } \\
\text { tributary } \\
\text { south of } \\
\text { Lost Dog } \\
\text { Wash }\end{array}$ & 22 & $\begin{array}{l}\text { Lat } 33^{\circ} 34^{\prime} 51^{\prime \prime}, \text { long } 111^{\circ} 49^{\prime} 16^{\prime \prime}, \\
\text { in sec. } 26, \text { T. } 3 \mathrm{~N} ., \text { R. } 5 \text { E., } \\
\text { Maricopa County, } 3 \text { miles } \\
\text { northeast of Scottsdale, } \\
\text { tributary to Indian Bend } \\
\text { Wash. }\end{array}$ \\
\hline
\end{tabular}

Lost Dog Wash near the southern end of McDowell Mountains
Lat $33^{\circ} 35^{\prime} 40^{\prime \prime}$, long $111^{\circ} 48^{\prime} 55^{\prime \prime}$, in sec. 23, T. 3 N., R. 5 E., Maricopa County, 8 miles nor theast of Scottsdale, tributary to Indian Bend Wash. the PD. Another distinct flattening and then steepening occurs at another diffluence about 9,000 feet downstream from the PD. Tyson Wash acts as a base-level stream.

The PD is wide, $f(a t$, and has a capacity several times larger than the 100-year flood. Only small channels are in the DFA. Several entrenched channels are found in the middle DFA, and no channels are in the lower DFA near the toe. The soil in the DFA is lighter in color in the active washes. Soils in the lower DFA are lighter in color than the soils in the middle DFA. An increase in the density of trees occurs along the defined washes, and sparse bushes are on the ridges. The channel profile has a concave shape with a generally decreasing slope below the PD. In the lower DFA, there are no channels, and there is extensive potential for sheetflow.

The channel at the PD is entrenched in old-fan deposits. In the DFA, a few large channels and many small channels are separated by low ridges. The entire DFA generally is lighter in color than the surrounding oldfan surfaces. A significant decrease in the number of rocks covered with desert varnish occurs in the DFA compared to the surrounding old-fan surface. A distinct increase occurs in the density of vegetation in the DFA. Many scattered trees and bushes are in the DFA especially along the larger channels. Channel profile shows a distinct depositional mound from the PD to about 4,000 feet downstream from the PD. The chamel profile in the middle and Lower DFA is concave. The channels become entrenched and are tributary at the toe of the DFA.

Colorado

River

tributary

near

Ehrenberg
Lat $33^{\circ} 34^{\prime} 47^{\prime \prime \prime}$, long $114^{\circ} 24^{\prime} 31^{\prime \prime}$, in sec. 27, 'T. 3 N., R. 21 W., Yuma County, 7 miles east of Ehrenberg, tributary to the Colorado River.

\section{Centennial \\ Wash \\ tributary \\ at Big \\ Horn}

Mountains
Lat $33^{\circ} 39^{\prime} 56^{\prime \prime}$, long $113^{\circ} 11 / 47^{\prime \prime}$, in sec. 29, T. 4 N., R. 9 W.', Maricopa County, 19 miles south of Aguila, tributary to Centennial Wash.
The channel at the PD is wide, flat, and braided. In the DFA, there are two distinct channels below the PD. The DFA has a general braided appearance with one major anabranch and a few potential anabranches. The DFA has light-colored soils with fewer brown and red-colored soils than the adjacent areas. Desert varnish occurs on the surrounding old-alluvial deposits. A marked increase occurs in the density of vegetation in the DFA. Channel profile shows a distinct depositional lobe from just below the PD to about 1 mile downstream from the PD. Downstream from the depositional lobe, the slope of the active channel is uniform. The Colorado River acts as a base-level stream.

The PD is at a mountain pass and has a main channel that generally is flat and about $0.5-\mathrm{mile}$ wide. In the DFA, there are numerous small channels with many diffluences. Between the small channels, there are generally low ridges and a few scattered island-like high ridges (old-fan remnants). The soils in the DFA are distinctly lighter in color than the surrounding old-fan surface. Significant desert varnish occurs on the old-fan surfaces and old-fan remnants. Scattered bushes and trees are along the larger channels. The channel profile has a uniform slope from the PD to 
Table 1.--Location and selected characteristics of sample sites--Cont inued

\begin{tabular}{|c|c|c|}
\hline site name & $\begin{array}{c}\text { Site } \\
\text { number } \\
\text { (fig. 1) }\end{array}$ & Location of primary diffluence \\
\hline $\begin{array}{l}\text { Centennial Wash } \\
\text { tributary } \\
\text { at Big } \\
\text { Horn } \\
\text { Mountains-- } \\
\text { Continued }\end{array}$ & 25 & $\begin{array}{l}\text { Lat } 33^{\circ} 39^{\prime} 56^{\prime \prime}, \text { long } 113^{\circ} 11,47^{\prime \prime}, \\
\text { in sec. } 29, \text { T. } 4 \mathrm{~N} ., \text { R. } 9 \mathrm{W.}, \\
\text { Maricopa County, } 19^{\text {miles }} \\
\text { south of Aguila, tributary } \\
\text { to Centennial Wash--Continued }\end{array}$ \\
\hline $\begin{array}{l}\text { Centennial } \\
\text { Uash } \\
\text { tributary } \\
\text { near Big } \\
\text { Horn Peak }\end{array}$ & 26 & $\begin{array}{l}\text { Lat } 33^{\circ} 37^{\prime} 02^{\prime \prime}, \text { long } 113^{\circ} 10^{\prime} 02^{\prime \prime} \text {, } \\
\text { in sec. } 3, \mathrm{~T} .3 \mathrm{~N} ., \mathrm{R} .9 \mathrm{~W} ., \\
\text { Maricopa County, } 21 \text { miles } \\
\text { south of Aguila, tributary } \\
\text { to Centennial Wash. }\end{array}$ \\
\hline $\begin{array}{l}\text { Centennial } \\
\text { Wash } \\
\text { tributary } \\
\text { near Burnt } \\
\text { Mountain }\end{array}$ & 27 & $\begin{array}{l}\text { Lat } 33^{\circ} 33^{\prime} 42^{\prime \prime}, \text { long } 113^{\circ} 05^{\prime} 15^{\prime \prime} \text {, } \\
\text { in sec. } 33^{\prime} \text { T. } 3 \mathrm{~N} ., \text { R. } 7 \mathrm{~W} . \text {, } \\
\text { Maricopa County, } 27 \text { miles } \\
\text { south of Aguila, tributary } \\
\text { to Centennial Wash. }\end{array}$ \\
\hline
\end{tabular}

Upper Bouse Wash tributary near Little Harquahala Mountains
Lat $33^{\circ} 38^{\prime} 23^{\prime \prime}$, long $113^{\circ} 35^{\prime} 00^{\prime \prime}$, in sec. 34, T. 4 N., R. 13 W., Yuma County, 9 miles southeast of Hope, tributary to Upper Bouse Wash.
Selected characteristics about $5.5 \mathrm{miles}$ downstream from the PD where there is an abrupt decrease in slope. At this abrupt change in slope, the contours change from straight to concave (plan view). The Harquahala Plains acts as a base-level area.

The PD is in a canyon. In the DFA, a single large channel occurs, and several smaller channels are separated by low ridges. The soil along the active channels is lighter in color than the surrounding old-fan material. Vegetation is dense near the PD, but it is sparse throughout the the middle and lower DFA. The active channel profile shows a generally concave shape with a decrease of slope at the upper end of the inselbergs. The toe is where the contours are concave ( $p l$ an view), and the flow is tributary.

The PD is at a mountain pass and is bounded by a mountain on the left and a gradual slope on the right. Two large channels are separated by a low, wide ridge in the upper DFA. Several small channels are separated by low ridges in the middle and lower DFA. The soils of the DFA are lighter in color in the active chamels. Desert varnish occurs on the neighboring old fan and small amounts of desert varnish occur on the high ridges in the DFA. A greater number of small bushes on the DFA occur than on the surrounding old-fan surfaces. The channel profile generally is concave with small irregularities. The Harquahala Plains acts as a base-level area.

The PD is at an intersection point and near an inselberg. In the DFA, a small channel along each side of the upper DFA is separated by almost no relief across the DFA. The entire DFA is distinctly lighter in color than the bordering old-fan deposits. A distinct change in the amount of desert varnish occurs at the boundary of the DFA. Partial removal or burial of the desert varnish by major flood events occurs on the fringe of the DFA boundary. A distinct increase in the number of bushes occurs in the DFA. Scattered trees are at and downstream from the PD. The channel profile has a generally concave appearance, and a small depositional lobe is downstream from the PD. Harquahala Plains acts as a base-level area. At the toe of the DFA, the contours change from straight to concave ( $p$ lan view). A stock tank is in the middle DFA.

The PD is near two small inselbergs (possibly at the lower edge of a small pediment). In the DFA, two channels are separated by a wide, flat ridge about 1,000 feet downstream from the PD. About 3,000 feet downstream from the PD, several defined channels are separated by low ridges. The soil is slightly lighter in color in the DFA than on the surrounding old-fan deposits. A slight increase occurs in the density of the vegetation on the DFA, and scattered bushes and trees are along the larger channels. The channel profile generally is concave with some irregularities. Centennial Wash acts as a base-level stream and is about 1.5 mile downslope from the toe of the DFA. 
Table 1.--Location and selected characteristics of sample sites--Cont inued

\begin{tabular}{|c|c|c|c|}
\hline Si te name & $\begin{array}{c}\text { site } \\
\text { number } \\
\text { (fig. 1) }\end{array}$ & Location of primary diffluence & Selected characteristics \\
\hline $\begin{array}{l}\text { Centennial } \\
\text { Wash } \\
\text { tributary } \\
\text { near Red } \\
\text { Hills }\end{array}$ & 30 & $\begin{array}{l}\text { Lat } 33^{\circ} 44^{\prime} 08^{\prime \prime}, \text { long } 113^{\circ} 22^{\prime} 42^{\prime \prime}, \\
\text { in sec. } 35,{ }^{\prime}, 5 \mathrm{~N} ., \text { R. } 11 \mathrm{~W}^{\prime}, \\
\text { Yuma County, } 12 \text { miles south- } \\
\text { west of Gladden, tributary } \\
\text { to Centennial Wash. }\end{array}$ & $\begin{array}{l}\text { The channel at the PD has a wide and gently sloping right } \\
\text { bank. In the DFA, two dist inct channels are separated } \\
\text { by an old-fan remnant about } 1 \text { mile wide (the old-fan } \\
\text { remnant attains this width in the middle and lower } \\
\text { DFA). The old-fan remnant generally is 1D feet above } \\
\text { the level of the } 100-y e a r \text { flood. In the DFA, the soils } \\
\text { along the active channels are distinctly light colored. } \\
\text { Scattered trees and bushes are along the two distribu- } \\
\text { tary channels. The channel profile of the largest } \\
\text { distributary channel on the right of the DFA generally } \\
\text { is concave. The slope is fairly uniform from the PD to } \\
\text { about } 2 \text { miles downstream. At this point, the slope } \\
\text { decreases slightly to the toe of the DFA. In the lower } \\
\text { DFA, the two confined channels develop separate } \\
\text { distributary-flow systems. Harquahala Plains acts as a } \\
\text { base-level area. }\end{array}$ \\
\hline
\end{tabular}

Scaddan Wash near Quartzite

Colorado Wash near Quartzite
31 Lat $33^{\circ} 38^{\prime} 33^{\prime \prime}$, long $114^{\circ} 06^{\prime} 30^{\prime \prime}$, in sec. 34, T. 4 N., R. $18 \mathrm{~W}$., Yuma County, 7 mi les east of Quartzite, tributary to Tyson Wash.

Lat $33^{\circ} 37^{\prime} 42^{\prime \prime}$, long $114^{\circ} 06^{\prime} 42^{\prime \prime}$, in sec. 4, T. 3 N., R. 18 W. Yuma County, 7 miles east of Quartzite, tributary to Tyson Wash.
The channel at the PD is deeply incised. In the upper DFA, two distinct channels are separated by a high ridge. In the middle and lower DFA, several distinct channels also are separated by high ridges. The active channels in the DFA are distinctly lighter in color than the old-fan remnants. Extensive desert varnish occurs on the old-fan remnants with a distinct boundary along the active chamels. Scattered trees and bushes are along the active channels, and some vegetation is on the ridges. The channel profile generally is concave and is composed of three segments of uniform slope. The first segment ends near the mountain front adjacent to an inselberg where floodflow is unconfined. The second segment ends near the toe of the DFA. The third segment is short and ends at the toe where the flow is tributary, and the contours are clearly concave (plan view). Tyson Wash is about 3 miles downstream from the toe of the DFA.

The channel at the PD has a gently sloping bank on the $r i g h t$ side. In the DFA, there are two distinct channels separated by a high ridge in the upper DFA. The middle and lower DFA have several distinct channels separated by high irregular ridges. The active channels in the DFA are distinctly lighter in color than the old-fan remants. Extensive desert varnish occurs on the old-fan remants and a distinct boundary appears along the active channels. Scattered trees and bushes are along active channels, and some vegetation is on the ridges. The channel profile generally is concave and composed of three segments that are less distinct than the segments for site 31. The first segment ends near an inselberg. The second segment occurs at the same elevation as the second segment of site 31 , but distributary flow occurs below this point. The contours are concave at the toe ( $p l a n$ view), and the flow is tributary. Tyson Wash is about 3 miles downstream from the toe of the DFA.
Tyson Wash tributary at the front of the Plomosa Mountains
Lat $33^{\circ} 33^{\prime} 58^{\prime \prime}$, Long $114^{\circ} 08^{\prime} 33^{\prime \prime}$, in sec. 32, T. 3 N., R. 18 W., Yuma County, 8 miles southeast of Quartzite, tributary to Tyson Wash.
The channel at the PD is wide and flat. In the upper DFA, a wide main channel occurs with a small secondary channel separated by a low, wide ridge. In the middle and lower DFA, large island-like fan remnants occur. The edge of the DFA has distinctly lighter-colored 
Table 1.--Location and selected characteristics of sample sites--Cont inued

\begin{tabular}{|c|c|c|c|}
\hline $\begin{array}{l}\text { Tyson Wash } \\
\text { tributary } \\
\text { at the front } \\
\text { of the Plomosa } \\
\text { Mountains-- } \\
\text { Cont inued }\end{array}$ & 33 & $\begin{array}{l}\text { Lat } 33^{\circ} 33^{\circ} 58^{\prime \prime}, \text { long } 114^{\circ} 08^{\prime} 33^{\prime \prime}, \\
\text { in sec. } 32, \text { T. } 3 \mathrm{~N} ., \mathrm{R} .18 \mathrm{~W} ., \\
\text { Yuma County, } 8 \mathrm{mi} \text { les south- } \\
\text { east of Quartzite, tributary } \\
\text { to Tyson Wash-- Cont inued. }\end{array}$ & $\begin{array}{l}\text { soils. Extensive desert varnish occurs on old-fan } \\
\text { remnants with a distinct boundary along the active } \\
\text { channels. Scattered trees and bushes are along the } \\
\text { active channels, and some vegetation is on the ridges. } \\
\text { The channel profile is slightly concave with two } \\
\text { segments of uniform slope. The end of the first } \\
\text { segment occurs at a diffluence. Tyson Wash acts as a } \\
\text { base-level stream. }\end{array}$ \\
\hline $\begin{array}{l}\text { Alamo Wash } \\
\text { at Ranegras } \\
\text { Plain }\end{array}$ & 34 & $\begin{array}{l}\text { Lat } 33^{\circ} 30^{\prime} 57^{\prime \prime \prime}, \text { long } 113^{\circ} 47^{\prime} 27^{\prime \prime \prime}, \\
\text { in sec. } 15, \text { T. } 2 \text { N., R. } 15 \text { W., } \\
\text { Yuma County, } 28 \text { miles south- } \\
\text { east of Quartzite, tributary } \\
\text { to Bouse Wash. }\end{array}$ & $\begin{array}{l}\text { The PD is at a mountain pass. The channel at the PD is } \\
\text { entrenched in old alluvium and is bounded by a mountain } \\
\text { on the left bank. In the upper DFA, two distinct } \\
\text { chamels are separated by a high flat ridge. In the } \\
\text { middle and lower DFA, many channels are separated by } \\
\text { low ridges. Large areas in the DFA have light-colored } \\
\text { soils. There are scattered large areas of darker soil. } \\
\text { A large area of desert varnish occurs along the entire } \\
\text { length of the DFA that separates two active regions of } \\
\text { the DFA. Vegetation is sparse except along the larger } \\
\text { channels where there are scattered trees and brush. } \\
\text { The channel profile is slightly concave with two } \\
\text { segments of uniform slope. Ranegras Plain acts as a } \\
\text { base-level area. }\end{array}$ \\
\hline
\end{tabular}

Tiger Wash near Big Horn Mountains
35

Lat $33^{\circ} 43^{\prime} 48^{\prime \prime}$, long $113^{\circ} 17^{\prime} 28^{\prime \prime}$, in sec. 34, T. 5 N., R. 10 W., Maricopa County, 12 miles south of Gladden, tributary to Centennial Wash.
The PD is at a mountain pass. The right bank of the channel is composed of old-fan deposits, and the left bank is a mountain. In the upper DFA, many deeply incised channels are separated by high ridges. In the middle and lower DFA, many small channels are separated by low ridges. In the DFA, the soils along active channels are light in color. The density of bushes increases in the DFA, and scattered trees are along the active channels. The channel profile is concave. In the middle and lower DFA, floodwater will be unconfined, and there probably will be large areas of sheetflow during major flooding.

36 Lat $33^{\circ} 30^{\circ} 52^{\prime \prime}$, long $112^{\circ} 37^{\prime} 07^{\prime \prime}$, in sec. 13, T. 2 N., R. 4 W., Maricopa County, 10 miles nor th of Buckeye, tributary to the Hassayampa River.
The PD is at the lower edge of the pediment. Two distinct channels about 3,000 feet downstream from the PD are separated by a low ridge. In the middle and lower DFA's, many small channels are separated by low ridges. The soils in the DFA are lighter in color than the surrounding areas. A slight increase occurs in the density of bushes in the DFA. The channel profile has a hump at a depositional lobe below the PD. Downslope from the hump, the profile generally is concave. The Hassayampa $R$ iver acts as a base-level stream and is a few miles downstream from the toe of the DFA.

The PD is at the lower edge of the pediment. Several small channels generally are separated by low ridges and a couple of high ridges. The soil is lighter in color in the active channels of the DFA. In the DFA, there is a slight increase in the density of the bushes. The channel profile is slightly concave with a constant slope downstream from a small depositional lobe. The Hassayampa River acts as a base-level stream and is a few miles downstream from the toe of the DFA. 
Table 1.--Location and selected characteristics of sample sites--Cont inued

\begin{tabular}{|c|c|c|c|}
\hline Si te name & $\begin{array}{c}\text { site } \\
\text { number } \\
\text { (fig. 1) }\end{array}$ & Location of primary diffluence & Selected characteristics \\
\hline $\begin{array}{l}\text { Hassayampa River } \\
\text { tributary no. } 3 \\
\text { near the } \\
\text { southern end } \\
\text { of the White } \\
\text { Tank Mountains }\end{array}$ & 38 & $\begin{array}{l}\text { Lat } 33^{\circ} 31^{\prime} 35^{\prime \prime}, \text { long } 112^{\circ} 39 \prime 13^{\prime \prime}, \\
\text { in sec. } 10, \mathrm{~T} .2 \mathrm{~N} ., \mathrm{R} .4 \mathrm{~W} . \text {, } \\
\text { Maricopa County, } 12 \text { miles } \\
\text { north of Buckeye, tributary } \\
\text { to the Hassayampa River. }\end{array}$ & $\begin{array}{l}\text { The PD is on apparent old-fan deposits about } 1 \text { mile } \\
\text { downstream from the lower edge of the pediment. In the } \\
\text { DFA, several small channels generally are separated by } \\
\text { low ridges and a few high ridges. The soil in the DFA } \\
\text { is lighter in color along the active channels. In the } \\
\text { DFA, there is a slight increase in the density of } \\
\text { bushes. The channel profile is slightly concave. The } \\
\text { Hassayampa River acts as a base-level stream a few } \\
\text { miles downstream from the toe of the DFA. }\end{array}$ \\
\hline $\begin{array}{l}\text { Hassayampa River } \\
\text { tributary no.4 } \\
\text { near the } \\
\text { southern end } \\
\text { of the White } \\
\text { Tank Mountains }\end{array}$ & 39 & $\begin{array}{l}\text { Lat } 33^{\circ} 32^{\prime} 38^{\prime \prime}, \text { long } 112^{\circ} 38^{\prime} 35^{\prime \prime}, \\
\text { in sec. } 3, \mathrm{~T} .2 \mathrm{~N} ., \mathrm{R} .4 \mathrm{~W} . \text {, } \\
\text { Maricopa County, } 13 \text { miles } \\
\text { north of Buckeye, tributary } \\
\text { to the Hassayampa River. }\end{array}$ & $\begin{array}{l}\text { The PD is at the lower edge of the pediment. The } \\
\text { channels in the DFA are deeply incised and are } \\
\text { separated by high ridges. Soils in the DFA are lighter } \\
\text { in color than soils in the surrounding areas. A slight } \\
\text { increase occurs in the density of bushes in the DFA. } \\
\text { The channel profile is slightly concave with a fairly } \\
\text { constant slope below a small depositional mound. The } \\
\text { Hassayampa River acts as a base-level stream a few } \\
\text { miles downstream from the toe of the DFA. }\end{array}$ \\
\hline
\end{tabular}


are associated with several types of landforms and a wide range of headwater-drainage areas.

Zones of flood hazard in the deserts of southwestern Arizona are related to geomorphic characteristics of the mountains, piedmonts, and base-level plains. Some general relations between geomorphology and flood hazards are illustrated in figure 2. For this study, flood-hazard zone 1 is the area inundated by the 100-year flood on base-level streams and conforms to the present regulatory flood used by the Federal Emergency Management Agency (1991). Flood-hazard zone 2 is on the base-level plain adjacent to zone 1 and is land subject to erosion along the base-level stream (Hjalmarson, 1988). Zone 2 also includes land subject to inundation by rare floods such as the 500-year flood and is approximately equivalent to FEMA's flood-insurance rate zone X (Federal Emergency Management Agency, 1991, p. 8-2). Zone 3 includes generally flat, undissected alluvial-plain areas where floodflow is shallow and not confined in channels. Zone 3 also includes former flood plains of base-level streams.

Zone 4 includes the slightly dissected alluvial slopes that commonly exhibit a distributary-drainage system. The flood potential of zone 4 has been overlooked (Aldridge, 1968). Typical landforms in the areas of zone 4 are bajadas and single alluvial fans.

The rate of sediment deposition or, in effect, the dynamic characteristics of fans is complex and variable. Some fans seem to aggrade at a rapid rate, and the active channels change frequently. Many fans in southwestern Arizona appear to be less dynamic than fans in areas of southern California (Edwards and Thielmann, 1984) and Nevada (French, 1984) where recent tectonic activity probably has been greater. Soil characteristics, including the age of the bajada soils, indicate that little aggradation or degradation has occurred on some fans and bajadas in Arizona during the Holocene Epoch (about the past 10,000 years). DFA's appear to occupy about 30 percent of the land area in southwestern Arizona (Cooley, 1977).

Floodwater entering the gentler sloping alluvial plains (zone 4) from the confined steeper ephemeral streams in zones 5 and 6 commonly spreads into confined and unconfined distributary channels with a corresponding decrease of velocity and depth. The sediment-laden flow commonly is decreased further by infiltration into the sandy channel beds and adjacent sandy interfluves. Because less water and thus less energy are available to transport sediment, deposition occurs in and along the channels and commonly forms mounds of alluvial material downslope from the primary diffluences. In places, distributary channels may completely fill with sediment resulting in channel avulsions. All the flow from smaller floods may be completely lost to infiltration, depositing entire sediment loads in the DFA. Large floods traversing zone 4 can remobilize and transport the deposited sediment to lower lands. Flood-hazard zone 4 generally is an aggrading area that has small unstable channels and unconfined floodflow or has floodflow in many channels that divide and join.

Flood-hazard zones 5 and 6 include a variety of landforms where the 100-year flood is confined to rigid channels that generally drain areas less than $100 \mathrm{mi}^{2}$. The mountainous areas (zone 6) are the source of weathered rock debris, and stream channels commonly have little 
GEOMORPHIC COMPONENTS

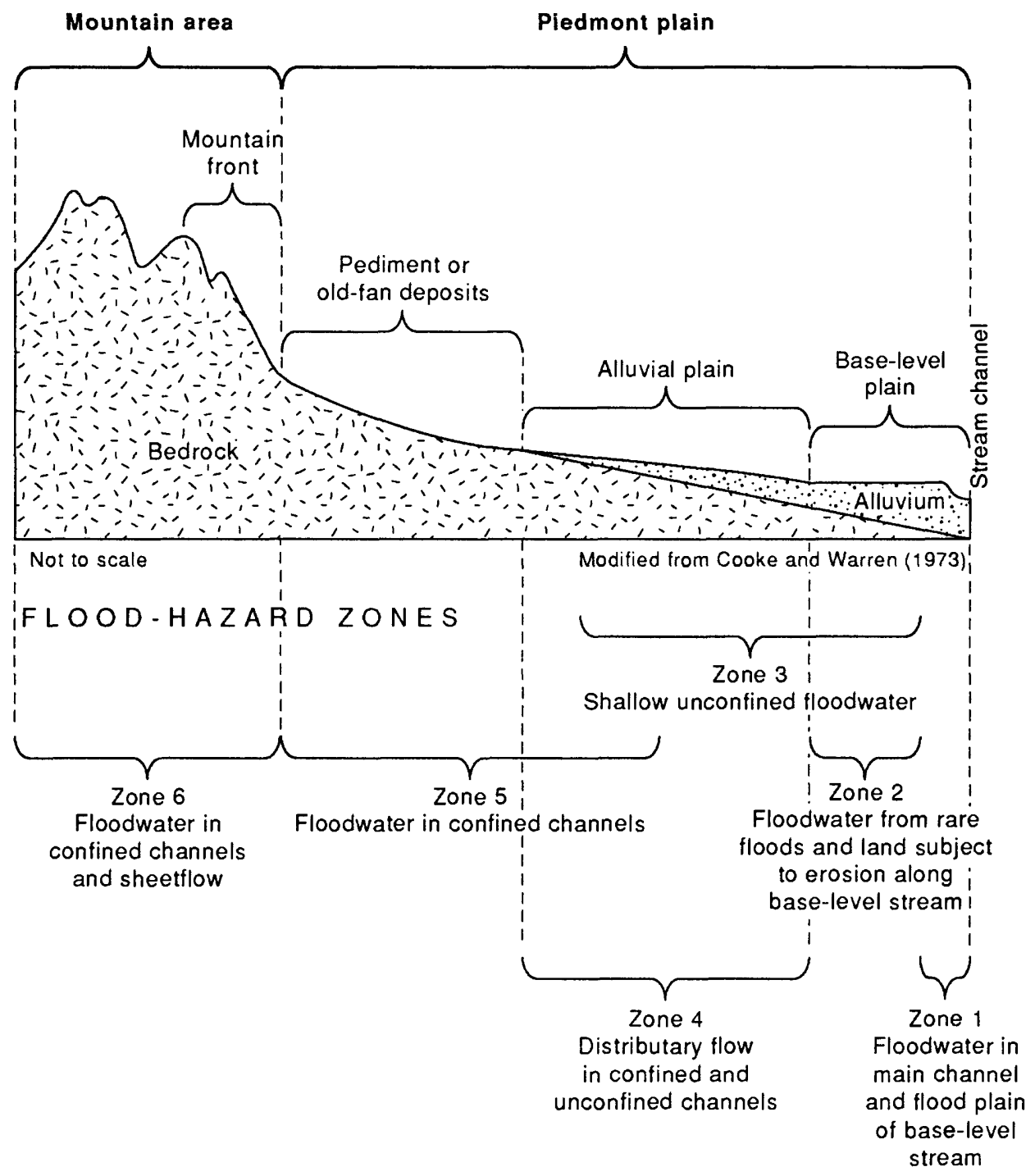

Figure 2.-Diagrammatic geologic section of typical geomorphic components and flood-hazard zones. 
fine-grained material. A sharp break in the gradient is present at the junction of the mountain front and the piedmont plain (zone 5) (fig. 2).

The upper piedmont plain commonly is a pediment area that is sparsely covered by a thin veneer of detritus or old-fan deposits that are relatively stable or are eroding. The stream channels in the upper piedmont area have a mixture of fine- and coarse-grained material, including boulders, and they generally convey the 100 -year discharge without much overbank flow or lateral erosion.

The number and magnitude of floods entering DFA's of zone 4 at the primary diffluences are highly variable. For example, at streamflow-gaging station, Salt River tributary at South Mountain Park, at Phoenix (fig. 1), on an ephemeral stream draining a 1.75-square-mile basin in the Phoenix Mountains, less than one large flood a year delivers material beyond the mountain front. From 1962 to 1986, the gaging station had 8 years of no flow and only 3 years with multiple floods that could transport substantial volumes of material from the mountainous basin. The volume of eroded material passing the gaging station, which is upstream from the primary diffluence, is unknown; however, consideration of the runoff potential may provide some insight to the volume of sediment that leaves the basin. Little potential exists for large volumes of material to be transported during the average year because the average annual runoff is less than 6 acre-ft. Using records of streamflow during 1962 to 1986 , the volume of runoff for storms is estimated at this location by the equation:

$$
V=0.06 Q^{0.7}
$$

where

$$
\begin{aligned}
& V=\text { volume of storm runoff, in acre-feet, and } \\
& Q=\text { flood-peak discharge, in cubic feet per second. }
\end{aligned}
$$

For a discharge of $500 \mathrm{ft}^{3} / \mathrm{s}$, which is a discharge approximately equal to the 10-year flood, the storm runoff is about 5 acre-ft. Only with large concentrations of suspended sediment and a large bedload can this amount of runoff deliver much material to a DFA.

A crude estimate of the annual sediment yield for Salt River tributary at South Mountain Park is about 30,000 $\mathrm{ft}^{3} / \mathrm{yr}$ using a variation of the Universal Soil Loss Equation (Renard and others, 1974). This amount of yield equates to a sediment concentration of about 11 percent for the floods that transport sediment from this basin. If this concentration is assumed for the 10 -year flood, about 0.55 acre-ft of sediment might be transported from the 1.75-square-mile basin.

Although few data are available on how much sediment is needed to cause avulsions, the avulsion activity on DFA's below basins like Salt River tributary at South Mountain Park does not appear to be substantial in relation to engineering time (see section "Glossary of Terms"). The sediment may be deposited in several channels over a total reach of perhaps a few thousand feet. For channels of a few tens of feet wide, the average 
depth of the deposited material would be on the order of hundreths or perhaps a few tenths of a foot. Where the channel gradient is small and the floodflow is unconfined, the depth of the deposited material can be much greater. Under these conditions, it is possible that a channel could be plugged during a single flood. Where the volume of runoff and sediment yield are small and the channels are large and separated by high ridges, however, the avulsive activity probably is not great.

Some DFA's have few distributary channels and floodflow commonly is confined to defined channels. The confined floodlfow provides sufficient energy to transport much of the delivered sediment through the DFA to base-level streams. These DFA's appear to contain minor amounts of locally deposited material, and most distributary channels appear to be stable in engineering time.

Streams draining large mountainous basins generally will have a greater number of floods that can deliver material to DFA's. The volume of runoff, however, is small for most of the basins in the study area, and water is insufficient to deliver large volumes of material. Thus, the amount of aggradation and avulsive activity on DFA's in southwestern Arizona generally is small in relation to engineering time.

\section{TYPES AND DEGREES OF FLOOD HAZARD}

The potential flood hazard on DFA's is associated with several factors, such as depth and velocity of flow, the rate of rise of flood height (flashiness), the magnitude and frequency of floodflows and debris flows, scour and fill along the channel bed and banks, the portion of land above the floodflow, and the erratic relocation of flow paths. Erratic change of flow paths is a major characteristic of DFA's that distinguishes many of these areas from other stream systems. The depth and velocity of floodflow for tributary basins in southern Arizona depends on the size of the drainage basin and to a lesser degree on the mean basin elevation, main channel length and slope, and basin shape (Eychaner, 1984). The magnitude and frequency of floods can be estimated for ungaged tributary streams (Eychaner, 1984; Roeske, 1978); however, the magnitude and frequency of debris flows are unknown or poorly defined. On the basis of conveyanceslope estimates of the velocity and depth of the 100-year flood at the primary diffluences of the sample sites, the Froude number typically is about 1 , and critical and supercritical flow velocities are the rule in parts of the main channels (table 2). The magnitude of the flood hazard in the upper parts of DFA's is related primarily to basin size. The type of DFA's is related primarily to the potential overtopping by the 100-year flood of the ridges that separate distributary-flow channels. The degree of flood hazard is related to the potentially erratic paths of floodflow across the DFA's.

DFA's have two or more divergent channels that are separated by wide or high ridges. Distributary channels are more widely separated than anabranches or braided channels where the multiple channels are separated by small islands and bars. Many distributary channels appear to have independent stream terraces, and channel braids commonly appear to be part of a wide flat channel bed confined by defined banks. 
Table 2.--Summary of channel characteristics, estimated discharge, and Froude number of the 100-year flood for the primary diffluences

$[\leq$, Less than or equal to, $>$, greater than, $\geq$, greater than or equal to, $<$, less than]

\begin{tabular}{|c|c|c|c|c|c|c|c|}
\hline $\begin{array}{c}\text { Site } \\
\text { number }\end{array}$ & $\begin{array}{c}\text { Estimated } \\
\text { Manning's } \\
n \text {, in } \\
\text { feet }^{1 / 6}\end{array}$ & $\begin{array}{l}\text { Slope, } \\
\text { in foot } \\
\text { per } \\
\text { foot }\end{array}$ & $\begin{array}{l}\text { 100-year } \\
\text { flood } \\
\text { discharge, } \\
\text { in cubic } \\
\text { feet per } \\
\text { second }\end{array}$ & $\begin{array}{c}\text { Top } \\
\text { width, } \\
\text { in } \\
\text { feet }\end{array}$ & $\begin{array}{l}\text { Area, } \\
\text { in } \\
\text { square } \\
\text { feet }\end{array}$ & $\begin{array}{c}\text { Average } \\
\text { velocity, } \\
\text { in feet } \\
\text { per } \\
\text { second }\end{array}$ & $\begin{array}{l}\text { Esti- } \\
\text { mated } \\
\text { Froude } \\
\text { number } \\
\text { in main } \\
\text { channel }\end{array}$ \\
\hline 1 & 0.035 & 0.0210 & 4,400 & 302 & 512 & 8.6 & $\leq 1$ \\
\hline 2 & .041 & .0222 & 5,400 & 410 & 324 & 7.5 & 1 \\
\hline 3 & .035 & .0166 & 3,500 & 664 & 655 & 5.3 & 1 \\
\hline 4 & .040 & .0243 & 890 & 57 & 110 & 8.1 & 1 \\
\hline 5 & .035 & .0287 & 3,600 & 461 & 459 & 7.8 & $>1$ \\
\hline 6 & .042 & .0329 & 6,150 & 249 & 567 & 10.8 & $>1$ \\
\hline 7 & .040 & .0108 & 8,200 & 110 & 556 & 14.7 & $>1$ \\
\hline 8 & .035 & .0133 & 3,300 & 647 & 649 & 5.1 & 1 \\
\hline 9 & .025 & .0108 & 7,600 & 201 & 597 & 12.7 & $>1$ \\
\hline 10 & .028 & .0140 & 1,400 & 71 & 143 & 9.8 & $>1$ \\
\hline 11 & .030 & .0080 & 3,100 & 261 & 353 & 8.8 & $>1$ \\
\hline 12 & .035 & .0232 & 2,100 & 118 & 218 & 9.6 & $>1$ \\
\hline 13 & .040 & .0231 & 2,600 & 355 & 402 & 6.5 & $\geq 1$ \\
\hline 14 & .044 & .0356 & 2,200 & 208 & 254 & 8.7 & $>1$ \\
\hline 15 & .030 & .0296 & 1,200 & 76 & 116 & 10.3 & $>1$ \\
\hline 16 & .035 & .0270 & 1,500 & 171 & 213 & 7.0 & $\geq 1$ \\
\hline 17 & .045 & .0156 & 2,200 & 69 & 247 & 8.9 & $\leq 1$ \\
\hline 18 & .030 & .0126 & 1,700 & 271 & 318 & 5.3 & $\leq 1$ \\
\hline 19 & .040 & .0150 & 1,100 & 98 & 172 & 6.4 & $\leq 1$ \\
\hline 20 & .025 & .0275 & 3,800 & 239 & 328 & 11.6 & $>1$ \\
\hline 21 & .031 & .0112 & 2,000 & 195 & 293 & 6.8 & 1 \\
\hline 22 & .035 & .0116 & 4,400 & 353 & 725 & 6.1 & $<1$ \\
\hline 23 & .045 & .0288 & 3,500 & 114 & 325 & 10.8 & 1 \\
\hline 24 & .040 & .0170 & 2,200 & 278 & 371 & 5.9 & 1 \\
\hline 25 & .031 & .0110 & 5,100 & 1,123 & 1,016 & 5.0 & $\leq 1$ \\
\hline 26 & .040 & .0208 & 1,600 & 106 & 196 & 8.2 & 1 \\
\hline 27 & .040 & .0134 & 3,000 & 200 & 428 & 7.0 & $\leq 1$ \\
\hline 28 & .025 & .0126 & 2,500 & 179 & 291 & 8.6 & $>1$ \\
\hline 29 & .025 & .0241 & 1,600 & 90 & 135 & 11.9 & $>1$ \\
\hline 30 & .040 & .0206 & 3,700 & 157 & 384 & 9.6 & $>1$ \\
\hline 31 & .040 & .0406 & 1,000 & 47 & 91 & 11.0 & $>1$ \\
\hline 32 & .040 & .0375 & 1,200 & 203 & 191 & 6.3 & $>1$ \\
\hline 33 & .040 & .0099 & 3,400 & 539 & 746 & 4.5 & $<1$ \\
\hline 34 & .045 & .0080 & 10,300 & 340 & 1,371 & 7.5 & $<1$ \\
\hline 35 & .039 & .0093 & 10,700 & 937 & 1,865 & 5.7 & $<1$ \\
\hline 36 & .030 & .0178 & 2,600 & 203 & 310 & 8.4 & $>1$ \\
\hline 37 & .025 & .0159 & 2,300 & 136 & 231 & 10.0 & $>1$ \\
\hline 38 & .025 & .0148 & 2,000 & 149 & 209 & 9.6 & $>1$ \\
\hline 39 & .025 & .0134 & 2,000 & 97 & 190 & 10.5 & $>1$ \\
\hline
\end{tabular}


To define differences and similarities of potential flood hazards, the DFA's were classified based on measurable and readily observable morphologic features. An apparent difference between these complex systems of divergent stream channels is the number and size of the the ridges separating the distributary-flow channels that are above the level of the 100-year flood. In the upper portion of DFA's, there are differences in the apparent stability of ridges separating channels and in the topographic relief across the DFA's perpendicular to the general direction of flow. Some distributary channels are separated by high ridges far above the apparent potential level of the 100-year flood and other distributary channels are separated by low ridges that can be difficult to distinguish. Some distributary channels are deeply incised with stableappearing erosion-resistant banks and other distributary channels appear to move laterally with ease. Some interfluves are covered with older deposition as shown by dark-colored potentially oxidized soils; other interfluves are covered with light-colored soils that indicate more recent deposition by floodflow. At the risk of oversimplifying these complex systems while recognizing the need for a common frame of reference, five types of DFA's were identified on the basis of differences in ridge stability and the potential amount of land inundated by the 100-year flood.

The level of the 100-year flood in the distributary channels was estimated using the Manning equation. Cross sections that define local relief and channel size in the upper DFA's and at the primary diffluence (table 2) were determined in the field and from topographic maps. Channe1roughness coefficients were estimated from ground and aerial reconnaissance. The amount of discharge in a distributary channel was difficult to estimate because at each diffluence the flow will be either in the channel to the right, in the channel to the left, or in both channels. For the diffluences observed for this study, flow most likely will be in both channels except when there is major blockage of one of the channels. The amount of flow in the left and right channels depends mostly on the relative conveyance and gradient of the channels. At most sites used for this study, reliable estimates of the amount of flow in the separated channels were difficult to obtain because the geometry where the channels fork can change during floodflow.

Floodflow for the 100 -year flood was apportioned in the distributary channels on the basis of relative conveyance of the channels at the primary diffluence and downstream bifurcations. Where the channel conveyance appeared about the same, the flow was assumed to divide in equal amounts. After the flow was apportioned in the channels of the upper DFA's, the 100-year flood level and the portion of land above flood level was estimated. To allow for possible channel blockage at the channel forks, the minimum likely channel conveyance was used to estimate the flood leve1.

The five qualitative types of $\mathrm{DFA}^{\prime} \mathrm{s}$ reflect the potential amounts of flood hazard related to the amount of land in the DFA's that will be inundated by the 100-year flood. Type 4A is used for the smallest amount of hazard for DFA's in flood-hazard zone 4 (fig. 2) and is for areas between distributary channels below a single diffluence where, because the channels are fairly stable, the apportionment of floodflow in the two channels can be determined using conveyance-based hydraulic methods. The greatest potential hazard (type 4E) is for areas where the floodflow is unconfined by interfluves and can spread over the DFA in a random fashion. 
Types 4B-4D reflect the increasing amounts of land that potentially can be inundated by the 100 -year flood. This classification is qualitative and does not imply any equispacing of potential amount of inundated 1 and between the types. Hopefully, this classification because of its general nature can be used to consistently categorize DFA's at a fundamental level. A further description of the types of DFA and a simple method used to quantitatively define the degree of flood hazard follows.

To meet an objective of this study to quantitatively relate potential flood hazards to physical features of the drainage basins and DFA's, a second classification level with increasing specificity was used. The types of DFA's were further subdivided and ranked by flood-hazard degree. The goal of this classification is to quantify the random nature of flow paths using a numerical scale that reflects the portion of the DFA that may be inundated over an engineering time period. Thus, for the convenience of engineers, a value of 1 to 10 was assigned to DFA's that estimates the degree of flood hazard associated with the random nature of floodflow in $\mathrm{DFA}^{\prime} \mathrm{s}$.

A flood-hazard degree of 1 is for the simplest type of floodflow where classic hydraulic methods can be used to estimate the apportionment of flow and the portion of the DFA inundated by the 100-year flood. A flood-hazard degree of 10 is for the active fan with potential flow paths that are considered random. Methods developed by the Federal Emergency Management Agency (1991, Appendix 5) can be used to estimate the distribution of floodflow in the DFA's with a flood-hazard degree of 10 .

The presence or absence of trees and large shrubs in the upper part of the DFA and along defined distributary channels also was used to refine the estimate of the degree of flood hazard. For example, it may be difficult to precisely estimate the flood-hazard degree for type $4 \mathrm{C}$ based only on the topography and color of soils along the ridges. The presence of large trees along the defined channels can indicate that flow paths are relatively more stable and thus, a value of 5 should be used instead of perhaps a value of 6 . Conversely, the presence of wide areas of established trees can indicate that flow paths are unconfined and (or) change location rather frequently and a degree of 7 should be used instead of perhaps a value of 6 .

This method of estimating the degrees of flood hazard may not be precise for some DFA's. Other investigators may have other interpretations that cause inconsistent values of the degree. To facilitate the quantitative analysis presented in this report, however, this method is used for the initial estimate of flood-hazard degree. Some of the initial potential uncertainties of the method are removed by the relations defined in the subsequent analysis.

Regional flood-frequency relations were used to estimate the peak discharge of the 100 -year flood at the primary diffluences (table 2). Losses of floodflow on the DFA's were assumed to be offset by runoff generated on the DFA's, so the peak discharge was assumed to be constant downstream from the primary diffluence. This assumption is conservative because the peak discharge probably is reduced by infiltration, which potentially could be $20 \mathrm{in./hr}$ (Murphy and Moore, 1980), and by storage as floodflow spreads over wide interfluvial areas. 
Type 4A: Floodflow of the 100-year flood is confined to two distributary-flow channels (fig. $3 \mathrm{~A}$ ). A flood-hazard degree of 1 is for stable channels at the diffluence where the percentage of flow in each distributary channel can be determined. A flood-hazard degree of 2 is for unstable channel geometry at the diffluence and the percentage of flow in each distributary channel is unknown and can only be estimated, but the flow is contained in the channels. The channel instability commonly is not great enough to promote avulsion. No sample sites were assigned a flood-hazard degree of 1 , and three sample sites had a flood-hazard degree of 2 .

Type 4B: Floodflow for frequent floods (less than about the 50-year flood) is confined to two defined distributary channels separated by small ridges; however, floodflow of the less frequent 100 -year flood can spread over the ridges and coalesce (fig. $3 \mathrm{~A}$ ). The flood-hazard degree is related to the likelihood of the ridges being overtopped. A degree of 4 is used when the ridges are low in relation to the level of the 100 -year flood. A degree of 3 is used when the ridges generally are high relative to the 100-year flood and the channels appear stable. One site in the sample of $39 \mathrm{DFA}^{\prime} \mathrm{s}$ was given a flood-hazard degree of 3 and no sites were given a flood-hazard degree of 4 .

Type 4C: Channels divide and combine and are separated by at least a few stable ridges that are commonly above the expected level of the 100 year flood (fig. 3B). The expected quantity of flow in the channels commonly is impossible to determine precisely. The degree of hazard is related to the number of ridges that could be overtopped. Flood-hazard degrees of 5 and 6 are used where the estimated level of the 100-year flood is below most of the ridges and about two-thirds and one-half, respectively, of the DFA is above the level of the 100-year flood. A flood-hazard degree of 7 is used where more than one-half of the defined ridges may be overtopped. Flood-hazard degrees of 5,6 , and 7 were assigned to 3,1 , and 2 sample sites, respectively. At several of the sample sites, the primary diffluence was located where the channel was constricted at the toe of a mountain. Distributary flow occurred upstream from the primary diffluence 
at some of these sites; however, floodflow was in a single channel at the mountain. A characteristic profile for a site with a primary diffluence at a mountain constriction and a flood-hazard type of $4 \mathrm{C}$ and a degree of $7(4 C / 7)$ is shown in figure 3D.

Type 4D: Channe1s are separated by low ridges, divide and combine or bifurcate and remain divided, and are separated by low ridges (fig. 3B). Low flows originating on upland slopes will likely occur in the larger distributary channels and large floodflows will occupy many distributary channels. Floodwater can overtop most of the ridges, and the channels are unstable. A degree of 8 is used where the location of the channels is unlikely to change and the ridges are not easily eroded. A flood-hazard degree of 9 is used where the location of channels can change but some separation of flow appears to remain between ridges. Most of the DFA's in the sample were type 4D. Degrees of 8 and 9 were assigned to 5 and 16 sites, respectively. Several of the sample sites had primary diffluences in reaches constricted at a mountain constriction as shown in figure $3 \mathrm{D}$ for flood-hazard type $4 \mathrm{C}$.

Type 4E: Where floodwater occurs over the entire DFA, the DFA typically is an active alluvial fan where flow velocities are high and channels can migrate (fig. 3C). A flood-hazard degree of 10 is used because flow paths are not separated by ridges and appear random. Eight sites clearly had a flood-hazard degree of 10 where floodflow paths appeared to be erratic and unconfined. The likelihood of debris flows may be higher than for the other types of distributary flow.

To summarize, flood-hazard types 4A, 4B, and 4E and degrees 1-4 and 10 can be reliably determined using common hydraulic methods including conveyance-slope estimates, the standard step method of determining discharge of branching channels, and the FEMA method of identifying alluvial-fan hazards. Other types and degrees may be less certain because, for example, it can be difficult to precisely distinguish between type 4D/8 and type $4 \mathrm{C} / 7$. The difference is based largely on whether many of the ridges adjacent to the distributary channels in the upper DFA can be expected to be overtopped during the 100-year flood. Degrees of 6 to 9 may have errors of \pm 1 . A degree of 5 may have been assigned erroneously to a site with a flood-hazard degree of 6 . Other methods can be used to classify and quantify the flood hazards on DFA's; however, this method is presented as a basis for further discussion and analyses in this report. 
24

A. GENERAL SETTING FOR

FLOOD-HAZARD TYPES 4A AND 4B
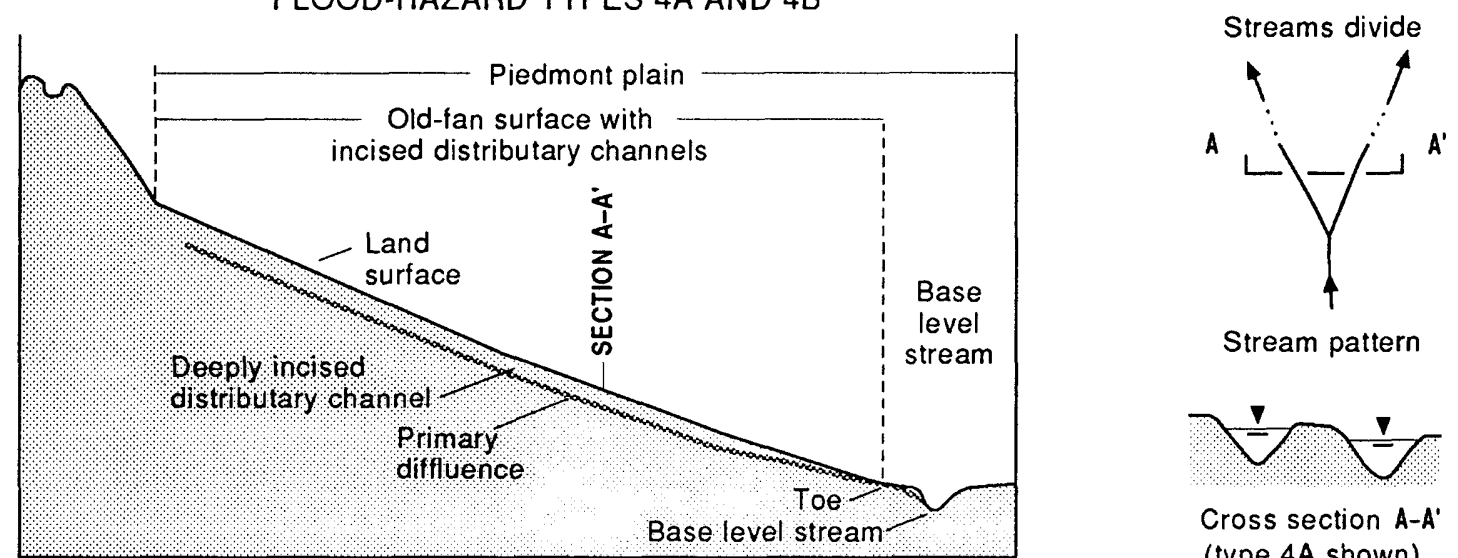

Stream pattern

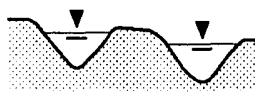

Cross section $A-A^{\prime}$ (type 4A shown)

Not to scale

B. GENERAL SETTING FOR

FLOOD-HAZARD TYPES 4C AND 4D

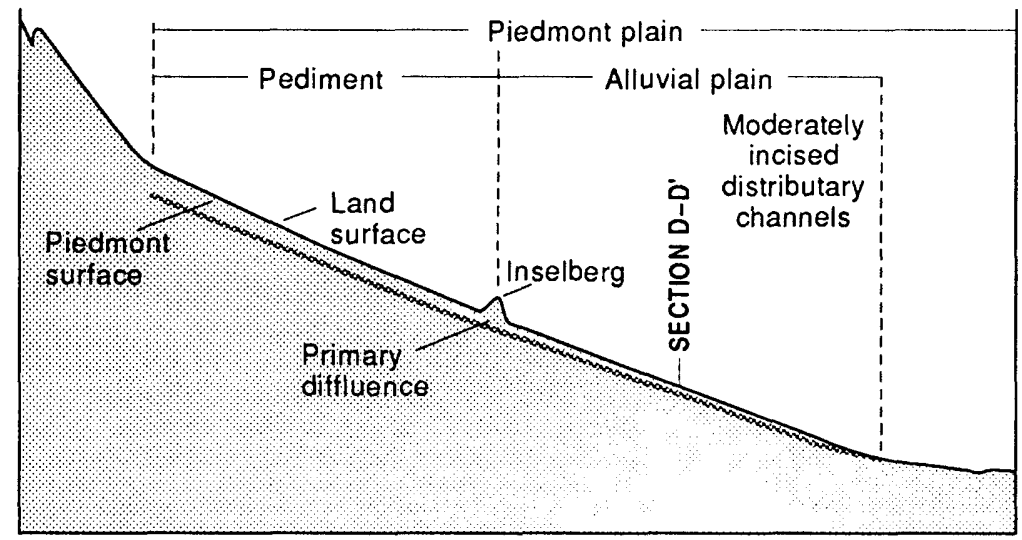

Not to scale

Streams divide

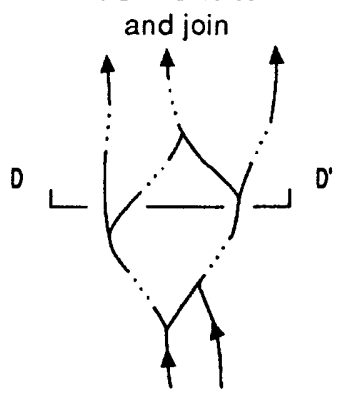

Stream pattern

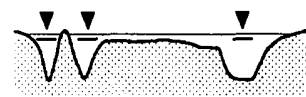

Cross section D-D' (type 4D shown)

Figure 3.-Typical diagrammatic profiles, stream patterns, and cross sections for types of flood hazards in distributary-flow areas in southwestern Arizona. 
C. GENERAL SETTING FOR FLOOD-HAZARD TYPE 4E

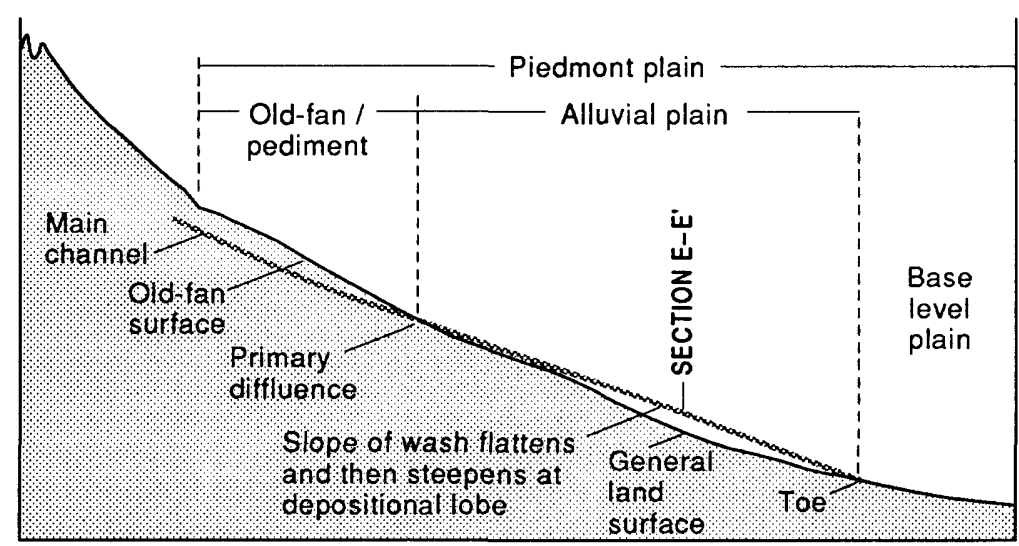

Not to scale

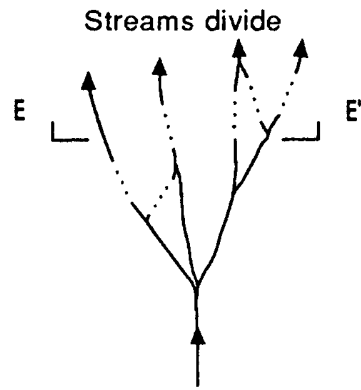

Stream pattern

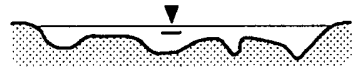

Cross section $E^{-E^{\prime}}$

D. GENERAL SETTING FOR STREAM

CHANNEL CONSTRICTED AT MOUNTAIN WITH FLOOD-HAZARD TYPE 4C

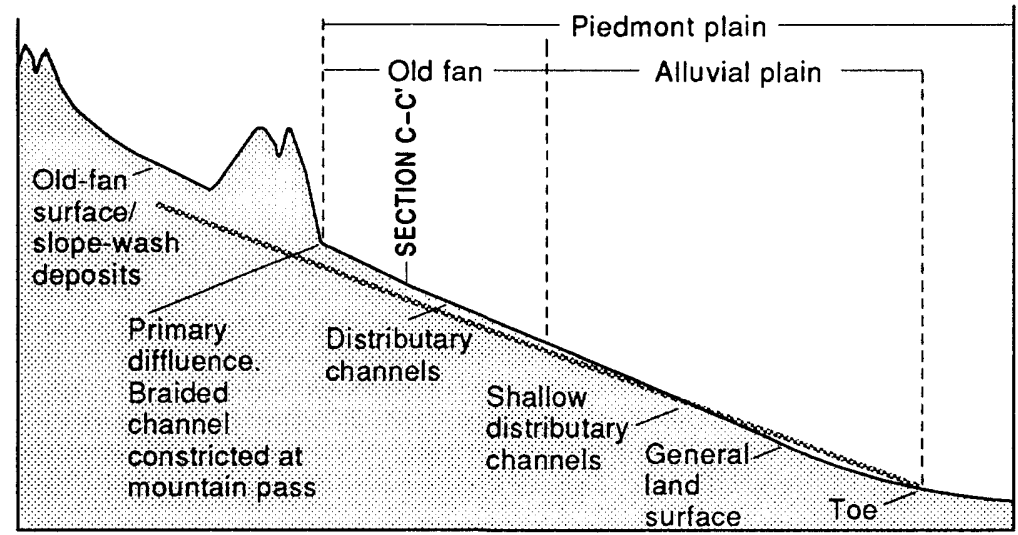

Not to scale

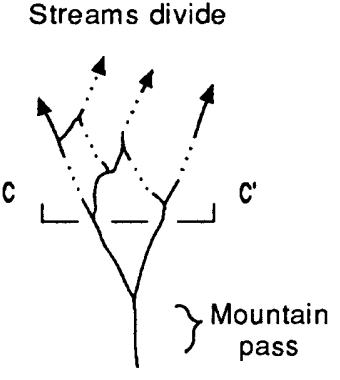

Stream pattern

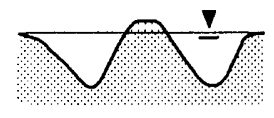

Cross section $\mathrm{C}-\mathrm{C}^{\prime}$ (type 4C shown)

\section{EXPLANATION}

\section{FLOOD HAZARD TYPES}

4A Flow to the 100-year flood confined to two distributary channels

4B Flow of about the 50-year flood confined to two distributary channels but flow of the 100 -year flood can spread over interfluves and coalesce

4C Flow of the 100-year flood in several distributary channels separated by at least a few stable ridges
4D Flow of the 100-year flood in many distributary channels that have unstable beds and banks and are separated by low ridges

$4 \mathrm{E}$ Flow of the 100-year and probably smaller floods is unconfined or is in small channels that can migrate
WATER LEVEL

CHANNEL BED

Figure 3.-Continued. 
Assessment of the potential hazard of debris flows debouching on DFA's is beyond the scope of this study. The type and degree of flood hazard, however, may be related to the debris-flow occurrence. Stream channels of DFA's that have a large amount of debris-flow deposits may avulse more frequently than channels of DFA's that have a large amount of water-1aid deposits. Flow paths probably are more erratic and the flood-hazard degree is larger for DFA's that have more frequent channel avulsions.

Debris flows are slurry-like masses of water and debris that commonly originate on steep unvegetated slopes and rapidly move down confined channels. The flow, which includes boulder, cobble, gravel, and sand debris, enters unconfined channels of DFA's; the deposited fluvial material tends to be unsorted along the channel bed and banks. The dynamic characteristics of debris flows and certain basin conditions that are necessary for the occurrence of debris flows in an engineering timeframe of about 100 years are complex. Evidence of debris flows was observed during this study; however, the potential hazards are not precisely defined and only a crude assessment is made.

During this study, the effects of a small debris flow were observed at a small unnamed wash on the north slope of Picacho Peak (fig. 1, site 4). The flow occurred between field inspections of the site probably between April and June 1989. Principal observations were that:

1. Flow was confined to a small entrenched channel at the primary diffluence with a depth of about $2 \mathrm{ft}$ and a width of $20 \mathrm{ft}$. Small mounds of small boulders and cobbles were deposited along the channel banks as the channel widened downstream from the primary diffluence.

2. Deposited rocks were stacked nearly $1 \mathrm{ft}$ high in places. Leaf litter was on the ground shoreward of the deposited rocks but no litter was on the deposited rocks. Flow, therefore, did not occur shoreward of the deposited rocks.

3. From the primary diffluence to about $400 \mathrm{ft}$ downslope, the deposits of rocks were about $10 \mathrm{ft}$ wide and 4 in. deep. Two parallel depositional lobes started at the end of the 400-foot-long deposit.

4. The larger lobe was at the end of the long deposit and was about $200 \mathrm{ft}$ long, $40 \mathrm{ft}$ wide (average), and about 4 in. deep.

5. The second lobe was to the right and was about $150 \mathrm{ft}$ long, $20 \mathrm{ft}$ wide, and $4 \mathrm{in.} \mathrm{deep.}$

6. The debris flow followed the crest of the alluvial fan and did not follow the axis of maximum gradient or either of the small defined channels near the edges of the fan. 
Although Melton (1965) stated that debris flows are rare in southern Arizona, the observations listed above indicate that debris flows do occur. Because the debris flow did not follow the axis of maximum gradient or the small defined channels, the direction of debris flows is difficult to predict. The type of flood hazard for site 4 was $4 \mathrm{E}$ and had a flood-hazard degree of 10 . The debris-flow deposits may contribute to the random appearance of the channels.

\section{RANDOM MANNER OF DISTRIBUTARY-FLOW AREAS}

The random manner of floodflow in DFA's is described by the randomness of the channel links and the distribution of flow paths across the longitudinal center of DFA's. The distribution of active channels across the DFA for sites with high degrees of flood hazard is used as a measure of the probability of floodflow crossing the same elevation of DFA's. The observed frequency of different types of channel links in DFA's for many of the sample sites was compared with the expected frequency of random links as a potential measure of the randomness of flow paths.

\section{Random-Link Mode1}

The randomness of the channel links of the DFA's was evaluated using a method developed by Smart and Moruzzi (1972) and by Morisawa (1985). A random-link model was used to define the expected frequency of the different types of channel links. The method tests for differences between the observed and expected frequency of six types of channel 1 inks. The topologic model is independent of the size of the DFA. A link is a channel segment defined by the types of vertices at the ends of the channel segment. The three types of vertices are forks (F) where a channel bifurcates, joins $(J)$ where channels combine, and outlets ( 0 ) where the channels leave the toe of the DFA. The number of forks is greater than or equal to the number of joins. The six possible links are FF, FJ, JF, JJ, JO, and FO. A chi-square test is used to determine if it is likely that the links occur in a random manner by evaluating if the observed and expected frequency of the type of links are significantly different at the 5 -percent level of significance.

The procedure by Morisawa (1985) was used to analyze the random manner of the distributary channels for the 39 sites. Distributary channels for each DFA were defined on 7.5-minute orthophotoquad maps, and the frequency of each link was tabulated (Kemna, 1990). Only 18 of the sites (table 3) could be used for the analysis because the orthophotoquad maps for several sites were unclear and a required minimum number of vertices could not be obtained for many sites. Many sites with the primary diffluence on the lower part of the piedmont plain were excluded because the minimum number of vertices were unavailable upslope from the toe to the primary diffluence. The statistical test indicated that the measured frequency of links for two-thirds of the sites was significantly different $(p<0.05)$ from the expected frequency of links. Five of the six sites where the channel links appeared to occur randomly had flood-hazard degrees of 9 or 10. The sixth site had a flood-hazard degree of 2, although a short 


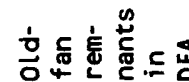

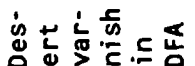

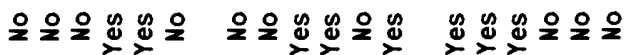

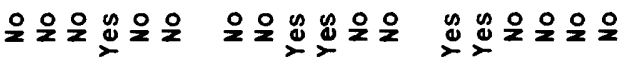

鬼点

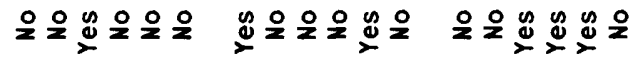

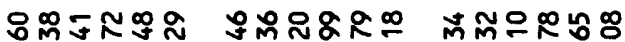

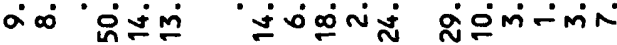

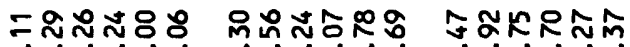

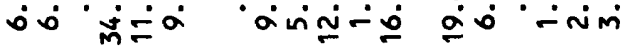

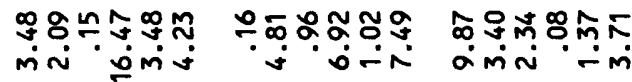

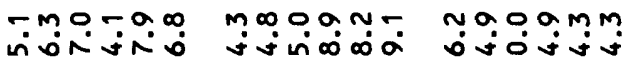
\begin{tabular}{l|l}
0 & 0 \\
0 & 0
\end{tabular}

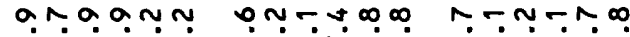

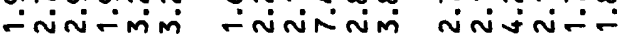

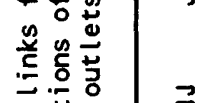

NNONM- MNTFAN UOONDO

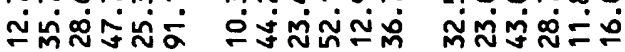

moNnor omoumn aON InOD

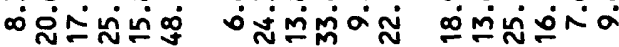

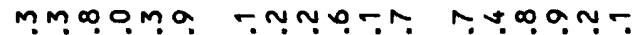

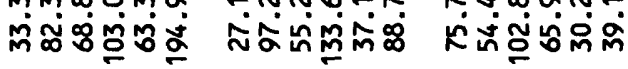

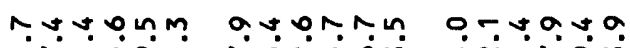

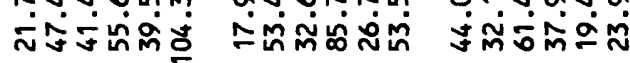

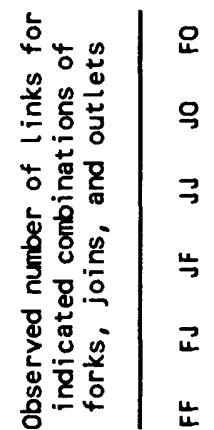

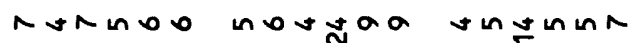
-omman ornomo manona

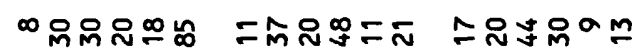

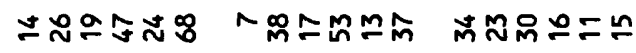

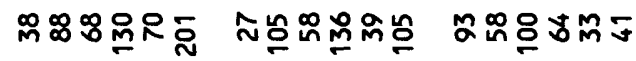

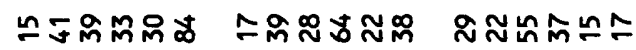

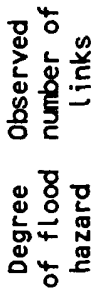

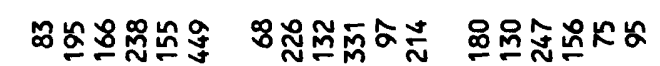
innacona nagaan orgogaa 离弯 $-m o N \infty a$

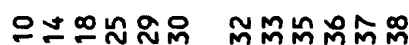


distance downstream from the primary diffluence in the DFA, the hazard was 8 or 9 .

By plotting the drainage-basin area against the area of the DFA for the sites used in the random-link model, separate relations for sites with and without random-channel links are apparent (fig. 4). The ratio of DFA and drainage-basin area (DFA/DA) for sites with random links is less than the DFA/DA ratio for sites with nonrandom links. For sites with small drainage areas, the DFA's for the sites with random links are about 50 percent of the size of the DFA's for sites with nonrandom links. For sites with large drainage areas, the apparent difference is about 30 percent. The difference is significant at the 0.05 probability level but because the upper end of the relation for the random links is based only on one site, the difference between the relations for the larger drainage-basin areas is considered less certain. The discharge intensity-flood-peak discharge at the primary diffluence divided by the DFA-is much greater for the sites with random links. For example, for a drainage area of $5 \mathrm{mi}^{2}$, the estimated 100-year flood peak discharge from Roeske (1978) is about $2,500 \mathrm{ft}^{3} / \mathrm{s}$ for sites in southwestern Arizona. The corresponding discharge intensity for sites with random links is about $1,100\left(\mathrm{ft}^{3} / \mathrm{s}\right) / \mathrm{mi}^{2}$, or about twice the intensity of $588\left(\mathrm{ft}^{3} / \mathrm{s}\right) / \mathrm{mi}^{2}$ for sites with nonrandom links. Thus, on the basis of the smaller DFA/DA ratio and the corresponding greater potential discharge intensity for sites with random links, the potential is greater for floodwater to spread over larger parts of the DFA of sites with random links.

The drainage area and area of the DFA for the sites that could not be used in the random-link model also were plotted (fig. 4). All sites with a degree of flood hazard of 9 or 10 where the links may occur in a random manner were coded. Except for sites with large drainage areas, the position of the points for degrees 9 and 10 is in general agreement with the relation for the sites with random links. Although the points widely scatter about the relation, this general agreement supports the relation that is based on only 6 sites. Likewise, the sites with flood-hazard degrees other than 9 or 10 plot in general agreement with the relation for sites with nonrandom links. A comparison of average discharge intensities for the random and nonrandom links and the high and low degrees of flood hazard also indicates that the degree of flood hazard is related to the random manner of channel links (table 4). The average discharge intensity for sites with random links and flood-hazard degrees of 9 or 10 are similar and approximately twice the discharge intensity for sites with nonrandom links and low degrees of flood hazard. As indicated by the scatter of the points (fig. 4 and table 4), exceptions appear to exist to the general relations between the random manner of channel links of DFA's and floodhazard degree.

Some of the wide range of discharge intensities for the sample of sites is the result of a geometric relation between discharge intensity and drainage-basin area. The sites with large drainage areas tend to have small discharge intensities. For example, the discharge intensities for sites with drainage areas greater than $20 \mathrm{mi}^{2}$ (sites 7,9, 25, 34, and 35; table 4) are much less than the average discharge intensity for their respective type of links and degree of flood hazard (table 4). Also, because the average drainage area for the 15 sites with degree of flood hazard of less than 9 is less than the average drainage area for the 24 sites with degrees of 9 or 10 , the difference in discharge intensity for 


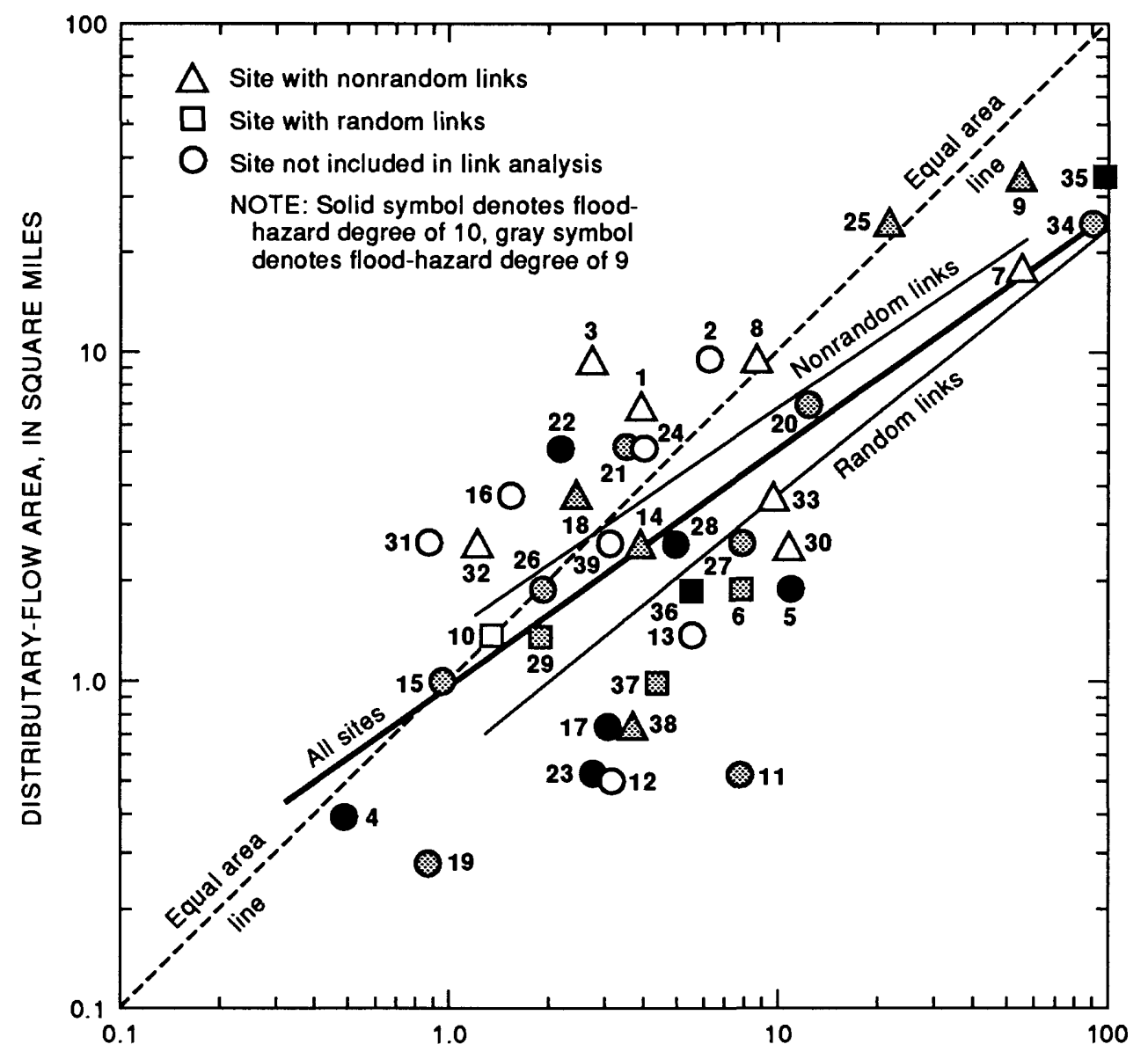

DRAINAGE AREA, IN SQUARE MILES

Figure 4.-Relations between distributary-flow area and drainage area for sites with random and nonrandom channel links.

the sites with low and high degrees of hazard may be slightly greater than that shown in table 4. Further refinement of the general relation between the discharge intensity and the degree of flood hazard to account for the scatter of points and the nonlinear effect of drainage area is not considered necessary for this study. Of importance for this study is the general fact that sites with random channel links and high degrees of flood hazard have greater discharge intensities than sites with nonrandon channel links and low degrees of flood hazard.

The implied relative stability of the system of distributary stream channels for sites with small discharge intensities is, in a general sense, supported by Lustig (1969). According to Lustig, in the Basin and Range province of the southwestern United States, there is a general relation between the stability of the system of stream channels downslope of the mountain front and the size of the contributing drainage basin in the mountain range. Lustig (1969, p. 69) discusses the process of mountain reduction and the associated enlargement of the pediment formations that predominate in southwestern Arizona. According to Lustig (1969), the 
Table 4.--Discharge intensities for sites that have random and nonrandom channel links and that have high and low degrees of flood hazard

\begin{tabular}{|c|c|c|c|c|c|}
\hline \multirow[b]{3}{*}{$\begin{array}{l}\text { Site } \\
\text { number }\end{array}$} & \multirow{3}{*}{$\begin{array}{c}\text { Degree of } \\
\text { flood } \\
\text { hazard }\end{array}$} & \multicolumn{4}{|c|}{$\begin{array}{c}\text { Discharge intensity of distributary-flow areas, } \\
\text { in cubic feet per second per square mile }\end{array}$} \\
\hline & & & $\begin{array}{l}\text { Degree of } \\
\text { flood } \\
\text { hazard }\end{array}$ & & $\begin{array}{c}\text { Degree of } \\
\text { flood } \\
\text { hazard }\end{array}$ \\
\hline & & $\begin{array}{l}\text { Random } \\
\text { links }\end{array}$ & $9-10$ & $\begin{array}{l}\text { Nonrandom } \\
\text { links }\end{array}$ & $1-8$ \\
\hline 1 & 5 & . . . & $\ldots$ & 680 & 680 \\
\hline 2 & 6 & - . . & $\ldots$ & . . - . & 540 \\
\hline 3 & 7 & - . . . & . . . & 380 & 380 \\
\hline 4 & 10 & . . . . & 2,100 & $\ldots$ & $\ldots$ \\
\hline 5 & 10 & - _ & 2,100 & . . . - & - . - - \\
\hline 6 & 9 & 3,600 & 3,600 & - _ _ & . \\
\hline 7 & 8 & $\ldots$ & $\ldots$ & 400 & 400 \\
\hline 8 & 5 & - . . & . . . & 400 & 400 \\
\hline 9 & 9 & - . . & 210 & 210 & $\ldots$ \\
\hline 10 & 2 & 1,000 & $\ldots$ & $\ldots$ & 1,000 \\
\hline 11 & 9 & $\ldots$ & 5,600 & . . . - & . \\
\hline 12 & 2 & - . . & $\ldots$ & - . . & 3,100 \\
\hline 13 & 8 & - . . & - . . & - . . & 1,700 \\
\hline 14 & 9 & . . . - & 970 & 970 & $\ldots$ \\
\hline 15 & 9 & $\ldots$ & 1,300 & $\ldots$ & . . . - \\
\hline 16 & 5 & $\ldots$ & $\ldots$ & $\ldots$ & 400 \\
\hline 17 & 10 & $\ldots$ & 3,500 & $\ldots$ & $\ldots$ \\
\hline 18 & 9 & - . . & 510 & 510 & _ . . . \\
\hline 19 & 9 & $\ldots$ & 3,400 & $\ldots$ & - . . \\
\hline 20 & 9 & $\ldots$ & 640 & . . - - & $\ldots$ \\
\hline 21 & 9 & - . . & 390 & . . . . & - . - \\
\hline 22 & 10 & - . . & 810 & - . . & - . \\
\hline 23 & 10 & - . . - & 5,800 & - . . & - . \\
\hline 24 & 3 & - - - - & $\ldots$ & . . . . & 440 \\
\hline 25 & 9 & - . - & 190 & 190 & $\ldots$ \\
\hline 26 & 9 & $\ldots$ & 800 & . . . - & - . . \\
\hline 27 & 9 & - . . & 1,100 & - . - . & - . - \\
\hline 28 & 10 & - _ & 940 & - _ - _ & - _ \\
\hline 29 & 9 & 4,100 & 1,100 & - _ - - & - . \\
\hline 30 & 2 & $\ldots$ & $\ldots$ & 1,400 & 1,400 \\
\hline 31 & 8 & . . - . & $\ldots$ & $\ldots$ & 350 \\
\hline 32 & 8 & - . . & $\ldots$ & 460 & 460 \\
\hline 33 & 7 & - . . & $\ldots$ & 990 & 990 \\
\hline 34 & 9 & - . & 410 & $\ldots$ & $\ldots$ \\
\hline 35 & 10 & 280 & 280 & - . - . & - . . \\
\hline 36 & 10 & 1,200 & 1,200 & - . - . & - _ - _ \\
\hline 37 & 9 & 2,200 & 2,200 & - . . & - . . \\
\hline 38 & 9 & $\ldots$ & 2,900 & 2,900 & - . . \\
\hline 39 & 8 & $\ldots$ & $\ldots$ & $\ldots$ & 850 \\
\hline Average & -- & 1,560 & 1,750 & 790 & 880 \\
\hline
\end{tabular}


predominately pediment landforms at the base of the mountain ranges in southwestern Arizona are more stable than the predominately alluvial-fan landforms at the base of the relatively larger mountain ranges in central and western Nevada and parts of eastern California. Lustig reports that the mountain ranges of southwestern Arizona are shorter, narrower, lower, and smaller than the mountain ranges of central and western Nevada and parts of eastern California. He attributes these differences to the different ages of the ranges of southwestern Arizona that have an older "relief age" or a longer "time span since topographic expression was achieved" (Lustig, 1969, p. 62). Thus, in general, the ranges of southwestern Arizona have become relatively stable and, consequently, the downstream drainage systems are also relatively stable. Similarly, as implied by the data for this study, sites with small-discharge intensities (analogous to mountain reduction and pediment enlargement) and nonrandom channel links and small degrees of flood hazard appear to have a more stable drainage network than sites with large-discharge intensities.

A major difference between DFA's with random links and DFA's with nonrandom links is the presence of desert varnish and old-fan remnants or inselbergs in the DFA (table 3). None of the sites with apparent random links had desert varnish or old-fan remnants in the DFA. Only one of the six sites with random links had inselbergs, and the two inselbergs at this site were small in relation to the size of the DFA. Five of the twelve nonrandom sites had desert varnish on ridges in the DFA. Seven of the twelve nonrandom sites had significant old-fan remnants or inselbergs in the DFA (table 3). The seven sites included the five sites with desert varnish on the interfluves, which supports the observation regarding the presence of old-fan remnants. Apparently, the old-fan remnants and inselbergs function to physically constrain the development of random fans. denser vegetation than adjacent land (table 1). Sites with nonrandom links commonly had vegetation on the interfluves of about the same density of the vegetation on the adjacent lands. Thus, for most of the sites with random channel links, the greater amount of vegetation density on the DFA's than on the adjacent lands indicates floodflow periodically spreads over large parts of the DFA. The more frequent shallow flooding of small floods appears to provide the water needed to establish vegetation that is large enough to withstand the force of large floods. For sites with nonrandom links, the presence of dense vegetation only along the large channels indicates that floodflow commonly is confined to the defined channels.

A relation between the random paths of the floodflow on the DFA's and the randomness of links is uncertain but appears likely on the basis of this site sample. The results of the expected frequency evaluation using the random-link model are supported by physical evidence. Old-fan remnants do not exist where the links were random. Six of the eight sites that were assigned a flood-hazard degree of 10 (fig. 4) have random links. Also, the differences in vegetation density for most of the DFA's with random links indicate that floodflow was random. A wider and (or) more frequent spreading of floodflow was needed to support the denser vegetation over wide areas. With a few exceptions, the random-link model appears to provide a measure of the potential randomness of flow paths of DFA's. Because the spatial distribution of the channel links was not evaluated 
using the random-link model, the randomness of the topological structure of the links does not necessarily indicate that the spatial distribution of the channel links is random.

\section{Distribution of Channels}

For sample sites with a high flood-hazard degree, the paths of floodflow appear erratic over most of the area of sampled DFA's. Several authors (Rachocki, 1981, chap. 5; Bul1, 1964, p. 114; French, 1984, p. 9-10) have presented evidence or analyses showing an unequal probability of floodflow crossing DFA contours. For this study, large active channels that emanate from primary diffluences of DFA's with flood-hazard degrees of 9 and 10 were assumed to be locations of floodflow. Departure of the channels from the central axis of the DFA near the longitudinal center of the DFA was measured, in percent of the distance to the edge of the DFA, for each of the channels. Average departure was computed for each site (table 5). Distribution of channels across the DFA's was nearly uniform

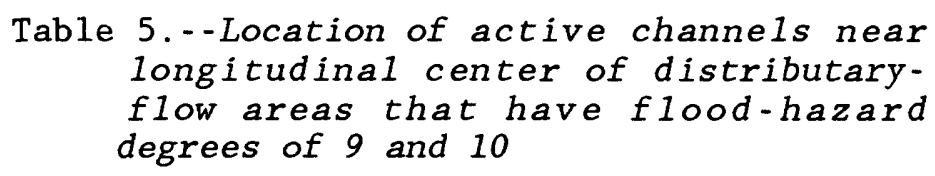

Table 5.--Location of active channels near longitudinal center of distributaryflow areas that have flood-hazard degrees of 9 and 10

\begin{tabular}{ccc}
\hline $\begin{array}{c}\text { Site } \\
\text { number }\end{array}$ & $\begin{array}{c}\text { Number of } \\
\text { active } \\
\text { channels }\end{array}$ & $\begin{array}{c}\text { Average departure } \\
\text { from central axis } \\
\text { in percent }\end{array}$ \\
\hline & & 80 \\
4 & 2 & 40 \\
5 & 4 & 30 \\
6 & 1 & 20 \\
9 & 3 & 30 \\
11 & 2 & 50 \\
14 & 2 & 70 \\
15 & 1 & 50 \\
17 & 4 & 90 \\
18 & 1 & 0 \\
19 & 1 & 60 \\
20 & 5 & 40 \\
21 & 4 & 80 \\
22 & 1 & 20 \\
23 & 1 & 50 \\
25 & 6 & 70 \\
26 & 3 & 80 \\
27 & 3 & 70 \\
28 & 1 & 30 \\
29 & 3 & 60 \\
34 & 10 & 50 \\
35 & 1 & 0 \\
36 & 0 & 50 \\
37 & 1 & 10 \\
38 & 1 & \\
& & \\
& &
\end{tabular}


with an average departure from the central axis of 47 percent of the distance to the edge of the DFA. Potential floodwater on the DFA's with high flood-hazard degree, therefore, is uniformly distributed across the the DFA surface and supports the analysis by Dawdy (1979).

\section{DEFINING DISTRIBUTARY - FLOW AREAS}

FA's commonly are on the piedmont and within intermontane basins. Many DFA's are situated near the junction of the piedmont and the base-level stream. Other DFA's are formed downslope from constricted stream channels where inselbergs, mountains, pediments, or old-fan remnants are present. Where floodflow is unconfined downstream from constricted reaches, the flow velocity decreases and sediment is deposited. A high potential exists for distributary flow in these aggrading areas.

Many DFA's of the sampled sites can be recognized on topographic maps and aerial photographs or by inspection from a high location. The ground inspection of characteristics is less effective except for detailed examination of soils, desert varnish, and channel geometry. The more easily recognizable characteristics are changes of soil color, changes of desert varnish, vegetation anomalies, map stream symbols showing bifurcating stream channels, a 'hump' in the longitudinal stream profile that shows a downslope flattening of channel gradient followed by a steepening of channel gradient, drainage texture, drainage-texture changes, and convex topographic map contours when viewed downslope. Several characteristics should be used to reliably locate the primary diffluence and to delineate the boundaries of DFA's.

The standard 7.5-minute series of topographic maps of the U.S. Geological Survey provides much of the information needed to delineate DFA's and is the primary source of data for this study. The blue-line (brown on older maps) map stream symbols depict many bifurcating intermittent streams of DFA's. Small wash or intermittent stream symbols that end abruptly in an area with smooth contours also may depict distributary flow. Broad areas of piedmont that are marked with the sand area symbol (stippled pattern) may depict aggrading areas and possibly distributary flow. Drainage-texture domains depicted by contour crenulation counts provide excellent clues to the type of 1 andform and potential DFA's. Smooth contours that are straight and parallel (or slightly convex pointing downstream in plan view) indicate mild relief that may result from distributary flow. When viewed downslope, concave-shaped contours with significantly large and narrow crenulations may reveal remnants of old fans. Convex-shaped contours depict a fan-shaped or radiating drainage pattern that commonly is a DFA.

Alluvial fans have been reported to have surface slopes of less than 10 percent (French, 1987, p. 36). The longitudinal channel slope of the DFA's measured on topographic maps for the 39 sample sites was 0.6 tto 3.2 percent. Some DFA's are inset fans where the primary diffluence is at the intersection of the longitudinal profiles of the streambed and the surface of the piedmont. Also, intersection points can be located where the drainage texture, as depicted by contour crenulations, along a large wash changes from large crenulations to nearly no crenulations on smoothto gentle-bending contours. The profiles of washes on the piedmont may 

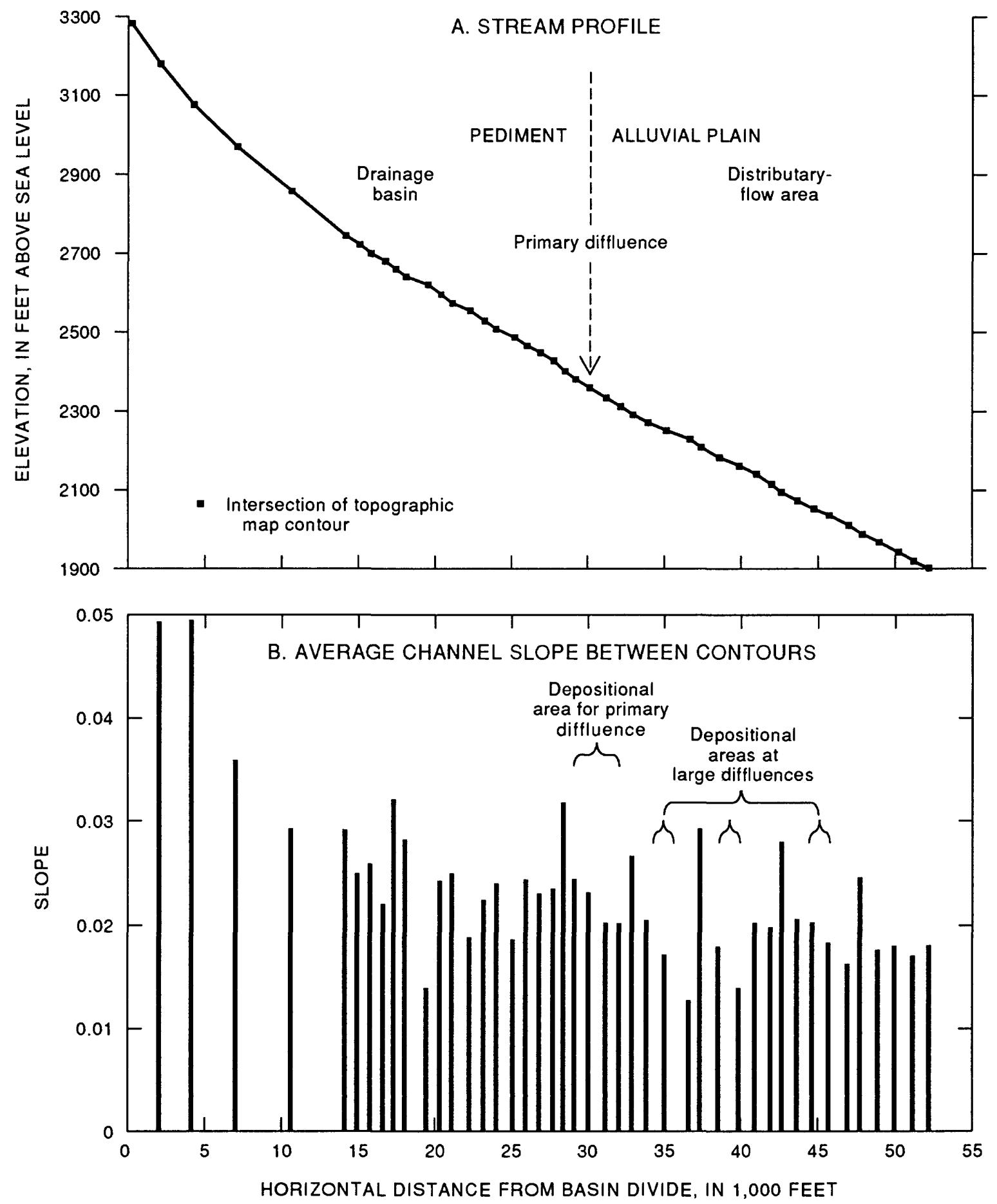

Figure 5.-Stream profile and average slope of channel between topographic-map contours showing location of primary diffluence for site 1 . 
show a pattern of flattening or steepening, which is characteristic of primary diffluences at intersections and most large diffluences in the DFA. At the primary diffluence of nearly all the sample sites, the longitudinal profile flattened and then steepened and several profiles had a distinct hump appearance (fig. 5A, B). The gradual slopes of the channels are at or downslope from primary diffluences, and the steep slopes are on the edge of the downstream depositional lobe (fig. 5B). Potentially misleading flattening or steepening sequences exist in narrow canyons where the stream is not in regime or equilibrium and is influenced by adjacent or underlying erosion-resistant rock.

The increase in density of vegetation on a piedmont may indicate the presence of a DFA. The denser vegetation is fed by the infiltration of unconfined floodwaters that periodically spread over the DFA. The green map symbols on topographic maps may depict denser vegetation on a DFA than on adjacent land. Vegetation differences can best be observed by aerial viewing and on orthophotoquad maps and aerial photographs. Divergent channels commonly can be identified on aerial photographs and orthophotoquad maps at the junction of a narrow line of vegetation along a wash and the irregularly shaped zone of trees and shrubs at the diffluence. The green-stippled pattern on topographic maps also may delineate the fan-shaped tentacles of DFA's.

The density of vegetation on and adjacent to DFA's can be affected by the underlying shallow ground water that is within the reach of the roots of the vegetation. The DFA material also can affect the vegetation density. Coarse and permeable material may transmit water below the root zone while water may be retained in the root zone where the fan material is fine and not very permeable. For the 39 sites, there were no obvious effects of shallow ground water or soil material on the density of vegetation.

Differences in soil color on the piedmont that could depict DFA's commonly are revealed on orthophotoquad maps and aerial photographs. Light-colored alluvium may represent recent deposition, and the reddish color of adjacent soils may be from many years of oxidation. A blackish-appearing surface can be from varnished rocks that take hundreds to thousands of years to form. Dark surfaces commonly form the boundaries of DFA's and indicate the limits of riverine flooding and significant deposition. The lighter surfaces commonly delineate the DFA's. Light-colored ribbons of sediment mark washes that debouch into fan-shaped tentacles at DFA's.

\section{$\underline{\text { Soils }}$}

The U.S. Soil Conservation Service has produced general soils maps $(1: 500,000$ and 1:600,000) for the entire State of Arizona. Soils are grouped in mapping units consisting of a few dominant soils and several minor soils that form a recognizable pattern over broad areas (Torrance, 1969, p. 1). Because of the relatively small scale, these maps are useful in locating large geomorphic features (such as the piedmont plain and base-level flood plains), but the maps are not useful in locating specific areas subject to distributary flow. Such broad mapping units commonly contain soil characteristics of both old fans and DFA's. 
Soil maps of a large scale $(1: 20,000$ and $1: 24,000)$ cover more than one-half of the State. These maps delineate soils characteristic of flooding and active deposition. Some examples of soils characteristic of DFA's include the Anthony and the mixed alluvial units (Richardson, 1971). The following are general characteristics of soils that are subject to flooding and are commonly found on DFA's. The color of soils on DFA's is typically more yellow and tan (7.5 YR to 10 YR on the Munsel Color Chart) than the redder soils of inactive areas ( 2 YR to 5 YR). The soils of DFA's generally lack lime masses and concretions. Any lime present generally is disseminated, but the soil may still effervesce slightly. DFA's commonly have soils with stratification near the surface. Lastly, the texture of soils on DFA's generally is loam and loamy sand to sandy loam and sand. These soils generally lack silty clay loam that is related to the weathering process (Christopher C. Cochran, Soils Specialist, U.S. Soil Conservation Service, written commun., 1989).

The soil color of the areas of active flooding on the DFA's of most of the 39 sample sites was distinctly lighter and less reddish than the soil color of surrounding less active areas (table 1). For some sites, a difference of soil color between areas of apparent active and inactive flooding was not distinct. For these sites, all soils appeared to be light tan or light yellow, and boundaries, if any, were difficult to distinguish. Color differences are especially difficult to distinguish at the toe of DFA's where the 1ight-colored soils of the DFA commonly irregularly blend with light-colored soils of base-level plains. Some sites where floodflow appeared to frequently spread over much of the DFA had distinctly lightercolored soils on the DFA than on the surrounding areas. Differences in soil color for the purpose of distinguishing areas of active and inactive flooding are best observed on color aerial photographs and from aerial reconnaissance. Dark-brown surfaces in central and southwestern Arizona could be a coating of desert varnish.

\section{Desert Varnish}

Desert varnish on stones of large noncohesive alluvial surfaces can be a reliable indication of the absence of significant floodflow during the past few thousand years. The age of rock varnish for 51 samples taken in Hawai and the southwestern U.S. commonly was more than 2,000 years (Dorn and others, 1989, p. 1365). A dark-brown desert varnish on the surface of stones exposed to the atmosphere can indicate that the stones have been undisturbed for perhaps 3,000 to 5,000 years (Dorn and oberlander, 1982). A black-surface stain indicates the absence of significant flood depths for perhaps 10,000 years or more. According to Dorn and Oberlander (1982), an arid varnish of blackish manganese-rich type takes many thousands of years to completely coat the tops of stones.

Areas with stones covered with dark desert varnish might have been covered occasionally with floodwater that did not significantly disturb the stones. Slow, shallow floodwater that inundated these darkcolored areas may not have had the energy to disturb the rocky surface. A surface covered with larger darkly stained stones and unstained smaller stones may indicate the occasional occurrence of floodwater of sufficient energy to move only the smaller stones. The gradation of desert varnish, for example, is apparent along the distributary channels of French Creek 
near Quartzite (site 7) where the ridges of the interfluves are blackish, the channels are light tan or whitish, and the sideslopes between the channels and ridges appear to gradually darken toward the ridges.

Incipient sediment-motion relations for large rocks (Wang and Wen Shen, 1985) can be used to roughly estimate flow depths needed to move varnished rocks. For example, where channel slope equals 0.03 , specific weight of water equals $62.4 \mathrm{lbs} / \mathrm{ft}^{3}$, specific weight of rock equals $165 \mathrm{lbs} / \mathrm{ft}^{3}$, and modified Shields parameter for large rocks equals 0.25 , tractive force and critical diameter for incipient-motion equations show that the flow depth, in feet, for incipient motion is about 13.8 times the rock diameter, in feet. The observed gradation of varnished rocks at a few sample sites may be explained by incipient-motion relations like the above. The absence of smaller varnished rocks near the channels indicated that small rocks have been moved. The absence of small varnished rocks along the sideslopes of distributary-flow channels, however, could be the result of small-stone movement by strong winds that are frequent in southwestern Arizona.

\section{Drainage Texture}

The spacing of drainage channels (drainage texture) can be used to distinguish the type of landform. DFA's have a characteristic drainage texture that differs from the drainage texture of other landforms. Also, primary diffluences can be identified at changes of drainage texture.

The primary diffluences of DFA's on alluvial plains downslope from mountains and (or) pediments commonly are at the upper end of the alluvial plain near the foot of the mountain or pediment. The transition zone between landforms generally is easy to identify because the transition from the mountain to the alluvial plain is direct and a marked change in the slope of the land surface at the mountain fronts is common. The transition zone between pediments and alluvial plains is more difficult to identify because the slope of the land surface is nearly constant or is changing only gradually.

A marked change in the drainage texture, however, occurs between pediments and alluvial plains. Drainage texture is measured as the number of low-order drainage channels (crenulations) along uniform widths of contour lines on topographic maps. An example of typical texture characteristics with a marked change at the head of the alluvial plain along a transect occurs at site 2 (fig. 6D). Drainage texture, as depicted by upslope crenulation on contour lines (see section "Glossary of Terms") commonly increases in transition from alluvial plains to pediments. According to Doehring (1970), the drainage texture of pediments is finer (more low-order drainage channels) in the upslope direction. Pediments commonly have many streams of various sizes from rills to streams with large incised channels, and many of these streams head on the pediment. Doehring (1970) also observed that the texture on alluvial fans generally was constant along the axis of fans. Thus, drainage texture is used to determine the approximate location of primary diffluences and to determine the type of landform. 

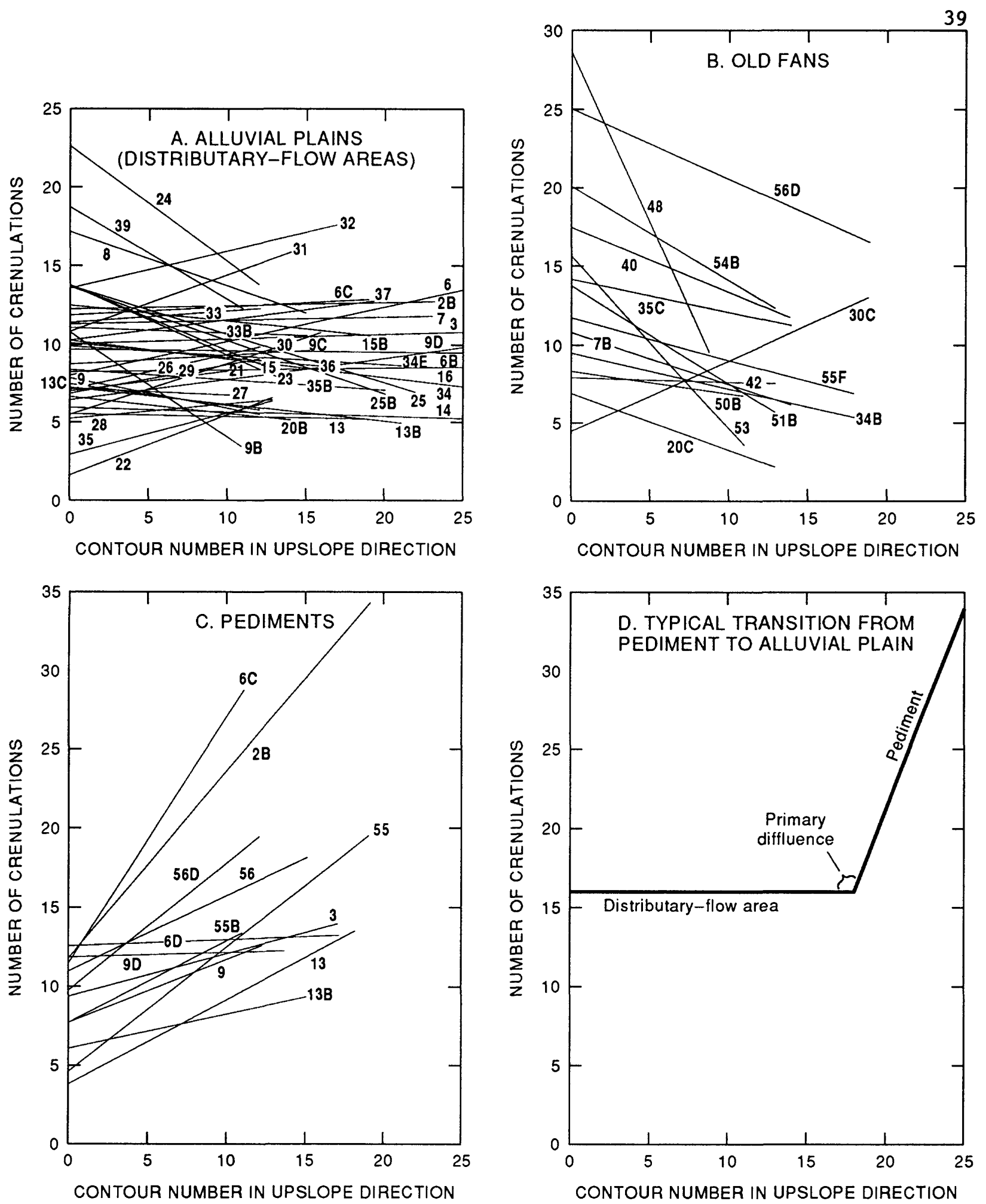

NOTE: Lines are regression lines for transects normal to trend of map contour lines at or near site number

Figure 6.-Drainage-texture relations for distributary-flow areas, old fans, pediments, and typical transition from pediment to alluvial plain. 
For this study, drainage-texture relations (fig. 6) were determined at approximately 70 locations on pediments, old fans, and alluvial plains at or near the 52 sites (fig. 1). The pediment, old-fan, and alluvial-plain areas were located using the map by Cooley (1977) and orthophotoquad maps. Contour crenulations along 1 -inch-wide transects were constructed approximately normal to the trend of at least 10 consecutive contour lines (Doehring, 1970) on 7.5-minute topographic maps. Contour crenulations are not uniformly mapped on all 7.5-minute topographic maps; thus, transects should be on single maps if adjustments for differences between maps are to be avoided. For each transect, a relation was evaluated between the number of crenulations and the contour number where the numbering starts at the most downslope contour. Transects were attempted at or near all the 39 sample sites and at 13 miscellaneous sites (table 6 ; fig. 6) where 10 consecutive contours on a single major landform could be obtained. Some sites (including 6B, 6C, 6D, 9B, 9C, 9D) were near the respective sample sites. A few sites, such as the DFA of 6D, did not have enough points and were not evaluated. Multiple transects were made at some distributary-flow sites, and transects were not made at 10 of the sites.

Forty-one transects were made on alluvial plains that included 29 of the sample sites. Thirty-four of the transects showed a nearly constant texture (fig. 6A), indicating an alluvial-fan surface (Doehring, 1970). Three of the transects showed a significant upslope increase in texture, and four of the transects had a significant decreasing texture. A 5 -percent level of significance was used to test the null hypothesis that the measured number of contour crenulations for each transect were the same in the upslope direction. Thus, the texture method may not always correctly identify a DFA. For example, the DFA's for sites 6 and $9 \mathrm{~B}$ had significant changes in texture and epitomize the problems that can occur when encountering heterogeneous texture domains at the transitional zone between an alluvial plain and a pediment. Also, the transect on the DFA of site 30 crossed texture domains and showed a significantly positive increase in texture. Doehring (1970) suggested that the transects should avoid texture-domain boundaries, and provides an excellent diagram of a texture-domain boundary.

If a texture transect crosses or includes large incised channels, the texture method may not identify the DFA. For example, the transect of site 39 included a large channel and showed a decrease in drainage texture (see section "Glossary of Terms") moving up the piedmont plain (fig. 6A). The texture method did not identify site 39 as a DFA because the transect revealed a significant decrease in crenulations. Yet, some old-fan remnants scattered throughout the DFA could have influenced the results of the analysis.

Ten of the twelve transects on pediments showed a statistically significant upslope increase in drainage texture (fig. 6C). Two transects (6D and 9D) showed no change in texture. The crossing of texture-domain boundaries could have influenced these results.

Texture measurements were made on 14 old fans that had no distributary flow (fig. 6B). Nine of the transects had a statistically significant upslope decrease of texture. Four of the transects had a small decrease of texture that was not statistically significant at the selected level. Reliable transects that do not cross large drainage channels were 
Table 6.--Location and type of landform for miscellaneous texture measurements

\begin{tabular}{|c|c|c|}
\hline $\begin{array}{l}\text { Site } \\
\text { number }\end{array}$ & Landform & Location of toe of measurement line \\
\hline 40 & old fan & $\begin{array}{l}\text { Lat } 33^{\circ} 33^{\prime} 37^{\prime \prime}, \text { long } 111^{\circ} 49^{\prime} 22^{\prime \prime} \text {, in sec. } 34, \mathrm{~T} .3 \mathrm{~N} \text {. } \\
\text { R. } 5 \mathrm{E} ., \mathrm{M} \text { Maricopa County, } 6 \mathrm{mi} \text { northeast of } \\
\text { Scottsdale. }\end{array}$ \\
\hline 41 & old fan & $\begin{array}{l}\text { Lat } 31^{\circ} 40^{\prime} 27^{\prime \prime}, \text { long } 111^{\circ} 04^{\prime} 32^{\prime \prime} \text {, in sec. } 24 \text {, } \\
\text { T. } 20 \mathrm{~S} ., \mathrm{R} .12 \mathrm{E} ., \text { Santa Cruz County, } 4 \mathrm{mi} \text { south } \\
\text { of Arivaca Junction. }\end{array}$ \\
\hline 42 & old fan & $\begin{array}{l}\text { Lat } 34^{\circ} 12^{\prime} 36^{\prime \prime}, \text { long } 113^{\circ} 17^{\prime} 42^{\prime \prime} \text {, in sec. } 16 \text {, } \\
\text { T. } 10^{\mathrm{N} .} \text {, R. } 10^{\mathrm{W} .} \text {, Yavapai County, } 13 \mathrm{mi} \text { east } \\
\text { of Alamo Lake State Park. }\end{array}$ \\
\hline 43 & old fan & $\begin{array}{l}\text { Lat } 32^{\circ} 43^{\prime} 13^{\prime \prime}, \text { long } 112^{\circ} 13^{\prime} 12^{\prime \prime} \text {, in sec. } 24 \text {, } \\
\text { T. } 8 \mathrm{~S} ., \mathrm{R} .1 \mathrm{E} ., \text { Maricopa County, } 10 \mathrm{mi} \text { south } \\
\text { of Freeman. }\end{array}$ \\
\hline 44 & old fan & $\begin{array}{l}\text { Lat } 32^{\circ} 06^{\prime} 30^{\prime \prime}, \text { long } 111^{\circ} 59^{\prime} 50 " \text {, in sec. } 19 \text {, } \\
\text { T. } 15 \mathrm{~S} ., \mathrm{R} .4 \mathrm{E} ., \text { Pima County, } 3 \text { mi northwest } \\
\text { of San Luis. }\end{array}$ \\
\hline 45 & old fan & $\begin{array}{l}\text { Lat } 33^{\circ} 45^{\prime} 23^{\prime \prime} \text {, long } 114^{\circ} 12^{\prime} 22^{\prime \prime} \text {, in sec. } 23, \mathrm{~T} .5 \mathrm{~N} ., \\
\text { R. } 19 \mathrm{~W} ., \text { Yuma County, } 7 \mathrm{mi} \text { north Quartzite. }\end{array}$ \\
\hline 46 & old fan & $\begin{array}{l}\text { Lat } 33^{\circ} 47^{\prime} 48^{\prime \prime} \text {, long } 112^{\circ} 51^{\prime} 30^{\prime \prime} \text {, in sec. } 2 \text {, T. } 5 \mathrm{~N} \text {, } \\
\text { R. } 6 \mathrm{~W} \text {, Maricopa County, } 13 \mathrm{mi} \text { southwest of } \\
\text { Morristown. }\end{array}$ \\
\hline 47 & Pediment & $\begin{array}{l}\text { Lat } 32^{\circ} 58^{\circ} 03^{\prime \prime}, \text { long } 111^{\circ} 11^{\prime} 53^{\prime \prime} \text {, in sec. } 26 \text {, } \\
\text { T. } 5 \text { S., R. } 11 \mathrm{E} \text {, Pinal County, } 7 \mathrm{mi} \text { east of Cactus } \\
\text { Forest. }\end{array}$ \\
\hline 48 & Pediment & $\begin{array}{l}\text { Lat } 32^{\circ} 57^{\prime} 07^{\prime \prime}, 1 \text { ong } 111^{\circ} 10^{\prime} 43^{\prime \prime} \text {, in sec. } 36 \text {, } \\
\text { T. } 5 \text { S., R. } 11 \text { E., Pinal County, } 7 \mathrm{mi} \text { east of Cactus } \\
\text { Forest. }\end{array}$ \\
\hline 49 & o1d fan & $\begin{array}{l}\text { Lat } 32^{\circ} 58^{\prime} 23^{\prime \prime}, \text { long } 111^{\circ} 20^{\prime} 45^{\prime \prime} \text {, in sec. } 20, \mathrm{~T} .5 \mathrm{~S} . \\
\text { R. } 10 \mathrm{E} ., \text { Pinal County, } 2 \mathrm{mi} \text { northwest of Cactus } \\
\text { Forest. }\end{array}$ \\
\hline 50 & Pediment & $\begin{array}{l}\text { Lat } 33^{\circ} 03^{\prime} 32^{\prime \prime}, \text { long } 111^{\circ} 06^{\prime} 33^{\prime \prime} \text {, in sec. } 27, \mathrm{~T} .4 \mathrm{~S} . \\
\text { R. } 12 \mathrm{E} ., \text { Pinal County, } 8 \mathrm{mi} \text { southeast of Price. }\end{array}$ \\
\hline 51 & old fan & $\begin{array}{l}\text { Lat } 33^{\circ} 03^{\prime} 05^{\prime \prime}, \text { long } 111^{\circ} 06^{\prime} 52^{\prime \prime} \text {, in sec. } 27, \mathrm{~T} .4 \mathrm{~S} . \\
\text { R. } 12 \mathrm{E} ., \text { Pinal County, } 8 \mathrm{mi} \text { southeast of Price. }\end{array}$ \\
\hline 52 & Pediment & $\begin{array}{l}\text { Lat } 33^{\circ} 03^{\prime} 08^{\prime \prime}, \text { long } 111^{\circ} 04^{\prime} 38^{\prime \prime} \text {, in sec. } 25, \mathrm{~T} .4 \mathrm{~S} . \\
\text { R. } 12 \mathrm{E} ., \text { Pinal County, } 10 \mathrm{mi} \text { southeast of Price. }\end{array}$ \\
\hline
\end{tabular}


difficult to obtain on several of the old fans. Also, transects can cross multiple old fans that retain different relict drainage patterns and adversely affect the measurements. The texture measurements on old fans may not be as reliable as the texture measurements on the other landforms; however, the measurements clearly show a general upslope decrease of texture.

The drainage texture on alluvial plains, pediments, and old fans in southwestern Arizona generally is different and $c$ an be used to distinguish the types of landforms. The drainage texture as shown on 7.5-minute topographic maps generally is unchanging on alluvial plains (fig. 6A), is decreasing in the upslope direction on old fans (fig. 6B), and is increasing in the upslope direction on pediments (fig. 6C). The changes in texture can be used to locate transition zones between pediments and alluvial plains where the primary diffluences commonly are located (fig. 6D). Measurements are made using procedures by Doehring (1970).

A strong dependence exists between the location of the primary diffluence on the piedmont plain and the presence of a base-level stream at or near the toe of the DFA. Using contingency tables for a chi-square test for dependence between variables, more observations than expected $(p<0.01)$ were made where the primary diffluence is on the lower half of the piedmont plain and a base-level stream is present. Similarly, fewer observations than expected were made where the primary diffluence is on the lower half of the piedmont plain and no base-level stream is present. Apparently, the primary diffluence tends to be in the lower part of the piedmont plain where a base-level stream is nearby.

\section{Primary Diffluence}

To locate the primary diffluence of a known DFA, select a point (point of origin) on a stream where the drainage area is to be computed using topographic maps ( $f i g .7$, step 1). The important steps (1-5) for locating the $P D$ are given in figure 7. Next, define the topographic divide for the basin above the point of origin (step 2). All direct runoff from precipitation within the topographic divide will be drained by the stream at the point of origin if the overall drainage system is tributary. If the drainage area can be defined, check that no channels cross the defined ridge line by using orthophotoquad maps or aerial photographs. If active stream channels cross the defined topographic divides and the divides cannot be delineated with supplementary information gleaned from the orthophotoquad maps, go to step 4. If the integrity of the topographic divides is confirmed, then check for DFA's within the drainage area (step 3).

Small DFA's within the drainage basin (step 3) may be of interest. The distributary channels of these nested DFA's converge into tributary channels above the point of origin. If a primary diffluence for a nested DFA is to be located, go to step 4 and establish a new point of origin in the nested DFA.

If the drainage area cannot be delineated (fig. 7, step 4), relocate the point of origin to the first primary diffluence upstream. Repeat the process starting at step 1 until the final primary diffluence is 
PRIMARY DIFFLUENCE

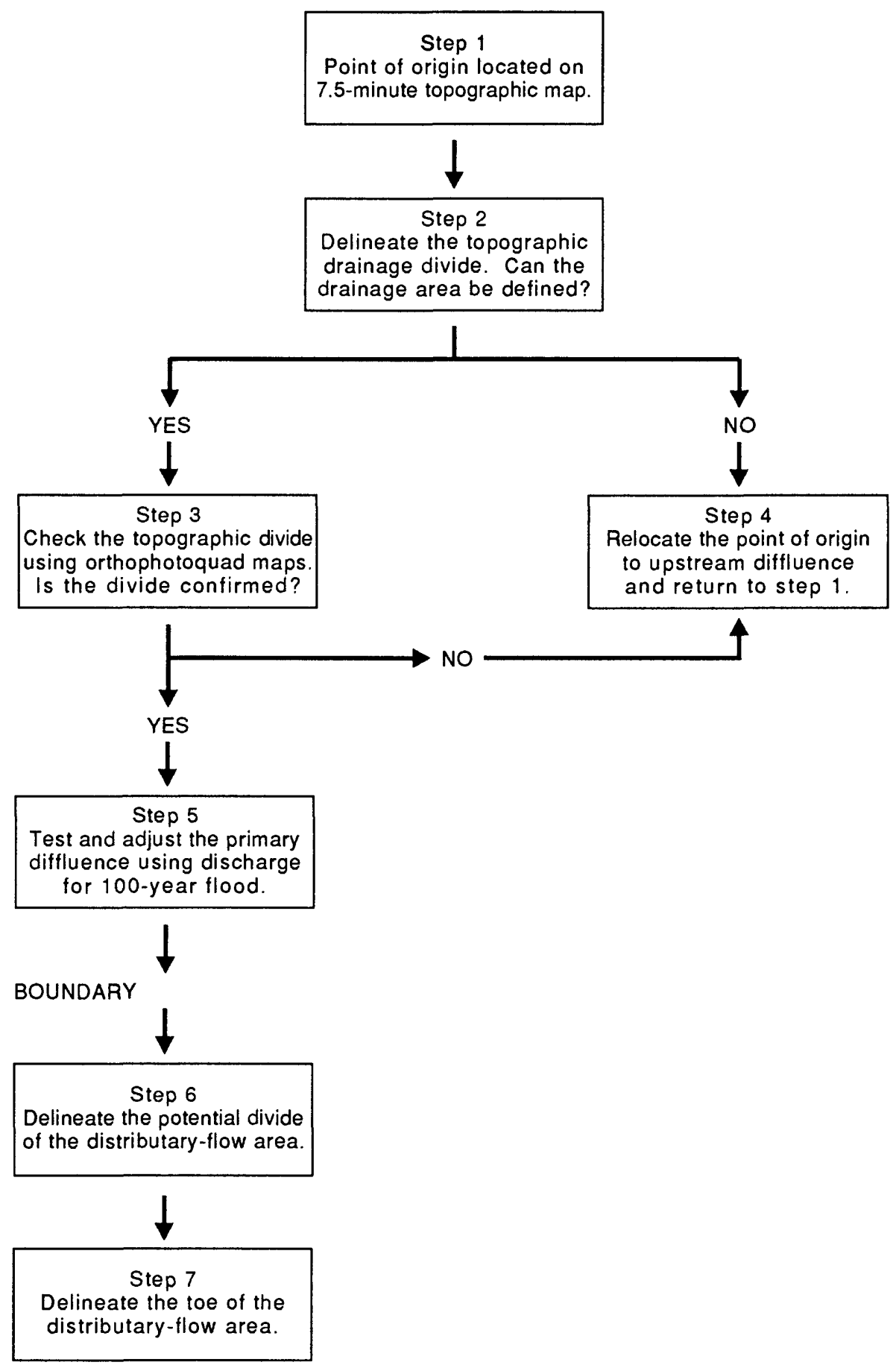


found and the drainage boundary is delineated. The characteristics of the soils, vegetation, desert varnish, slope of the stream channel, and drainage texture are used to confirm the location of the primary diffluence.

To confirm that the 100 -year flood is contained in the channel at the primary diffluence (fig. 7, step 5), determine the 100-year discharge for the basin of the primary diffluence using methods of Roeske (1978) or Eychaner (1984). Obtain channel geometry and roughness characteristics from field surveys, topographic maps, aerial photographs, conveyance-slope estimates, or slope-area computations. Determine if the 100-year flood is within the defined banks. If the channel just upstream from the selected primary diffluence cannot contain the 100-year flood, then the primary diffluence probably is upstream and a field inspection may be needed to precisely locate the primary diffluence.

In southwestern Arizona, the channels in many of the DFA's are on the upper slopes of the piedmont plain and are firmly entrenched. The surrounding surfaces have tributary drainage systems and are eroding. Bu11 (1977, p. 252) attributes the entrenchment of channels in the upper part of the alluvial fans to (1) climatic changes, (2) a complex response to a perturbation of the geomorphic system, and (3) incision by floodflow at a faster rate than the rate of mountain uplift. For tectonically stable areas, permanent entrenchment can occur on the upper slopes of the fan; such fans are characterized by large areas of erosion as well as areas of deposition (Bull, 1964, p. 112).

As the upper slopes of the fan become entrenched, the point of deposition commonly moves downslope on the piedmont plain. This point of deposition is called the intersection point and is the primary diffluence of many DFA's. Dawdy (1981, p. 379) clarified the application of his method (Dawdy, 1979) for evaluating flood hazards on alluvial fans by stating that in the case of permanently entrenched fans, his method should be applied below the intersection point.

Bull (1977, p. 252) claimed that many fan-head trenches are temporary and may exist only from 10 to 10,000 years before radically changing form and (or) position on the piedmont plain. He describes how the balance of stream power and the resisting power of the channels determines whether a given reach of channel will aggrade or degrade and if and how much the intersection point will move upslope or downslope on the piedmont plain. Climatic change and man's effects on the geomorphic system can result in the relocation of an intersection point (Bull, 1988, p. $160-161$ ).

For the study of flood hazards of DFA's, it was necessary to locate a stable primary diffluence in an engineering timeframe. The presence of developed soils on the surface adjacent to the channel upstream from the primary diffluence is evidence that recent erosion or deposition from large floods has not occurred. Other indicators of a surface not subject to distributary-flow hazards in engineering time include prolific desert varnish and the weathering-related filling of soil pore space with fine sediment (Hooke, 1967, p. 439-440). For the 39 sites used in this study, a major test for the permanency of a primary diffluence included the capacity of the channel as well as the color of the soil surrounding the banks of the channel upstream from the primary diffluence. The assumption 
was made that where light-colored soils exist, a strong chance also existed that deposition or possibly scour occurred in engineering time. The presence of darker-colored surfaces indicates the absence of major deposition in engineering time. Where light-colored soil indicated overflow channels or abandoned channels, the primary diffluence was relocated upstream to a more stable reach.

\section{Boundaries}

After the primary diffluence is located, the boundaries of the DFA can be defined following steps 6 and 7 (fig. 7). Starting at the primary diffluence, define the ridge lines on each side of the DFA (step 6). The ridge lines are on the shoreward side of the outermost channels. Tributaries to the DFA are severed, and the boundaries are continued on the opposite bank of the tributary. The potential drainage divides may appear to cross over into adjacent DFA's. Areas of overlapping DFA's are separated by a probable boundary that bisects the defined ridge lines for the two areas. The potential divides tend to be perpendicular to the topographic contours and split any $X$-shaped confluence-diffluences where the channels from each DFA join and then divide. The boundaries and probable boundaries are defined from the primary diffluence to the toe of the DFA.

In addition to using the topographic ridge lines to define the boundaries of the DFA, the drainage texture, soils, vegetation, and desert varnish can be used as discussed previously. The boundaries of many DFA's correspond to the boundaries of drainage-texture domains. Soil maps that delineate recent depositions of soil also may assist in boundary definition. Changes in vegetation density and the amount of desert varnish also are indices of the boundaries of DFA's.

The toes of DFA's are defined using several factors (step 7). Like the lateral boundaries, it may not be feasible to precisely define a narrow boundary at the toe. The toes of many DFA's appear to be irregularly shaped as fingers of sediment are deposited. The DFA cannot extend beyond the base-level stream. The washes and plains that form the base level represent the downstream limit of the toe. The toe also can be located where the stream patterns change from distributary to tributary over the width of the DFA. Soil color also may change, indicating lower limits of recent sediment deposition. Lastly, the slope profile of the land surface of the piedmont may show a rapid decrease in slope that corresponds to the location of the toe. The toe is located on the basis of the above considerations, and the boundary is drawn approximately parallel to the contours connecting the potential divides.

\section{MISCELLANEOUS RELATIONS BETWEEN GEOMORPHIC VARIABLES}

During this study, several relations between geomorphic variables of the DFA and drainage area were observed that can be or have been used to characterize DFA's. A few characteristics of the sample of 39 sites that are similar to characteristics of DFA's in other regions of the southwestern United States are presented. These general similarities 
indicate the methods used to define DFA's in this study might be useful for DFA's in other regions. For example, the size of the DFA for the sample sites is related to the size of the drainage area (fig. 8A). The relation has a slope of 0.71 and is similar to the relations by Bull (1964) that have a mean slope of about 0.9. The plotted points scatter widely about the relation with a standard deviation of $0.39 \log$ units but generally are within the limits of the relations for the groups of fans in California and Nevada. According to Bull (1977), the area of the DFA also is related to many other basin factors including lithology and erosivity of exposed rocks. Most of the basins are mountains that have either old-fan deposits or pediments between the primary diffluence and mountains. Only 13 of the sites have primary diffluences at the mountain front, 5 of the sites had the primary diffluence above the mountain front, and 1 site drains basin-fill deposits. Mountains that surround the drainage basins are composed of a variety of volcanic, intrusive, and metamorphic rocks. A relation is not apparent between the amount of the basin that is composed of hard-rock mountains and the size of the DFA's. The resistance to erosion of exposed rocks in the basins of the sites used for the study vary and are not defined for this study.

The mean-relief ratio of the DFA (MRDFA) for the sample sites also is related to the size of the drainage basin (fig. 8B). The MRDFA is the dimensionless ratio of the total relief of the DFA and the length of the DFA axis (table 7). The relief ratio, or slope, of the DFA decreases with increasing basin area. Similar relations were found by Bull (1964) for groups of fans in Fresno County, California. Bull found that the slope of DFA's that drain mudstone and shale basins generally was greater than the slope for sandstone basins of the same size. A cursory inspection of the lithology of the 39 sample sites does not clearly indicate a relation between the mean-relief ratio and the surface rocks of the drainage basin.

basin (MBE) as:

MRDFA is related roughly to the mean elevation of the drainage

$$
M R D F A=0.009\left(\frac{M B E}{1,000}\right)^{0.7}
$$

Standard deviation is +48 and -32 percent of the dependent variable. Mean elevation of the sample sites was from 1,240 to $5,670 \mathrm{ft}$. MBE is the average distance, in feet, above sea level computed by summing the products of 5 to 10 planimetered subareas ( $A$, in square miles) and their midrange elevations ( $E$, in feet) and dividing by the total basin area (DA, in square miles) and can be stated as:

$$
M B E=(\Sigma A E) / D A
$$

(Office of Water Data Coordination, 1977, p. 7-12)

Large DFA's tend to have large stream channels as indicated by the rough relation between the average contour-band width (L) and the area (FA) of the DFA. The relation is defined by the equation 


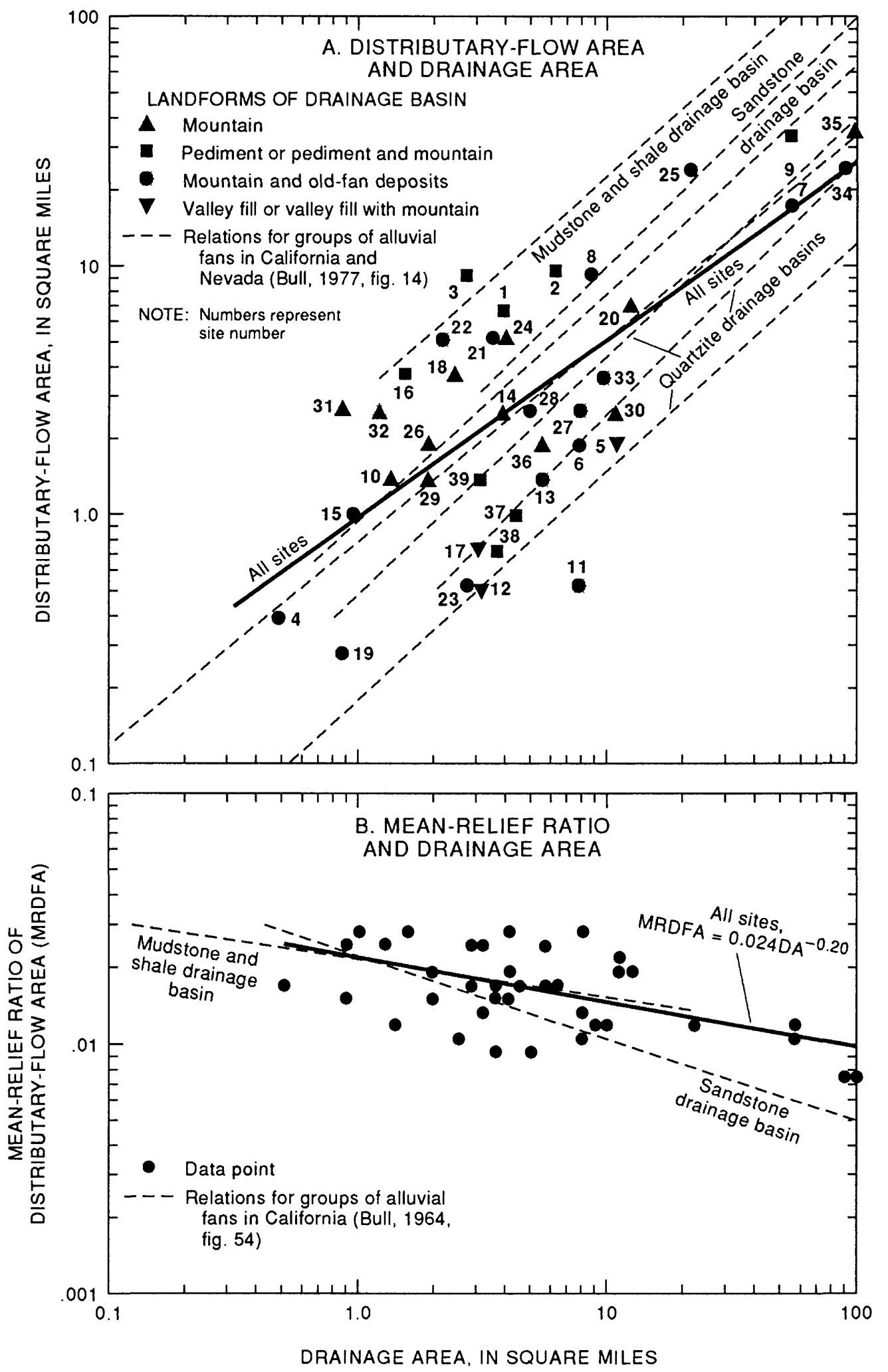

Figure 8.-Relations between distributary-flow area and drainage area and meanrelief ratio of distributary-flow area (MRDFA) and drainage area (DA) for sample sites in Arizona and groups of sites in Califonia and Nevada. 
Table 7. - Physiographic and hydrologic characteristics of sample sites

[B, degree of flood hazard; RN, ruggedness number of drainage basin; MRDA, mean-relief ratio of drainage basin; MRDFA, mean-relief ratio of distributary-flow area; $\mathrm{H}$, average contour sinuosity of distributary-flow area; $K$, average contour-band width of drainage bas in, in inches; $L$, average contour-band width of distributary-flow area, in inches; DA, drainagebasin area, in square miles; DFA, area of distributary-flow area, in square miles; MBE, mean-basin elevation, in feet; P, 10-year 24-hour precipitation, in tenths of inches; MAF, mountain-area factor; $V$, location factor of primary diffluence; $W, 100$-year flood at primary diffluence, in cubic feet per second; $\mathrm{CC}$, contour-band width just downstream from primary diffluence, in inches]

\begin{tabular}{|c|c|c|c|c|c|c|c|c|c|c|c|c|c|c|c|}
\hline $\begin{array}{c}\text { Site } \\
\text { number }\end{array}$ & B & RN & MRDA & MRDFA & H & K & L & $D A$ & DFA & MBE & $\mathbf{P}$ & MAF & v & $W$ & CC \\
\hline $\begin{array}{l}1 \\
2 \\
3 \\
4 \\
5\end{array}$ & $\begin{array}{r}5 \\
6 \\
7 \\
10 \\
10\end{array}$ & $\begin{array}{c}0.085 \\
.0721 \\
.0997 \\
.247 \\
.189\end{array}$ & $\begin{array}{c}0.0292 \\
.0273 \\
.0256 \\
.138 \\
.0812\end{array}$ & $\begin{array}{r}0.0198 \\
.0183 \\
.0173 \\
.0193 \\
.0247\end{array}$ & $\begin{array}{l}1.49 \\
1.45 \\
1.46 \\
1.18 \\
1.34\end{array}$ & $\begin{array}{r}0.47 \\
.49 \\
.49 \\
.33 \\
.92\end{array}$ & $\begin{array}{r}0.31 \\
.30 \\
.24 \\
.55 \\
.13\end{array}$ & $\begin{array}{c}3.89 \\
6.10 \\
2.79 \\
.479 \\
10.8\end{array}$ & $\begin{array}{c}6.46 \\
10.0 \\
9.11 \\
.429 \\
1.68\end{array}$ & $\begin{array}{l}2,590 \\
2,710 \\
2,660 \\
2,030 \\
4,660\end{array}$ & $\begin{array}{l}30 \\
30 \\
30 \\
28 \\
26\end{array}$ & $\begin{array}{l}1 \\
1 \\
1 \\
4 \\
1\end{array}$ & $\begin{array}{l}5 \\
5 \\
6 \\
8 \\
2\end{array}$ & $\begin{array}{r}4,380 \\
5,440 \\
3,450 \\
885 \\
3,560\end{array}$ & $\begin{array}{l}0.20 \\
.24 \\
.24 \\
.08 \\
.04\end{array}$ \\
\hline $\begin{array}{r}6 \\
7 \\
8 \\
9 \\
10\end{array}$ & $\begin{array}{l}9 \\
8 \\
5 \\
9 \\
2\end{array}$ & $\begin{array}{l}.119 \\
.0546 \\
.0905 \\
.0775 \\
.0996\end{array}$ & $\begin{array}{l}.110 \\
.0359 \\
.0685 \\
.0434 \\
.0779\end{array}$ & $\begin{array}{l}.0312 \\
.0108 \\
.0121 \\
.0115 \\
.0126\end{array}$ & $\begin{array}{l}1.18 \\
2.26 \\
1.54 \\
1.36 \\
1.71\end{array}$ & $\begin{array}{l}.38 \\
1.5 \\
.18 \\
1.2 \\
.40\end{array}$ & $\begin{array}{l}.09 \\
.65 \\
.20 \\
.56 \\
.26\end{array}$ & $\begin{array}{c}8.04 \\
56.0 \\
9.24 \\
58.4 \\
1.37\end{array}$ & $\begin{array}{c}1.71 \\
20.7 \\
8.17 \\
35.9 \\
1.38\end{array}$ & $\begin{array}{l}2,670 \\
2,060 \\
1,240 \\
3,310 \\
2,240\end{array}$ & $\begin{array}{l}30 \\
27 \\
25 \\
29 \\
34\end{array}$ & $\begin{array}{l}4 \\
4 \\
1 \\
2 \\
7\end{array}$ & $\begin{array}{l}8 \\
5 \\
5 \\
5 \\
7\end{array}$ & $\begin{array}{l}6,150 \\
8,200 \\
3,340 \\
7,580 \\
1,420\end{array}$ & $\begin{array}{l}.05 \\
1.0 \\
.32 \\
.22 \\
.25\end{array}$ \\
\hline $\begin{array}{l}11 \\
12 \\
13 \\
14 \\
15\end{array}$ & $\begin{array}{l}9 \\
2 \\
8 \\
9 \\
9\end{array}$ & $\begin{array}{l}.0543 \\
.0968 \\
.164 \\
.169 \\
.217\end{array}$ & $\begin{array}{l}.0348 \\
.0526 \\
.0636 \\
.0767 \\
.0930\end{array}$ & $\begin{array}{l}.0107 \\
.0261 \\
.0289 \\
.0322 \\
.0318\end{array}$ & $\begin{array}{l}1.99 \\
1.85 \\
1.11 \\
1.14 \\
1.30\end{array}$ & $\begin{array}{l}.76 \\
.80 \\
.78 \\
.98 \\
.31\end{array}$ & $\begin{array}{l}.27 \\
.15 \\
.11 \\
.08 \\
.15\end{array}$ & $\begin{array}{l}7.65 \\
3.17 \\
5.46 \\
3.77 \\
.989\end{array}$ & $\begin{array}{l}.549 \\
.682 \\
1.52 \\
2.26 \\
.916\end{array}$ & $\begin{array}{l}2,140 \\
3,960 \\
3,150 \\
3,440 \\
3,100\end{array}$ & $\begin{array}{l}30 \\
28 \\
27 \\
30 \\
30\end{array}$ & $\begin{array}{l}3 \\
6 \\
6 \\
7 \\
6\end{array}$ & $\begin{array}{l}2 \\
3 \\
6 \\
8 \\
7\end{array}$ & $\begin{array}{l}3,050 \\
2,060 \\
2,630 \\
2,230 \\
1,220\end{array}$ & $\begin{array}{l}.26 \\
1.1 \\
.10 \\
.08 \\
.06\end{array}$ \\
\hline $\begin{array}{l}16 \\
17 \\
18 \\
19 \\
20\end{array}$ & $\begin{array}{r}5 \\
10 \\
9 \\
9 \\
9\end{array}$ & $\begin{array}{l}.221 \\
.0609 \\
.121 \\
.199 \\
.155\end{array}$ & $\begin{array}{l}.0556 \\
.0251 \\
.0707 \\
.141 \\
.0924\end{array}$ & $\begin{array}{l}.0312 \\
.0192 \\
.00980 \\
.0161 \\
.0202\end{array}$ & $\begin{array}{l}1.38 \\
1.63 \\
1.29 \\
1.29 \\
1.39\end{array}$ & $\begin{array}{l}.33 \\
1.1 \\
1.0 \\
.36 \\
1.2\end{array}$ & $\begin{array}{l}.18 \\
.20 \\
.15 \\
.15 \\
.31\end{array}$ & $\begin{array}{c}1.65 \\
3.60 \\
2.40 \\
.922 \\
12.7\end{array}$ & $\begin{array}{c}3.72 \\
.631 \\
3.32 \\
.320 \\
5.89\end{array}$ & $\begin{array}{l}3,950 \\
4,090 \\
1,870 \\
1,820 \\
5,670\end{array}$ & $\begin{array}{l}32 \\
26 \\
29 \\
29 \\
30\end{array}$ & $\begin{array}{l}3 \\
1 \\
6 \\
5 \\
9\end{array}$ & $\begin{array}{r}7 \\
3 \\
10 \\
4 \\
10\end{array}$ & $\begin{array}{l}1,540 \\
2,180 \\
1,700 \\
1,060 \\
3,830\end{array}$ & $\begin{array}{l}.14 \\
.14 \\
.22 \\
.08 \\
.12\end{array}$ \\
\hline $\begin{array}{l}21 \\
22 \\
23 \\
24 \\
25\end{array}$ & $\begin{array}{r}9 \\
10 \\
10 \\
3 \\
9\end{array}$ & $\begin{array}{l}.115 \\
.151 \\
.245 \\
.235 \\
.0551\end{array}$ & $\begin{array}{l}.0967 \\
.0898 \\
.143 \\
.105 \\
.0394\end{array}$ & $\begin{array}{l}.00912 \\
.00577 \\
.0270 \\
.0165 \\
.0127\end{array}$ & $\begin{array}{l}1.94 \\
1.26 \\
1.32 \\
3.75 \\
1.32\end{array}$ & $\begin{array}{l}.46 \\
.33 \\
.44 \\
1.4 \\
1.2\end{array}$ & $\begin{array}{l}.46 \\
.26 \\
.12 \\
.80 \\
.30\end{array}$ & $\begin{array}{l}3.41 \\
2.33 \\
2.81 \\
4.05 \\
21.6\end{array}$ & $\begin{array}{c}5.18 \\
5.46 \\
.600 \\
4.98 \\
26.4\end{array}$ & $\begin{array}{l}1,470 \\
1,740 \\
2,260 \\
1,600 \\
2,160\end{array}$ & $\begin{array}{l}27 \\
28 \\
28 \\
22 \\
26\end{array}$ & $\begin{array}{l}2 \\
3 \\
7 \\
8 \\
1\end{array}$ & $\begin{array}{l}9 \\
7 \\
8 \\
9 \\
6\end{array}$ & $\begin{array}{l}2,030 \\
4,400 \\
3,500 \\
2,210 \\
5,100\end{array}$ & $\begin{array}{l}.46 \\
.18 \\
.04 \\
.25 \\
.12\end{array}$ \\
\hline $\begin{array}{l}26 \\
27 \\
28 \\
29 \\
30\end{array}$ & $\begin{array}{r}9 \\
9 \\
10 \\
9 \\
2\end{array}$ & $\begin{array}{l}.173 \\
.101 \\
.103 \\
.253 \\
.208\end{array}$ & $\begin{array}{l}.128 \\
.0562 \\
.0548 \\
.130 \\
.124\end{array}$ & $\begin{array}{l}.0214 \\
.0130 \\
.00972 \\
.0165 \\
.0197\end{array}$ & $\begin{array}{l}1.37 \\
1.30 \\
1.09 \\
1.78 \\
2.52\end{array}$ & $\begin{array}{l}1.2 \\
1.1 \\
1.3 \\
1.2 \\
1.2\end{array}$ & $\begin{array}{l}.16 \\
.22 \\
.18 \\
.26 \\
.44\end{array}$ & $\begin{array}{c}1.99 \\
7.54 \\
5.25 \\
2.07 \\
11.1\end{array}$ & $\begin{array}{l}1.99 \\
2.77 \\
2.65 \\
1.44 \\
2.62\end{array}$ & $\begin{array}{l}2,170 \\
1,790 \\
1,870 \\
2,420 \\
3,110\end{array}$ & $\begin{array}{l}26 \\
26 \\
25 \\
26 \\
28\end{array}$ & $\begin{array}{l}9 \\
5 \\
4 \\
3 \\
9\end{array}$ & $\begin{array}{l}9 \\
8 \\
5 \\
9 \\
9\end{array}$ & $\begin{array}{l}1,550 \\
3,010 \\
2,520 \\
1,580 \\
3,660\end{array}$ & $\begin{array}{l}.46 \\
.21 \\
.18 \\
.17 \\
.47\end{array}$ \\
\hline $\begin{array}{l}31 \\
32 \\
33 \\
34 \\
35\end{array}$ & $\begin{array}{r}8 \\
8 \\
7 \\
9 \\
10\end{array}$ & $\begin{array}{l}.243 \\
.184 \\
.126 \\
.0482 \\
.0747\end{array}$ & $\begin{array}{l}.174 \\
.154 \\
.0694 \\
.0341 \\
.0708\end{array}$ & $\begin{array}{l}.0260 \\
.0287 \\
.0114 \\
.00706 \\
.0073\end{array}$ & $\begin{array}{l}2.05 \\
2.21 \\
3.09 \\
2.03 \\
1.75\end{array}$ & $\begin{array}{l}.48 \\
.90 \\
1.1 \\
.94 \\
2.5\end{array}$ & $\begin{array}{l}.35 \\
.43 \\
.44 \\
.58 \\
.51\end{array}$ & $\begin{array}{c}.847 \\
1.28 \\
9.73 \\
88.8 \\
95.9\end{array}$ & $\begin{array}{l}2.84 \\
2.62 \\
3.45 \\
25.2 \\
38.8\end{array}$ & $\begin{array}{l}1,770 \\
1,990 \\
1,720 \\
2,070 \\
2,600\end{array}$ & $\begin{array}{l}26 \\
26 \\
27 \\
27 \\
26\end{array}$ & $\begin{array}{l}8 \\
9 \\
4 \\
4 \\
4\end{array}$ & $\begin{array}{r}10 \\
10 \\
6 \\
6 \\
9\end{array}$ & $\begin{array}{r}1,010 \\
1,240 \\
3,420 \\
10,300 \\
10,700\end{array}$ & $\begin{array}{l}.52 \\
.20 \\
.14 \\
.77 \\
.56\end{array}$ \\
\hline $\begin{array}{l}36 \\
37 \\
38 \\
39\end{array}$ & $\begin{array}{r}10 \\
9 \\
9 \\
8\end{array}$ & $\begin{array}{l}.131 \\
.188 \\
.271 \\
.191\end{array}$ & $\begin{array}{l}.0837 \\
.0946 \\
.0948 \\
.110\end{array}$ & $\begin{array}{l}.0192 \\
.0175 \\
.0152 \\
.0137\end{array}$ & $\begin{array}{l}1.36 \\
1.47 \\
1.75 \\
2.37\end{array}$ & $\begin{array}{l}.94 \\
.73 \\
.71 \\
.81\end{array}$ & $\begin{array}{l}.14 \\
.15 \\
.19 \\
.41\end{array}$ & $\begin{array}{l}5.63 \\
4.30 \\
3.47 \\
3.26\end{array}$ & $\begin{array}{c}2.15 \\
1.03 \\
.700 \\
1.25\end{array}$ & $\begin{array}{l}2,130 \\
2,150 \\
2,160 \\
1,860\end{array}$ & $\begin{array}{l}26 \\
26 \\
26 \\
26\end{array}$ & $\begin{array}{l}6 \\
4 \\
4 \\
3\end{array}$ & $\begin{array}{l}7 \\
8 \\
6 \\
8\end{array}$ & $\begin{array}{l}2,610 \\
2,280 \\
2,050 \\
1,980\end{array}$ & $\begin{array}{l}.12 \\
.18 \\
.24 \\
.42\end{array}$ \\
\hline
\end{tabular}


where the coefficient of correlation is 0.52 and the standard deviation is +66 and -40 percent. $L$ is the average of the contour-band widths of four to six contours evenly spaced within the DFA, in inches, on a 7.5-minute topographic map (table 7). A crude relation exists between the MRDFA and the ruggedness number of the drainage area (RN). The equation

$$
M R D F A=0.047 R N^{0.49}
$$

resembles several equations from the analysis of old-alluvial fans in southern Arizona by Melton (1965).

\section{REGRESSION ANALYSIS}

Numerical models can supplement the methods of defining the flood-hazard degree. Multiple-regression analyses were used to develop and define flood-hazard relations that in turn can be used to estimate the degree of flood hazard for DFA's in southwestern Arizona. Independent variables were (1) the drainage area and DFA characteristics measured on 7.5-minute topographic maps and (2) precipitation intensity of the drainage basins (Miller and others, 1973). Many of the measured map characteristics used in this analysis are surrogates for the surface features.

Possible relations between the type of flood hazard and some general qualitative geomorphic characteristics of the 39 sites also were examined. Contingenyy tables for a chi-square test were used to test for dependence between the variables. The general geomorphic characteristics were the presence of a base-level stream, presence of a canyon mouth, location of the primary diffluence on the piedmont plain, and location of the primary diffluence relative to the mountain front. Relations between the qualitative geomorphic characteristics and the types of flood hazard were not discerned.

Several difficulties may occur by modeling flood-hazard degree; however, the difficulties are outweighed by the potential benefits. First, the models are an empirical means of defining the flood-hazard degree and do not imply any physical processes. Second, some characteristics that are hydrologically significant might not be used in the analysis because the regression analysis did not indicate significance at the 0.05 probability leve1. Third, a variable may not be statistically significant if the range of the variable is small. Perhaps the greatest difficulty with the regression analyses is that the reliability of the computed relations is directly related to the assigned numerical values for the flood-hazard degrees. Other valid rating schemes for flood hazard not used in this study may yield flood-hazard degree relations with different independent variables. Independent variables used in the following equations were significant in several other relations that used different numerical ratings of flood-hazard degree; those other relations and numerical ratings are not presented in this report. 
Table 8.-- Correlation matrix for independent variables used in the analysis

IRN, ruggedness number of drainage basin; MRDA, mean-relief ratio of drainage basin; MRDFA, meanrelief ratio of distributary-flow area; $\mathrm{H}$, average contour sinuosity of distributary-flow area; $K$, average contour-band width of drainage basin, in inches; $L$, average contour-band width of distributary-flow area, in inches; DA, drainage-basin area, in square miles; DFA, area of distributary-flow area, in square miles; MBE, mean-basin elevation, in feet; $P, 10$-year 24-hour precipitation, in tenths of inches; MAF, mountain-area factor; $V$, location factor of primary diffluence; $W, 100$-year flood at primary diffluence, in cubic feet per second; CC, contour-band width just downstream from primary diffluence, in inches]

\begin{tabular}{|c|c|c|c|c|c|c|c|c|c|c|c|c|c|c|}
\hline & RN & MRDA & MRDFA & H & $K$ & L & DA & DFA & MBE & $\mathbf{P}$ & MAF & $v$ & W & CC \\
\hline RN & 1.000 & & & & & & & & & & & & & \\
\hline MRDA & .789 & 1.000 & & & & & & & & & & & & \\
\hline MRDFA & .472 & .326 & 1.000 & & & & & & & & & & & \\
\hline H & .097 & .127 & -.219 & 1.000 & & & & & & & & & & \\
\hline$K$ & -.241 & -.163 & -.321 & .297 & 1.000 & & & & & & & & & \\
\hline$L$ & -.108 & -.006 & -.442 & .693 & .394 & 1.000 & & & & & & & & \\
\hline DA & -.469 & -.336 & -.428 & .112 & .597 & .515 & 1.000 & & & & & & & \\
\hline DFA & -.523 & -.404 & -.450 & .034 & .537 & .517 & .886 & 1.000 & & & & & & \\
\hline MBE & .005 & -.219 & .479 & -.268 & .122 & -.254 & .023 & -.009 & 1.000 & & & & & \\
\hline$P$ & -.152 & -.211 & .231 & -.384 & -.438 & -.292 & -.112 & -.077 & .352 & 1.000 & & & & \\
\hline MAF & .439 & .595 & .356 & .218 & .166 & .025 & -.148 & .295 & .045 & -.024 & 1.000 & & & \\
\hline$v$ & .443 & .604 & .108 & .144 & .147 & .194 & -.061 & -.044 & -.204 & -.105 & 0.591 & 1.000 & & \\
\hline$W$ & -.584 & -.458 & -.392 & .037 & .469 & .412 & .901 & .844 & .054 & -.017 & -.292 & -.146 & 1.000 & \\
\hline CC & -.323 & -.164 & -.267 & .374 & .295 & .405 & .469 & .334 & -.099 & -.159 & .098 & -.072 & .367 & 1.000 \\
\hline
\end{tabular}

The independence of the variables was evaluated by computing the correlation values between the independent variables used in the analysis (table 8). A correlation value of 0 means the variables are independent. Correlation values of 1.000 or $-1,000$ mean perfect correlation or inverse correlation, respectively, between the variables. To assure that variables used in the same regression analysis are not so highly related to adversely affect the regression analysis, variables with an absolute value of correlation of more than 0.7 were excluded from the analysis. Several of the variables (table 7) have been used in previous studies (Bu11, 1964; Melton, 1965; and Chow, 1964). In general, the variables can be measured easily and consistently by hydrologists and engineers. The independent variables, significant at the 0.05 probability level, explained a major part of the variation in the flood-hazard degree.

\section{Basin Characteristics}

The physiographic characteristics of the drainage basins that were used for the relations are the ratio of the area of the DFA divided by 
the area of the drainage basin, the mean-relief ratio of the drainage basin $(M R D A)$, the average contour-band width of the drainage basin $(K)$, and the mountain-area factor (see section "Glossary of Terms").

The ratio of the area of the DFA divided by the drainage-basin area is inversely related to the flood-hazard degree. Areas with small DFA's relative to the drainage-basin area are subject to large peak flows per unit area of DFA and, as a result, the flood-hazard degree will likely be great.

The intensity of precipitation $(P)$ was the only climatic characteristic used for this report. The 10-year 24-hour precipitation intensity values were obtained from the Precipitation Frequency Atlas of the Western United States (Miller and others, 1973). An inverse relation exists between the intensity of precipitation and the flood-hazard degree.

The mean-relief ratio of the drainage basin is a measure of the average slope of the drainage basin. A direct relation exists between the mean-relief ratio of the drainage basin and the flood-hazard degree. The greater the mean-relief ratio of the drainage basin, the greater the potential energy of the floodflow, which may increase the flood-hazard degree. Also, some studies have found that mean-relief ratio of the drainage basin is directly related to the sediment yield (Chow, 1964, section 17, p. 13). Increased sediment yields may contribute to avulsions and a greater flood-hazard degree.

The contour-band width (see section "Glossary of Terms") is the measured distance, in inches, between the tangent of the largest upslope crenulation and a parallel tangent line to the largest downslope crenulation (on the same contour). The crenulations represent canyons and stream channels and not mountain ridges. The average band width of four (small areas) to six (large areas) equally spaced contours over the drainage basin was used. A direct relation exists between the average contour-band width of the drainage basin and the flood-hazard degree. The average contour-band width of the drainage basin is a measure of the relief resulting from the depths of canyons and stream channels.

The mountain-area factor (MAF, table 7) is the ratio of the drainage-basin area that is not on the piedmont plain (typically composed of bedrock mountains) and the total drainage-basin area. The ratio is multiplied by 10 and rounded to one significant figure so that the values range from 1 to 10 . An inverse relation exists between the mountain-area factor and the flood-hazard degree. The mountain-area factor may be a surrogate for the effects of geology on the flood-hazard degree (including lithology and geologic structure).

\section{Characteristics of Distributary-Flow Areas}

Physiographic characteristics of the DFA that proved significant (5-percent level) for flood-hazard relations were the average contour sinuosity of the DFA and the contour-band width just downstream from the primary diffluence (table 7). The average contour sinuosity of the DFA is the average of the contour sinuosities of four (small areas) to six (large areas) contours evenly spaced within the DFA. The sinuosity of a contour 
is the ratio of the length of a contour (as measured on a map) and a straight line that splits the longitudinal trend of the contour. An inverse relation exists between the average contour sinuosity of the DFA and the flood-hazard degree. The contour sinuosity is a surrogate for the depth of channels, the number of defined channels, and the relief on the surface of the DFA. DFA's with a large flood-hazard degree may have many small undefined channels with small mapped contour crenulations and low contour sinuosities. In contrast, old-fan surfaces (fan remnants) typically have many steeply incised channels from local tributary-drainage systems. The greater the number of large channels and the greater the depth of each channel, the greater the average contour sinuosity of the DFA.

The contour-band width just downstream from the primary diffluence is the contour-band width of one contour within the region where distributary flow is established (usually three to four contour intervals downstream from the primary diffluence). An inverse relation exists between the contour-band width just downstream from the primary diffluence and the flood-hazard degree. The contour-band width just downstream from the primary diffluence is a surrogate for the relief of the DFA close to the primary diffluence (height of ridges and depth of channels). DFA's with large ridges and well-incised channels near the primary diffluence exhibit a large contour-band width and generally possess a low flood-hazard degree.

\section{Regression Equations}

The regression model for the estimation of the flood-hazard degree is of the general form:

$$
B=a+b X+c Y+\ldots
$$

which is a simple linear equation in which the independent variables $(\mathrm{x}, \mathrm{y}, \ldots)$ are the DA, DFA, and other basin and climatic characteristics. The regression coefficients are $b, c$, and so on, and the regression constant is a.

Three relations were defined that may be used to estimate the degree of flood hazard of DFA's in southwestern Arizona. The first relation is for all degrees of flood hazards and drainage areas. The second relation to be used for small drainage areas has a larger correlation coefficient and smaller standard error of estimate than the first relation. The third relation for flood-hazard degrees of 5 to 10 has the smallest standard error of estimate and is considered the most reliable to distinguish between the higher degrees of flood hazard. For all equations, only variables significant at the 0.05 probability level were retained.

Other models that included the mathematical transformation of variables to logarithms and second-degree polynomials were also used; however, little improvement was noted over equation 6 . Adequency of any model is difficult to evaluate using the sample of 39 sites because of the 
large number of sites with a flood-hazard degree of 9 and 10 and the few sites with degrees less than 6 . The distribution of the residuals for the various models was not ideal for the sites with the lower degrees of flood hazard. The residuals commonly appeared homoscedastic but nonrandom for the sites with lower degrees. Thus, the simple linear model was used, and the regression coefficients and constant were adjusted by giving more weight to the sites with low degrees of flood hazard. The weighted regression improved the distribution of the residuals without changing the sign of the regression coefficients and constant with only a small increase in the standard error of estimate.

The three estimating relations can be used to supplement the methods of defining the degree of flood hazard but the reader is reminded that the relations are statistical in nature and give the expected or average degree of flood hazard for a group of sites rather than a precise estimate of the degree at a specific site. The precision of the relations is reflected by the standard error of regression, which is rather large. Estimated values of the flood-hazard degree of more than 9.5 indicate a flood-hazard degree of 10. Estimated values of 9 and 10 indicate DFA's similar to those described by FEMA (1991). Use of the estimating relations for purposes other than those described in this report is not recommended.

The simplest estimating equation on the basis of data (table 7) for all 39 sample sites is

$$
B=28.7-3.42 H-0.600 P \text {, }
$$

where

$$
\begin{aligned}
B= & \text { flood-hazard degree, } \\
H= & \text { average contour sinuosity of four to six contours evenly } \\
& \text { spaced within the DFA, and } \\
P= & 10 \text {-year } 24 \text {-hour precipitation for the drainage basin. }
\end{aligned}
$$

The standard error of estimate is 2.5, the multiple-correlation coefficient is $0.53, H$ of the DFA ranges from 1.09 to 3.75 , and $P$ ranges from 2.2 to $3.4 \mathrm{in}$. The correlation coefficient is a measure of the degree of linear association between the flood-hazard degree and the independent variables. A correlation coefficient of zero indicates that the variables are independent, and a coefficient of 1 indicates a perfect linear relation.

For the 35 sites with drainage areas of less than about $22 \mathrm{mi}^{2}$, the estimating equation that has the largest correlation coefficient is:

$$
B=8.10+45.1 M R D A-2.91 H+4.81 K-0.691 M A F-3.12 C C,
$$

where

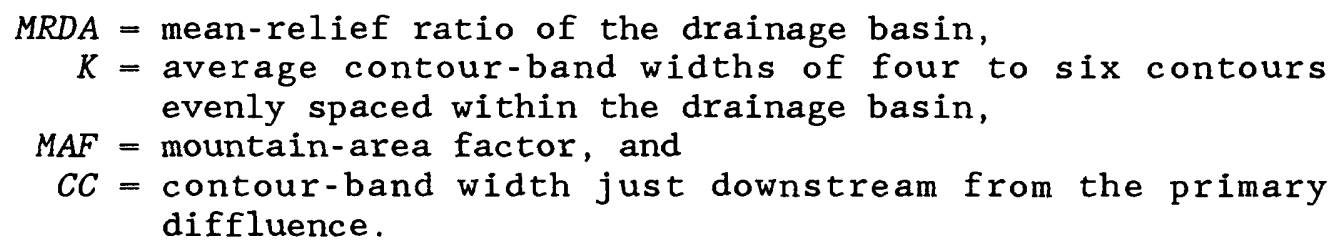


The standard error of estimate is 2.0, the multiple-correlation coefficient is 0.73 , and MRDA ranges from 0.0251 to 0.174 . The average contour sinuosity of the DFA ranges from 1.09 to $3.75, K$ ranges from 0.18 to 1.40 in., MAF ranges from 1 to 9, and lastly, $C C$ ranges from 0.04 to 1.1 in.

For flood-hazard types 4C, 4D, and 4E (degrees of 5-10) that have multiple bifurcations and joins, the estimating equation with the smallest standard error of estimate of 1.4 is

$$
B=6.21-0.620 D D+25.6 M R D A-1.19 H+2.70 K,
$$

where

$$
\begin{aligned}
D D= & \text { ratio of the area of the DFA divided by the area of the } \\
& \text { drainage basin. }
\end{aligned}
$$

The correlation coefficient is about 0.60 for the 35 sites with flood-hazard degrees from 5 to 10 . For equation 9, about 68 percent of the assigned values of flood-hazard degree were within a degree of flood hazard of 1.4 of the estimated values. The standard error of estimate is a measure of the departure of the estimated flood-hazard degrees from the assigned values. The range of values for $D D$ is 0.0718 to 3.35 . The range of values for the MRDA is 0.0251 to 0.174 . The range of values for $H$ is 1.09 to 3.09 . Lastly, the range of values for $K$ is 0.18 to 2.5 in.

The reader is reminded that the above estimates of the flood-hazard degree (equations 7-9) are based on measured variables that are surrogates for the actual physiographic characteristics. The flood-hazard degree undoubtedly is the effect of many physiographic and climatic characteristics and the long history of fluvial processes. The regression equations do not necessarily reflect a cause-and-effect relation. The equations can be one of several useful methods for defining the flood-hazard degree of DFA's.

\section{SUMMARY}

Flood hazards of DFA's (distributary-flow areas) are a complicated phenomenon. Amount and distribution of floodflow are difficult to define because flow paths are erratic and the boundaries of channels are unstable. A major problem is the transition from a geologic timeframe to an engineering timeframe. Geologically dynamic systems that experience mudflows, debris flows, major channel avulsions, and catastrophic floods may be stable in an engineering sense. The DFA's of sample sites in southwestern Arizona are the result of fluvial processes during the past 10,000 years; however, specific quantitative characteristics are influenced by much older landforms. Some DFA's are downslope from pediments, and other DFA's are on or in old-fan remnants. Other DFA's are influenced by inselbergs and adjacent DFA's. The occurrence of major channel avulsions are apparent on DFA's of some sites; however, the frequency of avulsions generally is unknown but probably is small in terms of an engineering timeframe. In terms of a 100-year recurrence interval, large avulsions and debris flows appear to be an unlikely occurrence at many of the sample sites. 
Five qualitative types of flood hazards were identified on the basis of interfluvial ridge stability and the potential amount of 1 and inundated by the 100-year flood. Ten degrees of flood hazards were assigned to provide a quantitative basis to relate potential flood hazards of DFA's to physical features. The 10 degrees of flood hazards are related to the random nature of flow paths on DFA's.

The flood-hazard degree, the location of the primary diffluence, and the boundaries of the DFA are defined using several techniques based on physiographic and climatic characteristics. The random-1ink model appears to provide a quantitative basis for verifying the degree of flood hazard. The drainage-texture method can be used to locate the primary diffluence and can be used jointly with other methods to locate the boundaries of the DFA. Multiple-linear regression equations can be used as one of several tools to define the flood-hazard degree using physiographic and climatic characteristics.

A single physiographic or hydrologic characteristic of a DFA is not considered a reliable index of flood-hazard degree; however, several characteristics can yield a reliable estimate. If, for example, (1) the channel links appear random using the random-link model, (2) the degree of flood hazard is 9 using a regression equation, (3) the soils generally are light colored in most of the DFA's, (4) the vegetation generally is more dense over the DFA except along a few higher ridges between the channels that divide and combine, (5) most of the interfluves between the channels in the upper DFA are below the expected level of the 100-year flood, and (6) there is no desert varnish in the DFA, then the degree of flood hazard probably is 9. The method is reliable where all of the quantitative and qualitative methods are applied to a DFA and all indicate a particular flood-hazard degree.

The primary diffluence and boundaries of DFA's are identified using methods based on physiographic and hydrologic characteristics. Primary diffluences commonly exist where (1) intermittent streams bifurcate, (2) channel slope decreases, (3) 100-year floodwater is confined and is at a lower elevation than oxidized soil and varnished rocks, and (4) the drainage texture changes. Distinguishing features that define DFA boundaries include topographic ridge lines, and changes in vegetation density, soil color, and drainage texture. Most DFA's with flood-hazard types 4C, 4D, and 4E have an unchanging drainage texture in the upslope direction. Where DFA's overlap, the boundaries are estimated using defined ridge lines and the joins and divides of channels shared by the overlapping DFA's .

\section{SELECTED REFERENCES}

Aldridge, B.N., 1968, Flood of September 13 near Marana, Arizona, in Rostvedt, J.0., and others, Summary of floods in the United States during 1962: U.S. Geological Survey Water-Supply Paper 1820 , p. 105-108.

Bates, R.L., and Jackson, J.A., eds., 1980, Glossary of geology: Falls Church, Virginia, American Geological Institute, second edition, 749 p. 
Bull, W.B., 1964, Geomorphology of segmented alluvial fans in western Fresno County, California: U.S. Geological Survey Professional Paper 352-E, 128 p.

1977, The alluvial-fan environment: London, Edvard Arnold, Ltd., Progress in Physical Geography, v. 1, p. 222-270.

1988 , Floods, degradation, and aggradation-Flood geomorphology: New York, John Wiley, p. 157-165.

Chow, V.T., ed., 1964, Handbook of applied hydrology: New York, McGraw-Hill, v.p.

Cooke, R.U., and Warren, Andrew, 1973, Geomorphology in deserts: London, B.T. Batsford Ltd., 394 p.

Cooley, M.E., 1977, Map of Arizona showing selected alluvial, structural, and geomorphic features: U.S. Geological Survey Open-File Report 77-343, 29 p.

Dawdy, D.R., 1979, Flood-frequency estimates on alluvial fans: American Society of Civil Engineers, Journal of the Hydraulics Division, v. 105, no. HY-11, p. 1407-1413.

1981, Flood-frequency estimates on alluvial fans-Closure: American Society of Civil Engineers, Journal of the Hydraulics Division, v. 107, no. HY-13, p. 379-380.

DMA Consulting Engineers, 1985, Alluvial fan flooding methodology-An analysis: Federal Emergency Management Agency Contract EMW-84-C-1488, 79 p.

Doehring, D.0., 1970, Discrimination of pediments and alluvial fans from topographic maps: Geological Society of America Bulletin, v. 81, no. 10, p. 3109-3115.

Dorn, R.I., and Deniro, M.J., 1985, Stable carbon isotope ratios of rock varnish organic matter-A new paleoenvironmental indicator: Washington, D.C., American Association for the Advancement of Science, Science, v. 227, p. 1472-1474.

Dorn, R.I., and Oberlander, T.M., 1982, Rock varnish: London, Edvard Arnold, Ltd., Progress in Physical Geography, v. 6, p. 317-367.

Dorn, R.I., and others, 1989, Accelerator mass spectrometry dating of rock varnish: Geological Society of America Bulletin, v. 101, p. $1363-1372$.

Edwards, K.L., and Thielmann, J., 1984, Alluvial fans-Novel flood challenge: American Society of Civil Engineers, Civil Engineering, November 1984, v. 54, no. 11, p. 66-68.

Eychaner, J.H., 1984, Estimation of magnitude and frequency of floods in Pima County, Arizona, with comparisons of alternative methods: U.S. Geological Survey Water-Resources Investigations Report $84-4142,69$ p. 
Federal Emergency Management Agency, 1991, Flood insurance study guidelines and specifications for study contractors: Federal Emergency Management Agency Report 37, Appendix 5, p. 1-7.

Federal Register, 1989, Federal Emergency Management Agency-National flood insurance program: Federal Register, v. 54, no. 43, Tuesday, March 7, 1989, p. 9528.

French, R.H., 1984, Flood hazard assessment on alluvial fans-An examination of the methodology: Reno, University of Nevada, Desert Research Institute Publication 45040, 40 p.

1987, Hydraulic processes on alluvial fans: Amsterdam, Elsevier, $244 \mathrm{p}$.

Hjalmarson, H.W., 1978, Delineation of flood hazards in the Cave Creek quadrangle, Maricopa County, Arizona: U.S. Geological Survey Miscellaneous Investigations Series Map I-843-B, 2 sheets.

1980, Delineation of flood hazards in the Biscuit Flat quadrangle and New River area, Maricopa County, Arizona: U.S. Geological Survey Miscellaneous Investigations Series Map I-843-C, 2 sheets.

1988, Flood-hazard zonation in arid lands: Arid lands-Hydrology, scour, and water quality: Transportation Research Record ISSN 026101981 1201, National Research Council, Transportation Research Board, p. 1-8.

Hooke, R.L., 1967, Processes on arid-region alluvial fans: Chicago, Illinois, University of Chicago Press, Journal of Geology, v. 75, p. 438-460.

Kemna, S.P., 1990, Some geomorphic models of flood hazards on distributary flow areas in southern Arizona: Tucson, University of Arizona, M.S. thesis, 171 p.

Langbein, W.B., and Iseri, K.T., 1960, General introduction and hydrologic definitions: U.S. Geological Survey Water-Supply Paper 1360-G, $19 \mathrm{p}$.

Lustig, L.K., 1969, Trend-surface analysis of the Basin and Range province, and some geomorphic implications: U.S. Geological Survey Professional Paper 500-D, 70 p.

Melton, M.A., 1965, The geomorphic and paleoclimatic significance of alluvial deposits in southern Arizona: Chicago, Illinois, University of Chicago Press, Journal of Geology, v. 73, no. 1, p. $1-38$.

Miller, J.F., Frederick, R.H., and Tracey, R.J., 1973, Precipitation frequency atlas of the western United States: National Oceanic and Atmospheric Administration Atlas 2, volume VIII-Arizona, $41 \mathrm{p}$. 
Morisawa, Marie, 1985, Topological properties of delta distributary networks in Woldenberg, M.J., ed., in Models in Geomorphology: London, Allen and Unwin, p. 239-268.

Murphy, B.J., and Moore, R.T., 1980, Maps showing relative slope stability and relative erodability, central Santa Cruz River Valley, Tucson area, Arizona: U.S. Geological Survey Miscellaneous Investigations Series Map I-844-0, 2 sheets.

Office of Water Data Coordination, 1977, National handbook of recommended methods for water-data acquisition: Reston, Virginia, U.S. Geological Survey, Office of Water Data Coordination, v.p.

Packard, F.A., 1974, The hydraulic geometry of a discontinuous ephemeral stream on a bajada near Tucson, Arizona: Tucson, University of Arizona, doctoral dissertation, $127 \mathrm{p}$.

Peterson, F.F., 1981, Landforms of the Basin and Range Province-Defined for soil survey: Reno, University of Nevada, Agricultural Experiment Station Technical Bulletin 28, 52 p.

Rachocki, Andrezej, 1981, Alluvial fans-An attempt at an empirical approach: New York, John Wiley, 161 p.

Renard, K.G., Simanton, J.R., and Osborn, H.B., 1974, Applicability of the Universal Soil Loss Equation to semiarid rangeland conditions in the southwest, in Hydrology and Water Resources in Arizona and the Southwest: American Water Resources Association and Arizona Academy of Science, Proceedings, April 19-20, 1974, Flagstaff, Arizona, v. 4, p. 18-32.

Richardson, M.L., 1971, General soil map of the Tortolita Mountains and surrounding area in Pima County, Arizona: U.S. Department of Agriculture, Soil Conservation Service, 43 p.

Roeske, R.H., 1978, Methods for estimating the magnitude and frequency of floods in Arizona: Arizona Department of Transportation Report ADOT-RS-15(121), 82 p.

Smart, J.S., and Moruzzi, V.L., 1972, Quantitative properties of delta channel networks: Berlin, Gebruder Borntraeger, Zeit, Geomorphology, v. 16, no. 3, p. 268-282.

Torrance, S.W., 1969, General soil map, Maricopa County: U.S. Department of Agriculture, Soil Conservation Service report, 25 p.

Wang, Sany-yi, and Wen Shen, Hsieh, 1985, Incipient sediment motion and riprap design: American Society of Civil Engineers, Journal of the Hydraulics Division, v. 111, no. 3, p. 520-538. 